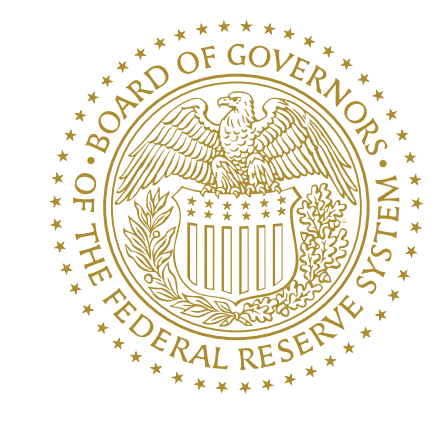

Report on the Economic Well-Being of U.S. Households in 2019 , Featuring Supplemental Data from April 2020
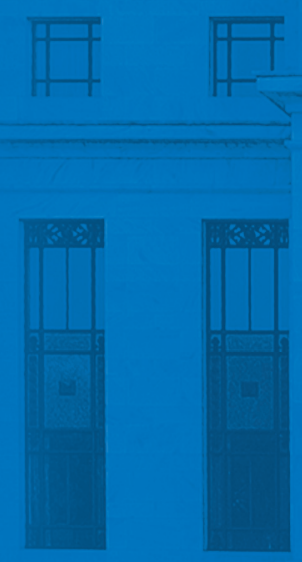

\title{
May 2020
}





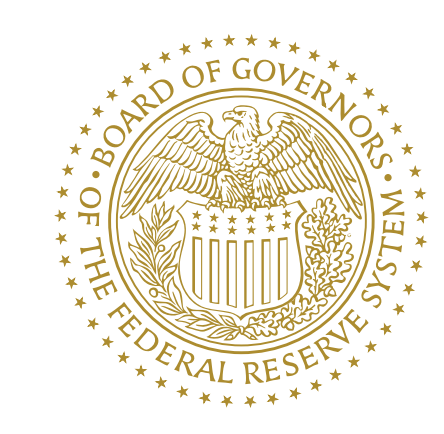

\section{Report on the Economic Well-Being of U.S. Households in 2019, Featuring Supplemental Data from April 2020}

May 2020 
This and other Federal Reserve Board reports and publications are available online at https://www.federalreserve.gov/publications/default.htm.

To order copies of Federal Reserve Board publications offered in print, see the Board's Publication Order Form (https://www.federalreserve.gov/files/orderform.pdf) or contact:

Printing and Fulfillment Mail Stop K1-120

Board of Governors of the Federal Reserve System

Washington, DC 20551

(ph) 202-452-3245

(fax) 202-728-5886

(email) Publications-BOG@frb.gov 


\section{Preface}

This survey and report were prepared by the Consumer and Community Research Section of the Federal Reserve Board's Division of Consumer and Community Affairs (DCCA).

DCCA directs consumer- and community-related functions performed by the Board, including conducting research on financial services policies and practices and their implications for consumer financial stability, community development, and neighborhood stabilization.

DCCA staff members Sara Canilang, Cassandra Duchan, Kimberly Kreiss, Jeff Larrimore, Ellen Merry, Erin Troland, and Mike Zabek prepared this report. Federal Reserve staff members Eric Belsky, Anna Alvarez Boyd, Andrea Brachtesende, David
Buchholz, Madelyn Marchessault, Josh Montes, Barbara Robles, Claudia Sahm, Kirk Schwarzbach, Susan Stawick, and Alison Weingarden provided valuable comments on the survey and report.

Robynn Cox, Jennifer Doleac, Keith Finlay, Ana Kent, Raven Molloy, Mike Mueller-Smith, Wilbert van der Klaauw, Sara Wakefield, and Abigail Wozniak provided helpful feedback on new survey questions for the main survey and the April 2020 supplemental survey. The authors would like to thank Bob Torongo, Poom Nukulkij, Mansour Fahimi, Frances Barlas, and Alyssa Marciniak for their assistance fielding the survey.

If you have questions about the survey or this report, please email SHED@frb.gov. 



\section{Contents}

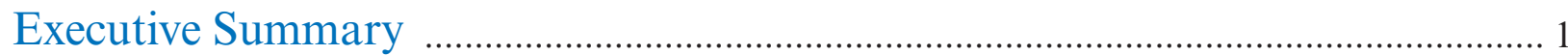

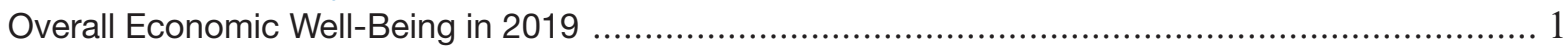

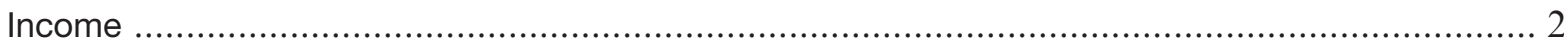

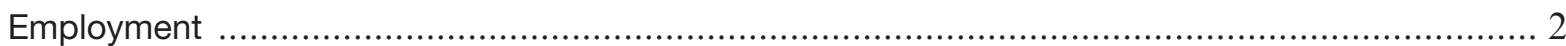

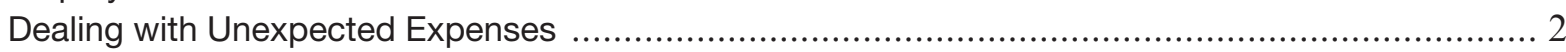

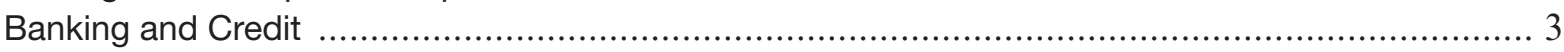

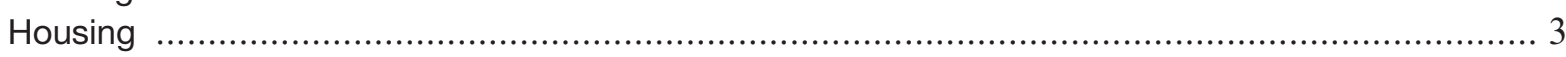

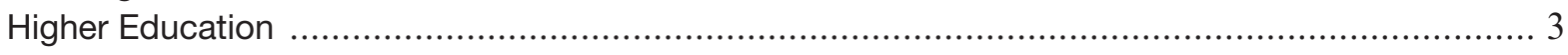

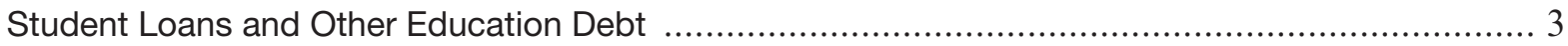

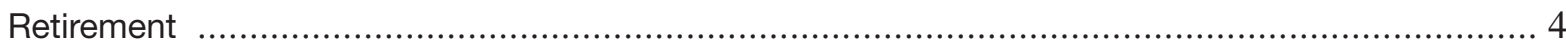

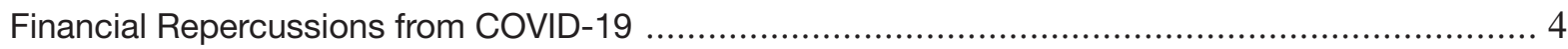

Overall Economic Well-Being in 2019 ................................................................................. 5

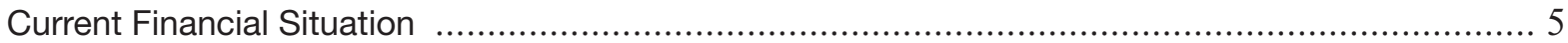

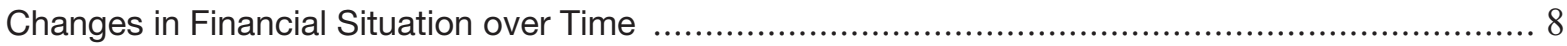

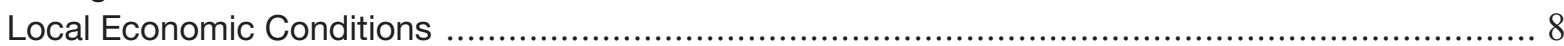

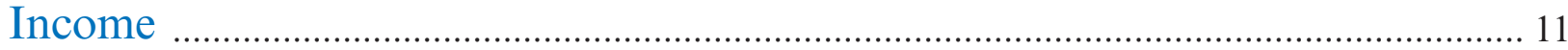

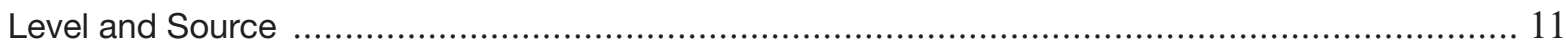

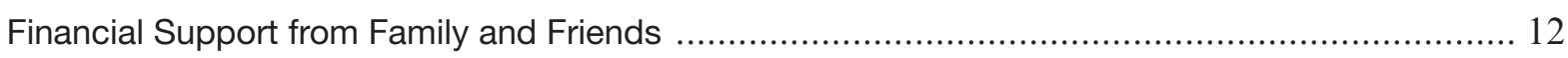

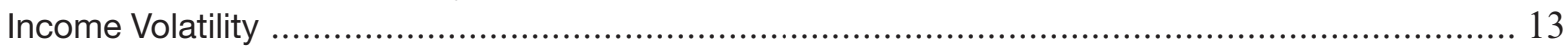

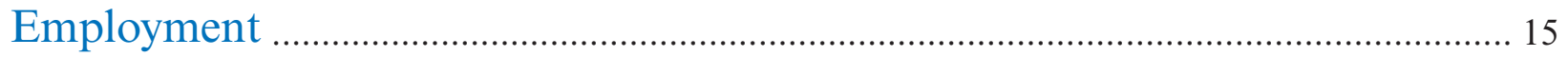

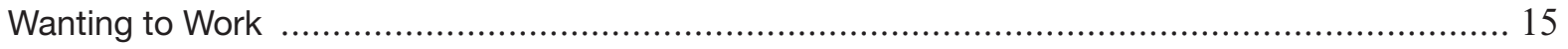

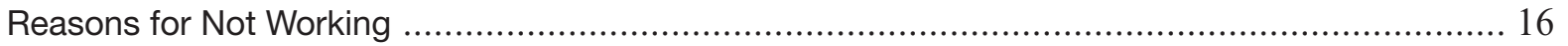

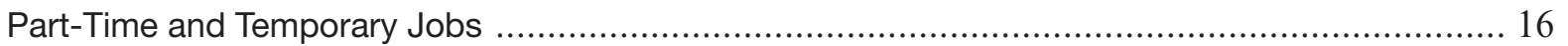

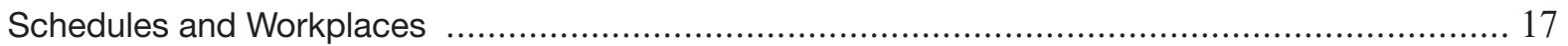

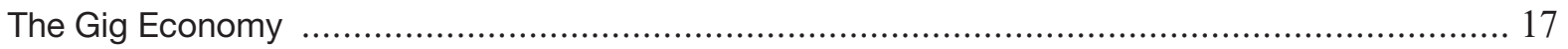

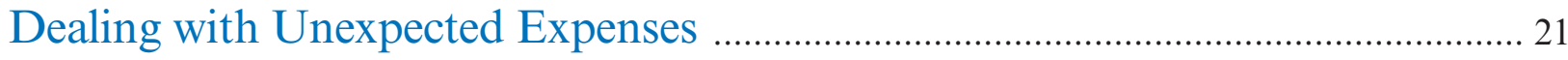

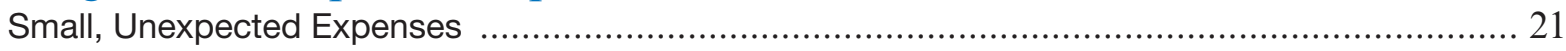

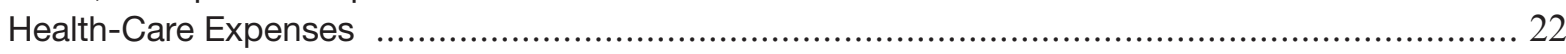

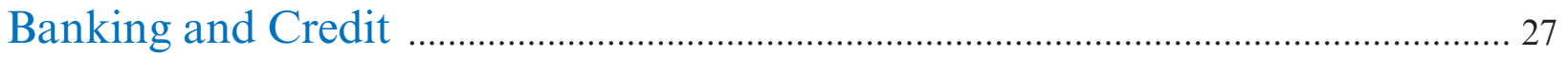

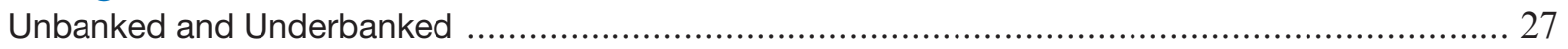

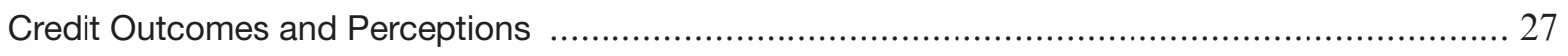

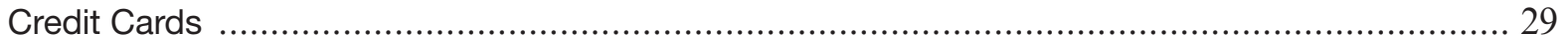

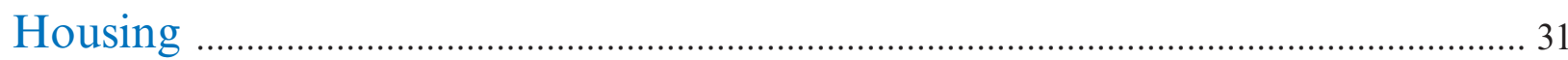

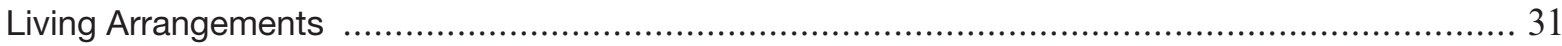




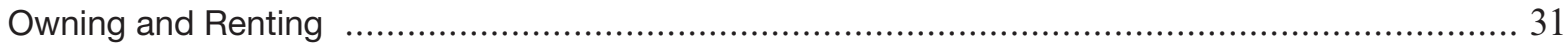

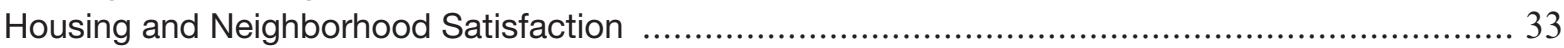

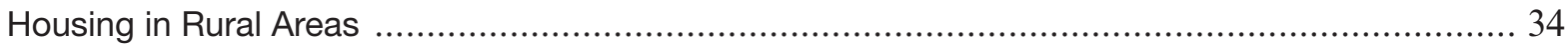

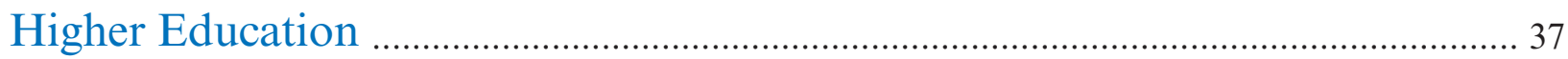

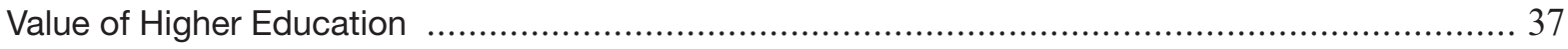

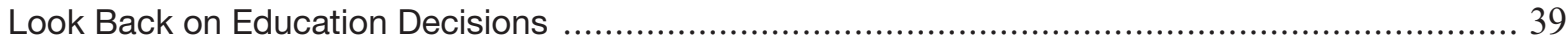

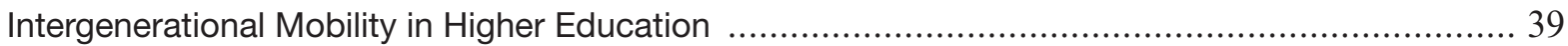

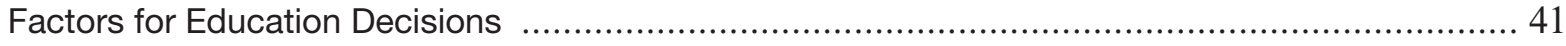

Student Loans and Other Education Debt ..................................................................... 43

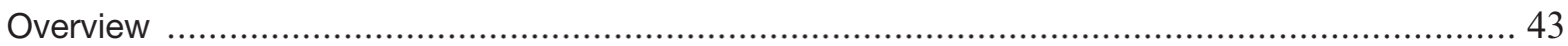

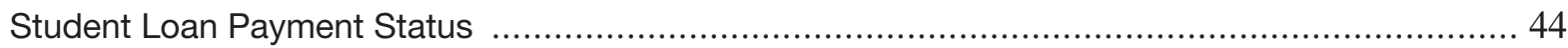

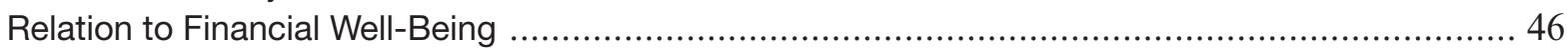

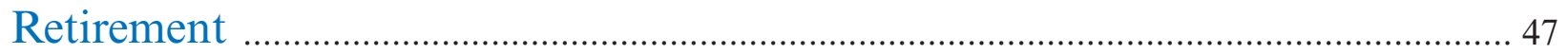

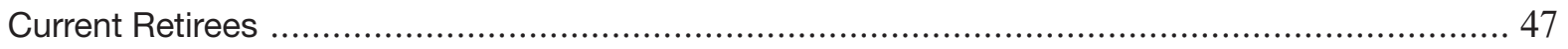

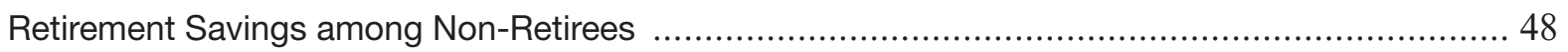

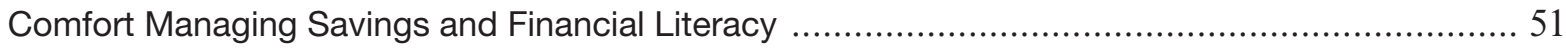

Financial Repercussions from COVID-19 _.................................................................... 53

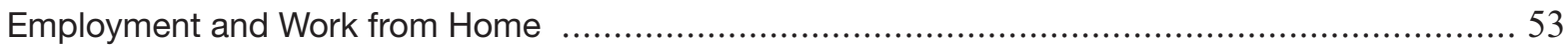

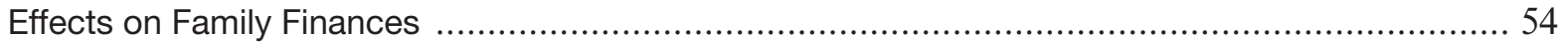

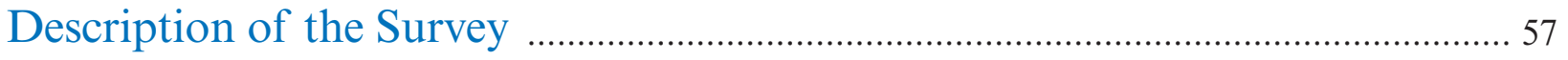

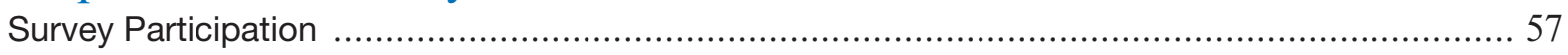

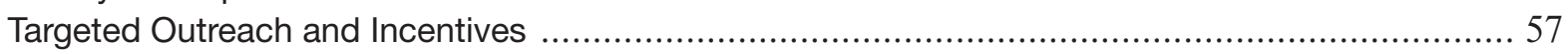

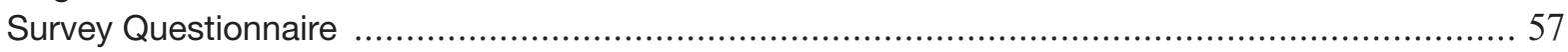

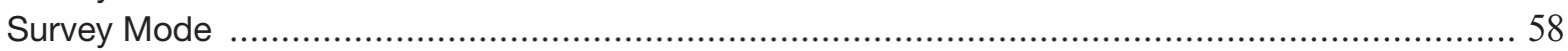

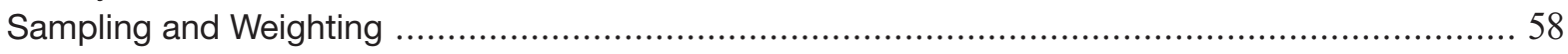






\section{Executive Summary}

This report describes the responses to the 2019 Survey of Household Economics and Decisionmaking (SHED) as well as responses to a follow-up survey conducted in April 2020. The Federal Reserve Board has fielded this survey each fall since 2013 to understand the wide range of financial challenges and opportunities facing families in the United States. ${ }^{1}$

The findings in this report primarily reflect the financial circumstances of families in the United States in late 2019, prior to the onset of COVID-19 and the associated financial disruptions. ${ }^{2}$ At that time, overall financial well-being was similar to that seen in 2018 for most measures in the survey. Consistent with economic improvements over the prior six years, families were faring substantially better than they were when the survey began in 2013. Even so, the results highlight areas of persistent challenges and economic disparities across financial measures, even before the spread of COVID-19 in the United States. In particular, the substantial disparities in overall well-being by race and ethnicity remained in 2019 , and the disparity by education widened in recent years.

Yet, while most adults were faring reasonably well financially, results also show that a substantial minority of adults were financially vulnerable at the time of the survey and either could not pay their current month's bills in full or would have struggled to do so if faced with an emergency expense as small as $\$ 400$. Even fewer had three months of emergency savings to cover expenses in the event of a job loss.

\footnotetext{
1 The latest SHED interviewed a sample of over 12,000 individuals with an online survey in October 2019. The anonymized data, as well as a supplement containing the complete SHED questionnaire and responses to all questions in the order asked, are also available at https://www.federalreserve.gov/ consumerscommunities/shed.htm.

2 The Centers for Disease Control and Prevention first reported community spread of COVID-19 in the United States on February 26, 2020 (https://www.cdc.gov/media/releases/2020/ s0226-Covid-19-spread.html) and first reported a death from COVID-19 in the United States on February 29, 2020 (https:// www.cdc.gov/media/releases/2020/s0229-COVID-19-first-death .html).
}

This highlights the precarious financial situation that some families were in prior to the COVID-19 pandemic.

The survey also explored long-run financial circumstances, including returns to education, housing satisfaction, and retirement savings. It included several new topics that have not been asked in previous years of the survey. In 2019, these new topics included self-perceptions of discrimination, differences in work locations by education level, and the repercussions of outstanding legal expenses and court costs. Additionally, the survey continued to monitor emerging issues that may be important to the economy in the future, such as experiences working in the gig economy. Each of these topics is described in this report.

Although the survey results reflect the financial situation at the end of 2019, many families have had their financial lives disrupted in 2020 due to COVID-19 and measures implemented to limit its spread. To understand the extent of these disruptions, the Federal Reserve Board also implemented a smaller follow-up survey in the first week of April 2020 with some of the same questions that were asked in the fall as well as several new questions focused on recent events. This supplemental survey demonstrated the substantial number of people experiencing layoffs or reductions in hours worked and the extent to which some families dealing with layoffs have struggled to pay their monthly bills. Yet, it also indicated that those not experiencing employment disruptions generally were still faring relatively well financially as of early April.

Key findings from the survey across the sections of this report include:

\section{Overall Economic Well-Being in 2019}

As of the end of 2019, overall economic well-being had improved substantially relative to when the survey 
began in 2013. However, differences in financial wellbeing remained - or had widened slightly - across education levels and across racial and ethnic groups.

- Seventy-five percent of adults were either doing okay or living comfortably financially. This result was unchanged from 2018 and was 13 percentage points higher than in 2013.

- Adults with a bachelor's degree or more were significantly more likely to be doing at least okay financially ( 88 percent) than those with a high school degree or less (63 percent). This gap in economic well-being by education widened by 6 percentage points since 2017 and, in 2019, was similar to that seen in the first year of the survey in 2013.

- Nearly 8 in 10 white adults and two-thirds of black and Hispanic adults were at least doing okay financially in 2019. The gaps in economic wellbeing by race and ethnicity remained at least as large as they were in 2013, even as the economy has strengthened and overall well-being improved.

- Sixty-three percent of respondents rated their local economic conditions as "good" or "excellent" in 2019 , with the rest rating conditions as "poor" or "only fair." This was nearly unchanged from 2018.

\section{Income}

Changes in family income from month to month remained a source of financial strain for some individuals. Financial support from family or friends, and especially parents, is one way that some people covered expenses.

- Three in 10 adults had family income that varied from month to month, with higher rates of volatility among workers in the construction or leisure and hospitality industries.

- One in 10 adults struggled to pay their bills because of monthly changes in income. Those with less confidence in their access to credit were more likely to report financial hardship due to income volatility.

- Ten percent of adults received financial assistance from someone living outside their home. Occasionally, people both gave and received support, as 2 in 10 people who received financial support also provided financial support to someone else.

\section{Employment}

Although most adults were working as much as they wanted to, many people were not working full time and wanted more work. Many adults also performed gig activities in the month before the survey, although few who participated in the gig economy were doing so as a primary source of income.

- Eighteen percent of adults-including 25 percent of black and Hispanic adults - were not working full time and wanted more work in late 2019.

- Among women ages 25 to 54 who were not working, 46 percent said that childcare or other family obligations contributed to their employment decision. Among similarly aged men who were not working, a smaller 23 percent cited childcare or other family obligations.

- Three in 10 adults engaged in at least one gig activity, or informal work, in the month before the survey, although many of those people spent a relatively small amount of time doing so. One in 10 adults spent 20 hours or more per month on gigs.

- Technology did not drive most of the gig work captured in the survey. Thirteen percent of all people who engaged in gig activities used an app or online platform to find customers and receive payments. The rest found customers or received payments some other way.

\section{Dealing with Unexpected Expenses}

The survey continued to observe improvements in preparedness for small financial setbacks, although some adults were unable to pay all of their bills in full or would have been unable to do so if a modest emergency arose. Medical expenses continued to be a concern for some families in 2019, as many adults skipped medical care or had outstanding bills from medical treatments.

- Sixteen percent of adults were not able to pay all of their current month's bills in full at the time of the survey. Another 12 percent of adults said they would be unable to pay all of their current month's bills if they had an unexpected $\$ 400$ expense that they had to pay.

- If faced with an unexpected expense of $\$ 400$, 63 percent of adults said they would cover it completely using cash or a credit card paid off at the 
end of the month - an improvement from half who would have paid this way in 2013.

- Twenty-five percent of adults skipped medical care, such as a visit to a doctor or dentist, in 2019 because they were unable to afford the cost, and 22 percent incurred a major unexpected medical expense during the year.

- Eighteen percent of adults had unpaid debt from their own medical care or from medical care for a family member.

\section{Banking and Credit}

Most adults had a bank account and were able to obtain credit from mainstream sources at the end of 2019. However, substantial gaps in banking and credit services existed - especially among racial and ethnic minorities.

- Six percent of adults did not have a bank account, including 14 percent of black adults, 10 percent of Hispanic adults, and 3 percent of white adults.

- Six in 10 adults were very confident that they would be approved for a new credit card if they applied. However, 4 in 10 black adults had this level of confidence in their ability to obtain a new credit card.

- Expectations for adverse credit outcomes can be a barrier to credit access. More than 1 in 10 adults chose not to apply for credit they wanted because they expected the application to be denied.

\section{Housing}

Most adults were satisfied with their housing and most own their own homes. However, younger adults, as well as those who are black or Hispanic, were less likely to own their own homes and to say that they were satisfied with their housing than the overall average. Renters faced varying degrees of housing strain, including some who report moving due to a threat of eviction.

- Nine in 10 adults overall were satisfied with their neighborhood, and nearly that many were generally satisfied with their own housing. Eight in 10 black and Hispanic adults were satisfied with their housing.

- Renters often said that they did not own because of difficulty getting a mortgage. Sixty-four percent of renters said that an inability to qualify for a mortgage or to come up with a down payment contributed to their decision to rent.

- Three percent of non-homeowners (about 3 million adults) said that their most recent move in the past two years was due to an eviction or the threat of an eviction. Moves resulting from an eviction or the threat of an eviction were twice as likely among non-homeowners without a child as they were among other non-homeowners.

\section{Higher Education}

Economic well-being generally rises with education, and most of those holding at least an associate degree said that attending college paid off. However, the likelihood of pursuing and completing higher education varied by race, ethnicity, and family background - in part due to additional barriers faced when pursuing such education.

- Among people with at least a bachelor's degree, 7 in 10 felt that their educational investment paid off financially, whereas 3 in 10 of those who started college but did not complete at least an associate degree shared this view.

- Many attendees of for-profit institutions would have chosen a different school if given the chance to make their decision again. Fifty-four percent of those who attended a for-profit institution would like to have attended a different school, versus onefourth of those attending a private not-for-profit or public institution.

- More than 6 in 10 black and Hispanic young adults who left or did not begin college did so, at least in part, to support their families financially. Needing to work to provide financial support was a reason for not starting or not completing a certificate or a degree for 4 in 10 white young adults.

\section{Student Loans and Other Education Debt}

Over half of young adults under age 30 who went to college took on some debt to pay for their education. Most borrowers were current on their payments or had successfully paid off their loans. However, those who failed to complete a degree, and those who attended for-profit institutions, were more likely to have fallen behind on their payments. 
- Among adults who had outstanding debt for their own education in 2019, the typical amount of debt reported in the survey was between $\$ 20,000$ and $\$ 24,999$.

- Although most education debt is in the form of student loans, this is not always the case. Twentythree percent of people with outstanding debt from their education indicated that at least part of this debt was on a credit card.

- Among borrowers under age 40, those who were first-generation college students were more than twice as likely to be behind on their payments as those with a parent who completed a bachelor's degree.

\section{Retirement}

While preferences play a role in the timing of retirement for the majority of retirees, unanticipated life events contributed to the timing of retirement for a substantial share. Although most people save for their retirement and manage these savings on their own, at the end of 2019 many non-retirees were struggling to save, and those who did so frequently expressed discomfort in making investment decisions.

- Collectively, health problems, caring for family, and forced retirements contributed to the timing of retirement for 47 percent of retirees.

- One-fourth of non-retirees indicated that they have no retirement savings, and fewer than 4 in 10 non-retirees felt that their retirement savings are on track.
- Nearly 6 in 10 non-retirees with self-directed retirement savings expressed low levels of comfort about making retirement decisions.

\section{Financial Repercussions from COVID-19}

The Federal Reserve fielded a supplemental survey in April 2020 to obtain an updated perspective on financial conditions. This survey was conducted after the passage of the Coronavirus Aid, Relief, and Economic Security (CARES) Act, but before most benefits were received. This supplemental survey found that nearly one-fifth of adults experienced either a job loss or a reduction in their hours in March 2020 as the spread of COVID-19 intensified in the United States. Over one-third of those who experienced a job loss or reduction in hours expect to have difficulty with their monthly bills.

- Thirteen percent of adults indicated that they lost a job in March 2020, and an additional 6 percent said that they had their hours reduced or took unpaid leave.

- Among those who lost a job in March 2020, 91 percent anticipated that they would return to work for the same employer or indicated that they had already returned to work.

- Eighteen percent of adults did not expect to be able to pay all of their April bills in full. Among those who lost a job or had their hours reduced, 35 percent did not expect to be able to pay all bills in full. 


\section{Overall Economic Well-Being in 2019}

The share of people reporting that they were doing at least okay financially was unchanged in 2019 relative to 2018 but remained significantly above that seen when the survey began in $2013 .{ }^{3}$ This generally positive assessment of economic well-being was consistent with the continued economic expansion and the low national unemployment rate at the time. Even so, the persistent disparities across education, race, and neighborhoods remained.

\section{Current Financial Situation}

Three-quarters of adults at the end of 2019 indicated they were either "doing okay" financially (39 percent) or "living comfortably" (36 percent), matching the rate in 2018. The rest were either "just getting by" (18 percent) or "finding it difficult to get by" (6 percent). The 75 percent of adults doing at least okay financially in 2019 remained well above the 62 percent doing at least this well in 2013 (figure 1). However, based on the results of a follow-up survey conducted in early April 2020, it is apparent that financial conditions have declined since that time (see box 1 and the "Financial Repercussions from COVID-19" section of this report).

3 The survey was fielded in October 2019 and results reflect financial situations at that time. References to "during 2019" refer to the 12-month period before the survey rather than the precise calendar year.

Figure 1. At least doing okay financially (by year)

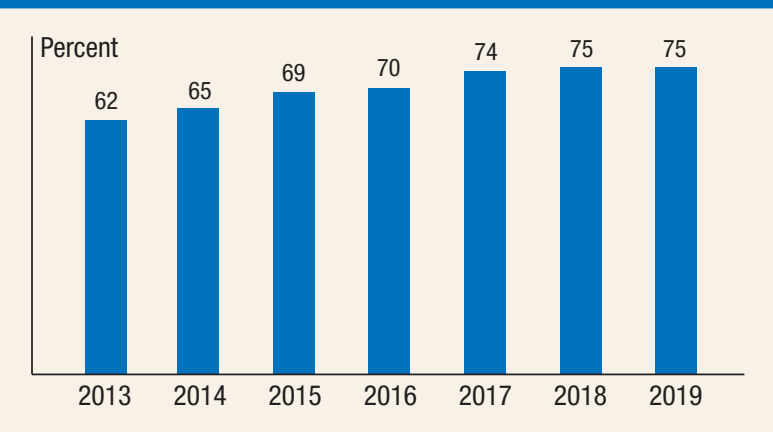

Despite the positive trend in overall well-being through 2019, differences across education groups remained substantial and grew in recent years. Adults with a bachelor's degree or more were significantly more likely to be doing at least okay financially ( 88 percent) than those with a high school degree or less ( 63 percent). This 25 percentage point difference in financial well-being by education grew by 6 percentage points over the two years from 2017 to 2019. However, the gap in 2019 was not statistically different from that observed in the first year of the survey in 2013 (figure 2).

Differences in financial well-being across racial and ethnic groups also persisted in 2019. Two-thirds of black and Hispanic adults reported that they were doing at least okay financially, compared to 8 in 10 white adults. ${ }^{4}$ These differences in well-being by race and ethnicity were statistically unchanged relative to 2018. Although white, black, and Hispanic adults all experienced improvements in their financial well-

\footnotetext{
4 Throughout this report, racial and ethnic groups are separated into white, black, and Hispanic adults. These categorizations represent the largest statistical groupings, but are neither exhaustive nor the only distinctions that are of importance to understand. Sample sizes in the survey for other races and ethnicities limit the reporting of reliable estimates for other racial and ethnic subpopulations.
}

Figure 2. At least doing okay financially (by year and education)

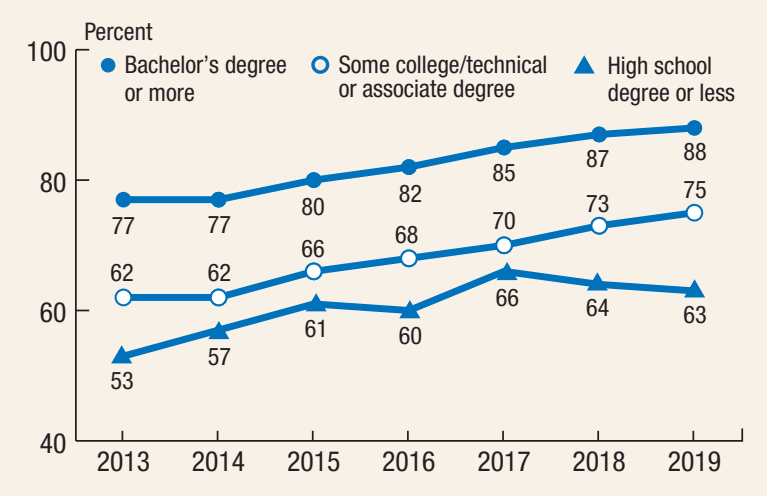




\section{Box 1. Overall Economic Well-Being in April 2020}

Although financial circumstances were generally positive for most adults at the end of 2019, financial conditions changed dramatically for many families beginning in March 2020 as the spread of COVID-19 intensified in the United States. For instance, according to the Department of Labor, record numbers of people filed initial claims for unemployment insurance benefits in the final weeks of March and the beginning of April. ${ }^{-1}$ Recognizing this changing financial landscape, the Federal Reserve Board fielded a supplemental survey ("April supplement") over the first weekend of April 2020 to obtain an updated picture of families' financial situations.

Consistent with the employment declines seen in other data, results from the April supplement point to the substantial job losses that were occurring. Thirteen percent of adults reported that they lost a job or were furloughed between March 1, 2020, and the time at which they completed the survey during the first weekend in April. However, as discussed further in the "Financial Repercussions from COVID-19" section of this report, most of those who lost a job expected in early April that the layoff would be temporary and that they would return to the same employer. An additional 6 percent of adults reported that they had their hours reduced or took unpaid leave.

1 U.S. Department of Labor, Unemployment Insurance Weekly Claims (April 9, 2020), https://oui.doleta.gov/press/2020/040920.pdf.
Similarly, fewer adults reported that they were at least doing okay financially in April 2020 than had been the case six months earlier. In the April supplement, 72 percent of adults were either "doing okay" financially (43 percent) or "living comfortably" (29 percent). This is down from the 75 percent of adults who were at least doing okay financially in the fall of 2019 and the 36 percent who were living comfortably.

These declines in self-reported financial well-being were concentrated among those who lost a job or had their hours cut (figure A). Among those adults not experiencing a job loss or reduction in hours, 76 percent were doing at least okay financially in April, which is similar to the overall share of adults who reported doing at least okay financially in the fall. Among those who experienced a job loss or hours reduction, 51 percent indicated that they were doing at least okay financially in April, whereas 48 percent were either struggling to get by or just getting by.

Recognizing that the April supplement was fielded relatively soon after families began to experience the financial repercussions of COVID-19, these results may not reflect the full extent of financial hardship that will result from the pandemic. Nevertheless, they provide an initial indication of how families were faring relative to the fall of 2019 as the economic environment changed around the country.

For more information, see "Financial Repercussions from COVID-19" later in this report.

Figure A. At least doing okay financially (by job loss or work hours reduced since March 2020)

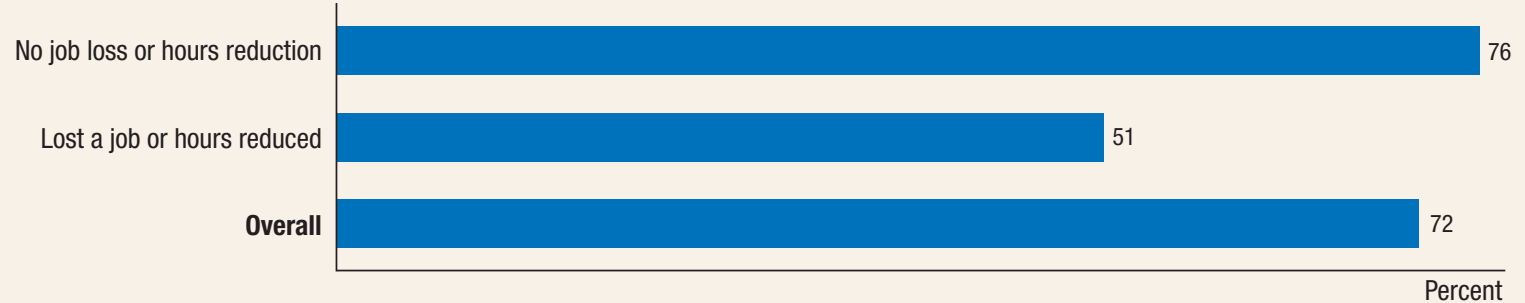

Note: April 2020 supplemental survey data.

being since the survey began in 2013, the gap in wellbeing across races and ethnicities remained at least as large (figure 3).

Although there are many potential reasons for these persistent gaps in financial well-being by race and ethnicity, one contributing factor may be discrimination. One-quarter of black adults, 18 percent of Hispanic adults, and 7 percent of white adults indicated that they personally experienced discrimination or unfair treatment in the past year because of their race, ethnicity, age, religion, disability status, sexual orientation, gender, or gender identity. ${ }^{5}$ Among the overall adult population, 12 percent of adults

\footnotetext{
5 The survey did not ask respondents about the area in their lives where they feel that discrimination occurred, although potential areas considered in earlier research include employment and credit access. For example, David Neumark provides a summary of research on discrimination in labor markets ("Experimental Research on Labor Market Discrimination," Journal of Economic Literature 56, no. 3 (2018): 799-866) while Robert Bartlett, Adair Morse, Richard Stanton, and Nancy Wallace consider discrimination in lending markets ("Consumer-
} 
Figure 3. At least doing okay financially (by year and race/ethnicity)

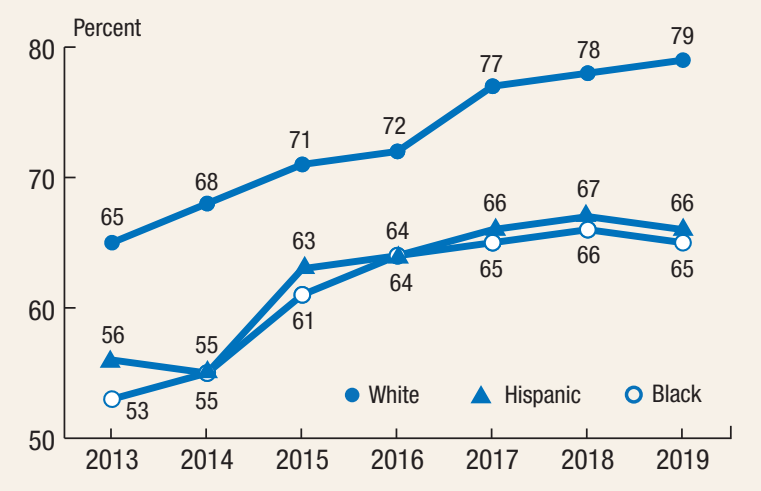

reported experiencing discrimination for one of these reasons.

Financial well-being also varied by sexual orientation in 2019. Sixty-four percent of adults identifying as gay, lesbian, or bisexual reported in 2019 that they were at least doing okay financially, compared to 77 percent of straight adults who had a similarly positive financial situation. ${ }^{6}$ The gap in well-being by sexual orientation was particularly strong among women who were married or living with a partner

Lending Discrimination in the FinTech Era," NBER Working Paper 25943 (2019)).

6 Survey respondents could report their sexual orientation as straight, gay or lesbian, bisexual, or something else. For the purposes of this report, we include those reporting something else as their sexual orientation with the group of those reporting that they are gay, lesbian, or bisexual. (figure 4). ${ }^{7}$ Among men who were married or living with a partner, there was no similar well-being gap by sexual orientation.

Other dimensions across which financial well-being differed include income, marital status, and neighborhood (table 1); as well as by exposure to crime or the criminal justice system (see box 2). Fiftyfive percent of adults with family income less than $\$ 40,000$ said they were doing okay financially, versus 95 percent of adults with income greater than $\$ 100,000$. Married individuals and those living with a partner were generally more likely to report that they were doing at least okay financially than unmarried individuals. ${ }^{8}$ People living in low- and moderateincome communities also reported lower levels of well-being than those living in middle- or upperincome communities.

There is also a small, but persistent, difference in financial well-being between those living in urban and rural areas. In 2019, individuals in rural areas were 4 percentage points less likely to report that they were at least doing okay financially than those in more urban environments - unchanged from the

\footnotetext{
7 This lower-rate of financial well-being among lesbian and bisexual female couples is consistent with the findings by Christopher Carpenter, who observed that same-sex female couples have substantially lower incomes than married heterosexual couples ("New Evidence on Gay and Lesbian Household Incomes," Contemporary Economic Policy 22, no. 1 (January 2004): 78-94).

8 Throughout this report, references to married individuals include both those who are married and those who are living with a partner.
}

\section{Figure 4. At least doing okay financially (by gender, marital status, and sexual orientation)}

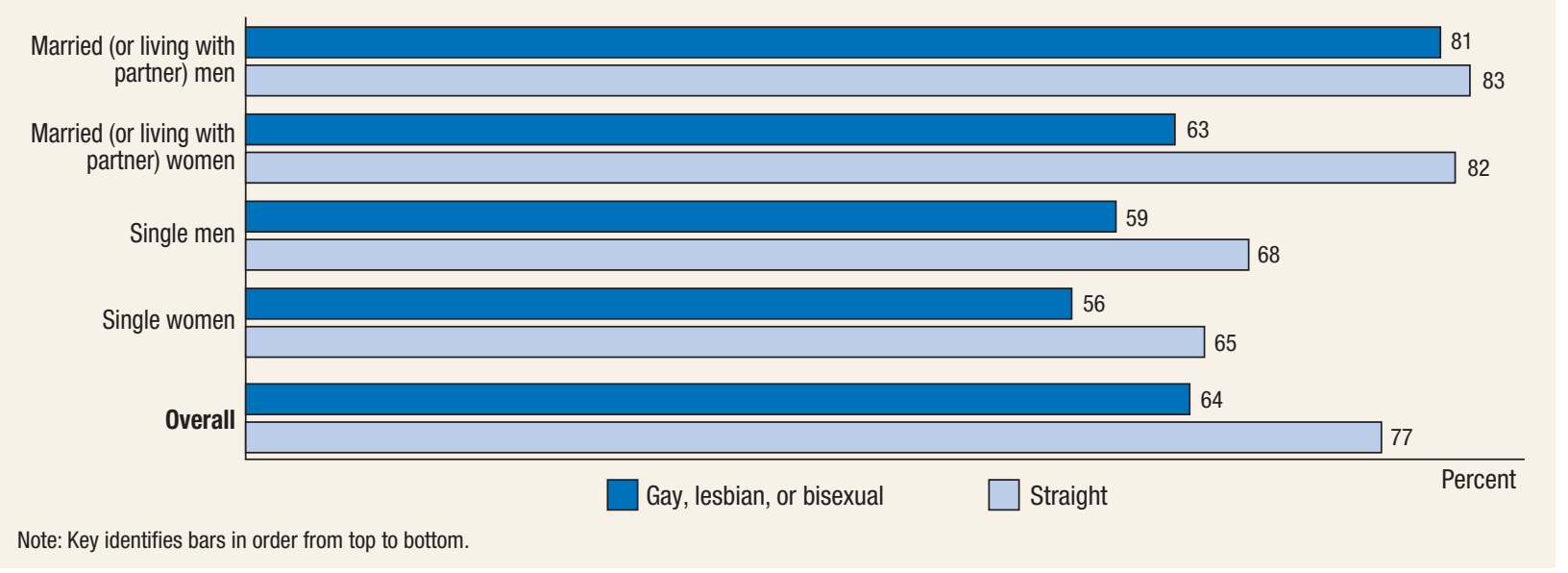


Table 1. Share of adults at least doing okay financially (by demographic characteristics)

Percent

\begin{tabular}{|c|c|c|c|}
\hline Characteristic & 2019 & $\begin{array}{c}\text { Change } \\
\text { since } 2018\end{array}$ & $\begin{array}{c}\text { Change } \\
\text { since } 2013\end{array}$ \\
\hline \multicolumn{4}{|l|}{ Family income } \\
\hline Less than $\$ 40,000$ & 55 & -1 & 13 \\
\hline$\$ 40,000-\$ 100,000$ & 81 & 2 & 15 \\
\hline Greater than $\$ 100,000$ & 95 & 1 & 13 \\
\hline \multicolumn{4}{|l|}{ Race/ethnicity } \\
\hline White & 79 & 1 & 14 \\
\hline Black & 65 & 0 & 12 \\
\hline Hispanic & 66 & 0 & 11 \\
\hline \multicolumn{4}{|l|}{ Marital status } \\
\hline Single & 65 & 0 & 10 \\
\hline Married or living with a partner & 81 & 1 & 14 \\
\hline \multicolumn{4}{|l|}{ Urban/rural residence } \\
\hline Urban & 76 & 1 & 13 \\
\hline Rural & 72 & 1 & 13 \\
\hline \multicolumn{4}{|l|}{ Neighborhood income } \\
\hline Low or moderate income ${ }^{1}$ & 64 & -2 & $n / a$ \\
\hline Middle or upper income & 80 & 1 & $\mathrm{n} / \mathrm{a}$ \\
\hline Overall & 75 & 1 & 13 \\
\hline
\end{tabular}

Note: Here and in subsequent tables and figures, percentages may not sum to 100 due to rounding and question nonresponse. Census tracts were not included in the 2013 SHED, so changes in neighborhood income since 2013 are not available.

1 Low- or moderate-income neighborhoods are defined here as those census tracts with a median household income less than 80 percent of the national median income.

n/a Not applicable.

difference seen in 2018. ${ }^{9}$ Additionally, while the financial well-being of those in both urban and rural areas rose by 13 percentage points since 2013, the 4 percentage point gap in well-being across these geographies in 2019 was nearly the same as it was when the survey began six years earlier.

\section{Changes in Financial Situation over Time}

The average well-being in a handful of broad categories across survey years could mask the degree of change - both positive and negative - within specific families. When asked directly about changes in their finances, adults in 2019 were twice as likely to report that their finances improved over the prior

\footnotetext{
9 Rural areas are defined throughout this report as being outside of a Metropolitan Statistical Area (MSA) and urban areas are those inside of a MSA, as defined by the Office of Management and Budget in 2010. This definition differs from the Census Bureau's definition of urbanized areas. For details, see U.S. Census Bureau, "2010 Urban Area FAQs," https://www.census .gov/programs-surveys/geography/about/faq/2010-urban-areafaq.html.
}

\begin{tabular}{|c|c|c|c|}
\hline Education & Worse off & $\begin{array}{l}\text { About } \\
\text { the same }\end{array}$ & Better off \\
\hline High school degree or less & 21 & 24 & 54 \\
\hline $\begin{array}{l}\text { Some college/technical or associate } \\
\text { degree }\end{array}$ & 22 & 22 & 56 \\
\hline Bachelor's degree or more & 18 & 20 & 62 \\
\hline Overall & 20 & 22 & 57 \\
\hline
\end{tabular}

12 months (32 percent) than worsened (14 percent). The remainder-54 percent of adults - said their finances were about the same as the prior year. This matches the change in well-being over time observed in the 2018 survey.

To get a longer perspective than year-to-year changes, individuals also compared their current economic well-being to their parents' at the same age. Looking across a generation, there is evidence of economic progress over time. A majority of adults (57 percent) said they were better off financially than their parents were (table 2). One-fifth said they were worse off than their parents were at the same age.

Having a bachelor's degree or more is generally associated with greater rates of upward economic mobility than having less education. This is particularly true among first-generation college graduates, among whom over two-thirds reported being better off financially than their parents were. ${ }^{10}$ The relationship between parents' educations and one's own education is discussed further in the "Higher Education" section of this report.

\section{Local Economic Conditions}

Along with questions about their own financial circumstances, people were asked to assess their local economy. Sixty-three percent of respondents rated local economic conditions as "good" or "excellent" in 2019, with the rest rating conditions as "poor" or "only fair." This was nearly unchanged from the 64 percent of adults who had a positive assessment of their local economic conditions in 2018.

The assessments differ widely by demographics and geography (table 3). Whereas 67 percent of white

\footnotetext{
${ }^{10}$ First-generation college graduates are those who have at least a bachelor's degree and who report that neither of their parents completed at least a bachelor's degree.
} 


\section{Box 2. Financial Experiences Related to Crime and the Court System}

More than 1 in 5 respondents in 2019 said they had an immediate family member who was ever incarcerated overnight or longer, and 1 in 10 have ever been the victim of violent crime. At the time of the survey, black and Hispanic adults, people with less income, and people with less education were disproportionately likely to report being affected by incarceration, violent crime victimization, and legal expenses (table A). There was also considerable overlap between those who had immediate family who had been incarcerated, victims of violent crime, and those who had unpaid legal expenses.

Criminal convictions have been shown to result in difficulty finding future employment. ${ }^{1}$ Yet, an additional repercussion that has recently received attention is the effect of court costs and legal fees on people's financial lives, in some cases, for years afterward. ${ }^{2}$ Six percent of all adults, and one-fifth of those who have had an immediate family member in prison or jail, indicated that their family had such debt at the time of the survey.

Individuals whose families had outstanding legal expenses frequently were carrying other forms of debt as well. For instance, 43 percent of those whose family had legal debt also had outstanding medical debt (figure A). Those with outstanding legal fees were also disproportionately likely to have credit card debt and more likely to carry student loan debtdespite being less likely to have gone to college than those without unpaid legal debts.

1 Devah Pager, "The Mark of a Criminal Record," American Journal of Sociology 108, no. 5 (2003): 937-75.

2 See Gene Nichol and Heather Hunt, "Court Fines and Fees: Criminalizing Poverty in North Carolina," North Carolina Policy Watch Report (2017) and Pamela Foohey, "Fines, Fees, and Filing Bankruptcy," North Carolina Law Review 98, no. 2 (2020): 419-26.
Table A. Exposure to crime and the court system (by demographic characteristics)

Percent

\begin{tabular}{c|c|c|c}
\hline Characteristic & $\begin{array}{c}\text { Ever have } \\
\text { family member } \\
\text { in prison } \\
\text { or jail }\end{array}$ & $\begin{array}{c}\text { Ever been } \\
\text { a victim of } \\
\text { violent crime }\end{array}$ & $\begin{array}{l}\text { Family currently } \\
\text { has unpaid legal } \\
\text { expenses, fines, } \\
\text { or court costs }\end{array}$ \\
\hline
\end{tabular}

Income

Less than $\$ 40,000$

$\$ 40,000-\$ 100,000$

Greater than $\$ 100,000$

Education

High school degree

or less

Some college/technical

or associate degree

Bachelor's degree

or more

Race/ethnicity

White

Black

Hispanic

Overall

\begin{tabular}{rrr}
28 & 12 & 10 \\
23 & 7 & 6 \\
14 & 7 & 3 \\
& & \\
29 & 9 & 9 \\
24 & 11 & 7 \\
13 & 6 & \\
& & 4 \\
19 & 8 & \\
36 & 11 & 5 \\
26 & 11 & 9 \\
$\mathbf{2 2}$ & $\mathbf{9}$ & $\mathbf{6}$ \\
\hline
\end{tabular}

Exposure to crime or the legal system correlates with lower levels of financial well-being. This was especially true among those who still had unpaid legal debts. Fifty-three percent of those whose family had outstanding legal debt were doing at least okay financially relative to over three-quarters of those without legal debt. Among those who ever had an immediate family member in prison or jail, 65 percent were doing at least okay financially.

(continued on next page)
Table 3. Self-assessment of the local economy as good or excellent (by select characteristics)

Percent

\begin{tabular}{l|c}
\hline \multicolumn{1}{c|}{ Characteristic } & Good or excellent \\
\hline Race/ethnicity & \\
White & 67 \\
Black & 46 \\
Hispanic & 57 \\
Urban/rural residence & \\
Urban & 65 \\
Rural & 53 \\
\hline Neighborhood income & \\
\hline Middle or upper income & 69 \\
Low or moderate income & 45 \\
Overall & $\mathbf{6 3}$ \\
\hline
\end{tabular}

adults viewed their local economic conditions as good or excellent, 46 percent of black adults and 57 percent of Hispanic adults rated their local economies favorably. Looking across geography, majorities of both urban and rural residents rated their economy as good, although those living in urban areas viewed their local economic conditions more favorably: 53 percent of adults living in rural areas rated their economy as at least good, compared to nearly two-thirds of those living in or near cities. Adults who live in low- and moderate-income neighborhoods were much less likely to report favorable local economic conditions than those in middle- or upper-income neighborhoods.

Subjective measures of local economic conditionslike these self-assessments - can add to our under- 


\section{Box 2. Financial Experiences Related to Crime and the Court System -continued}

\section{Figure A. Other forms of debt outstanding (by unpaid legal expenses)}

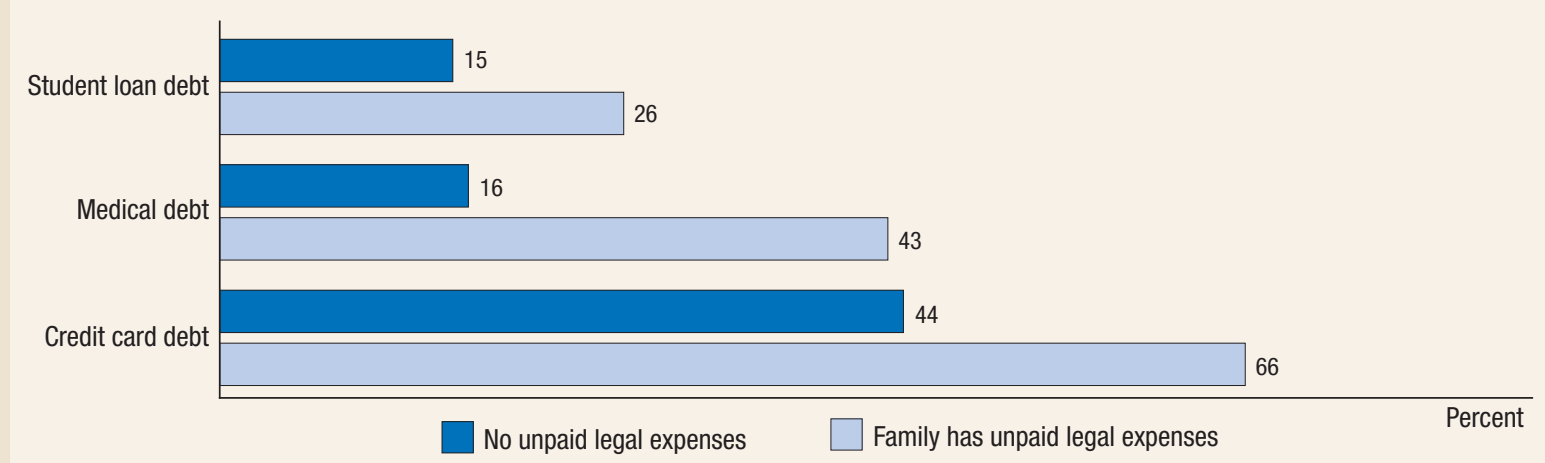

Note: Key identifies bars in order from top to bottom. Credit card debt among adults with at least one credit card.

Similarly, carrying debt from legal expenses correlates with less access to credit and banking products, which can exacerbate the financial challenges. Fewer than half of those whose family had unpaid legal debts were fully banked (table B). Four in 10 of those in this group were underbanked-meaning they had a bank account but also relied on one or more alternative financial service. Additionally, those whose family had outstanding legal expenses were both less confident that they would be approved for a credit card and were more likely to report a credit denial than those without these outstanding expenses.
Table B. Gredit confidence, credit denials, and banking status (by unpaid legal expenses)

Percent

\begin{tabular}{l|c|c|}
\hline \multicolumn{1}{c|}{$\begin{array}{c}\text { Credit and banking } \\
\text { status }\end{array}$} & No unpaid legal expenses & $\begin{array}{c}\text { Family has unpaid legal } \\
\text { expenses }\end{array}$ \\
\hline Credit experience & & \\
Confident about credit & 82 & 56 \\
Denied credit & 22 & 52 \\
Banking status & 5 & 13 \\
Unbanked & 14 & 39 \\
\hline Underbanked & 81 & 48 \\
\hline Fully banked & & \\
\hline
\end{tabular}

Note: "Denied credit" is among adults who applied for credit in the year before the survey. Fully banked individuals had a bank or credit union account and had not used an alternative financial service in the past year. standing of individual experiences. As one example, consider the 9 percent of adults in 2019 who personally knew someone who was currently addicted to opioids or prescription painkillers. ${ }^{11}$ Some research argues that economic decline in certain communities has contributed to the opioid epidemic. ${ }^{12}$ In 2019 ,

${ }^{11}$ In 2018, the SHED found that 21 percent of adults personally knew someone who has been addicted to opioids or prescription drugs. In order to obtain a more current measure of opioid addiction, the question was revised in 2019 to ask whether respondents personally know someone who is currently addicted to opioids or prescription drugs. This change in reference period means that the results are not comparable across these years.

${ }^{12}$ See Jeff Larrimore et al., "Shedding Light on Our Economic and Financial Lives?" FEDS Notes (Washington: Board of those who viewed their local economy as good or excellent were less likely to say that they personally knew someone who was dealing with addiction to opioids ( 8 percent) than were those who viewed their local economy as fair or poor (11 percent). Even after accounting for race, rural or urban status, and neighborhood income, the modest relationship between opioid exposure and self-assessed local economic conditions remains.

Governors of the Federal Reserve System, May 22, 2018), https://www.federalreserve.gov/econres/notes/feds-notes/ shedding-light-on-our-economic-and-financial-lives20180522.htm. 


\section{Income}

Income is central to most people's economic wellbeing. The ability to meet current expenses and save for the future typically depends on income being sufficient and reliable. Some depend on outside financial support from, or provide such support to, their family or friends. Frequent changes in the level of family income, referred to here as "income volatility," can be a source of economic hardship. This income volatility was disproportionately prevalent for those working in industries such as construction or leisure and hospitality in 2019.

\section{Level and Source}

Family income in this survey is the cash income from all sources that the respondent and their spouse or partner received during the previous year. Income is reported in dollar ranges as opposed to exact amounts. One-quarter of adults had a family income of less than $\$ 25,000$ during 2019 and 37 percent had less than $\$ 40,000$ (figure 5). ${ }^{13}$

Wages, salaries, and self-employment were the most common source of family income received, with 7 in 10 adults and their spouse or partner receiving wage income during 2019. Yet, over half of adults (54 percent) also received non-wage income in their family.

The sources of income varied substantially by race and ethnicity in 2019 (table 4). ${ }^{14}$ Sixty-two percent of

${ }^{13}$ The income distribution in the 2019 SHED is largely similar to the 2019 March Current Population Survey, although a higher fraction of adults in the SHED said that their income, and that of their spouse or partner, was at least $\$ 40,000$ and a lower fraction had incomes below $\$ 40,000$. The higher income may partly reflect the fact that unmarried partners were treated as one family in the SHED, while in the Current Population Survey they appeared independently.

${ }^{14}$ Although sources of income additionally vary with age, analyzing by age cohorts along with race and ethnicity did not weaken these results.

\section{Figure 5. Family income distribution}

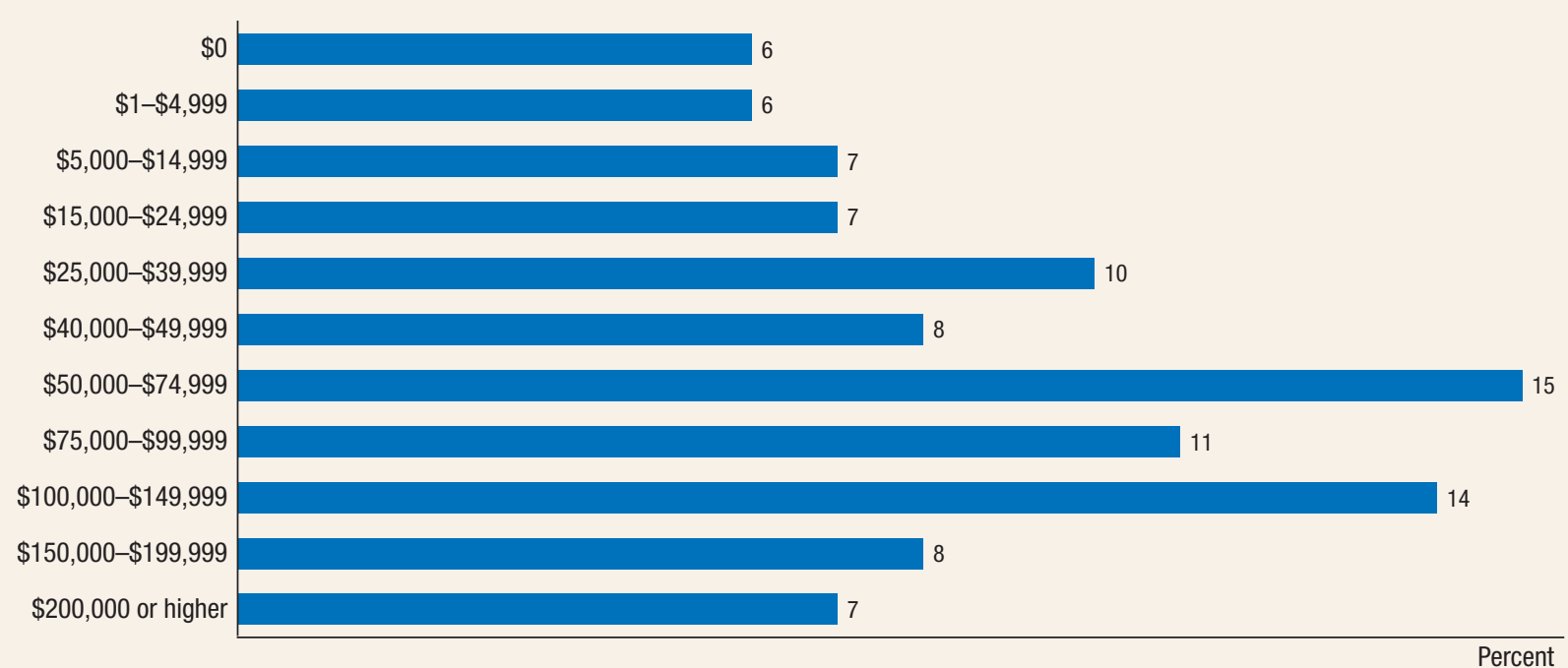

Note: Includes cash income only. 


\begin{tabular}{|c|c|c|c|c|}
\hline \multicolumn{5}{|l|}{ Percent } \\
\hline Source & White & Black & Hispanic & Overall \\
\hline \multicolumn{5}{|l|}{ Wages, salaries, or } \\
\hline Interest, dividends, or rents & 39 & 15 & 16 & 33 \\
\hline Social Security & 30 & 25 & 17 & 26 \\
\hline Pension & 23 & 18 & 10 & 19 \\
\hline \multicolumn{5}{|l|}{ Cash transfers other than } \\
\hline Social Security & 6 & 12 & 9 & 7 \\
\hline Non-cash transfers & 9 & 27 & 23 & 14 \\
\hline
\end{tabular}

Note: Respondents could select multiple answers.

black adults and 66 percent of Hispanic adults received wage or salary income. Seventy-one percent of white adults received wage or salary income. Similarly, while one-third of all adults received property income (interest, dividends, or rental income) in 2019, 15 percent of black adults and 16 percent of Hispanic adults received property income.

Assistance through social safety net programs also plays a role. Non-cash transfer programs supplemented income for some families. Overall, 14 percent of adults reported receiving support from one or more non-cash transfer program in the survey. This exceeds the 7 percent who received cash transfer income other than Social Security. ${ }^{15}$

Consistent with differences in overall income by race and ethnicity, black and Hispanic adults were disproportionately likely to receive both cash and non-cash transfer income. For example, 12 percent of black adults and 9 percent of Hispanic adults received a cash transfer other than Social Security. Similarly, 27 percent of black adults and 23 percent of Hispanic adults received non-cash transfer income. Each of these exceed the prevalence seen among the overall adult population.

\section{Financial Support from Family and Friends}

One in 10 adults received some form of financial support from a friend or family member living out-

\footnotetext{
${ }^{15}$ Non-cash transfer programs included were the Supplemental Nutrition Assistance Program (SNAP); the Special Supplemental Nutrition Program for Women, Infants, and Children (WIC); housing assistance; and free and reduced-price school lunches. Cash transfer programs included were Supplemental Security Income (SSI), Temporary Assistance for Needy Families (TANF), cash assistance from a welfare program, and unemployment income.
}

\begin{tabular}{|c|c|c|}
\hline Age & Receive support & Provide support \\
\hline $18-24$ & 38 & 10 \\
\hline $25-29$ & 18 & 10 \\
\hline $30-44$ & 9 & 15 \\
\hline $45-59$ & 5 & 24 \\
\hline $60+$ & 3 & 18 \\
\hline Overall & 10 & 17 \\
\hline
\end{tabular}

side of their home in 2019. Young adults were more likely to receive financial support, with nearly 4 in 10 people ages 18 to 24 and nearly 2 in 10 between ages 25 and 29 receiving such support. ${ }^{16}$ Conversely, adults age 30 and older were more likely to provide financial support to others. Providing support peaks at ages 45 to 59 , with one-quarter of adults in this age range providing such support (table 5).

Financial support is mainly between parents and adult children, with over two-thirds of recipients indicating the support they received came from a parent in 2019. An even higher 87 percent of recipients under age 30 indicated that the support came from a parent. Support also flows up generations. Although relatively few people over age 60 received support from outside their home, 56 percent of those who did received it from their adult children.

Those struggling financially were more likely to receive support than those doing at least okay: 20 percent compared to 6 percent in 2019. Yet despite experiencing their own financial challenges, 14 percent of those struggling financially also provided financial support. One-fifth of families who received support in the past year also provided support to someone else.

Financial support from family and friends takes many forms. Among young adults under age 25, nearly one-fourth received money for general expenses, 21 percent received money for other bills, and 15 percent received money for rent or mortgage payments. In addition, 16 percent received help with education or student loans. The most important forms of support were similar for people in their late 20 s (figure 6).

\footnotetext{
${ }^{16}$ This question asked specifically about support from outside the home. As discussed in the "Housing" section of this report, some people also lived with others for financial reasons.
} 
Figure 6. Forms of financial support received by young adults from someone outside of the home (by age)

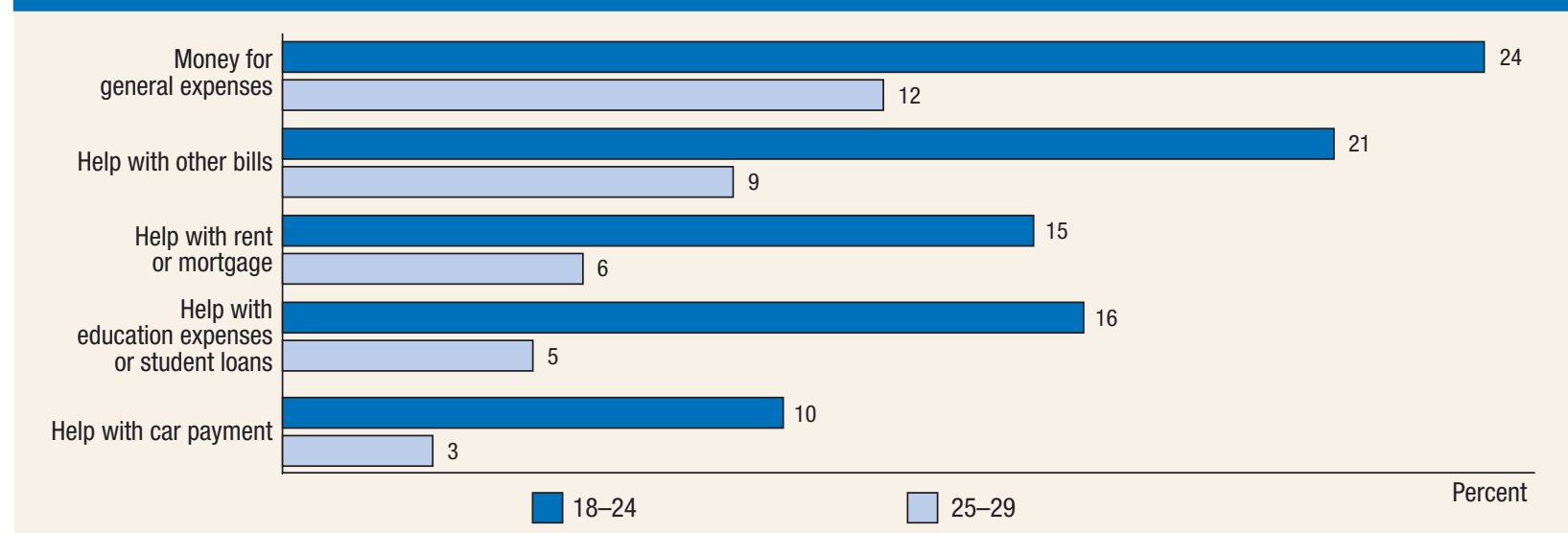

Note: Key identifies bars in order from top to bottom. Among all respondents, including those not receiving support. Respondents could select multiple answers.

\section{Income Volatility}

The level of income during the year as a whole may mask substantial changes in income from month to month. The survey considers how mismatches between the timing of income and expenses may lead to financial challenges.

Income in 2019 was roughly the same from month to month for 7 in 10 adults, varied occasionally for 2 in 10 , and varied quite often for slightly less than 1 in 10 . This generally matched the level of income volatility observed in $2018 .{ }^{17}$ Some families can manage these frequent changes in income easily, but for others this may cause financial hardship. In fact, over one-third of those with varying income, or 1 in 10 adults overall, said they struggled to pay their bills at least once in the past year due to varying income.

Income volatility varied by industry. Those in professional and business services, public administration, manufacturing, financial activities, information, and education and health services industries were more likely to report stable income. Fewer than 3 in 10 people working in each of these sectors reported income that varied at least occasionally in 2019. Those working in construction, or in the leisure and hospitality sector, were more likely to report unstable income. At least 4 in 10 workers in each of these industries reported that their income varied at least occasionally (figure 7).

\footnotetext{
${ }^{17}$ As discussed in the Report on the Economic Well-Being of U.S. Households in 2016, this volatility can occur for a variety of reasons. Some, such as irregular work schedules, may result in months with unexpectedly low incomes, whereas others, such as bonuses, may result in months with unexpectedly high incomes.
}

A substantial number of adults engage in "gig work," or informal paid activities. This can be used to smooth income for some. More frequently, however, those doing gig activities indicated that it is instead a source of volatility. Of those who participated in gig work, 27 percent said that their gig activities increased the volatility of their income. A smaller 6 percent of gig workers said that their gig activities reduced the amount of volatility. (Gig work, including details on specific activities, is discussed further in the "Employment" section of this report).

One way that those with volatile incomes can smooth consumption is through borrowing, but only if credit is available. Those who felt that credit was unavailable were more likely to report volatility-related financial hardships. Among adults who were not confident in their ability to get approved for a credit card, 3 in 10 experienced hardship from income volatility in the prior year. This compares to 6 percent of those who were confident in their credit availability who experienced volatility-related hardships (table 6). (Access to credit is discussed further in the "Banking and Credit" section of this report.)

Table 6. Income volatility and related hardship (by credit confidence)

Percent

\begin{tabular}{l|c|c|c} 
Credit confidence & Stable income & $\begin{array}{c}\text { Varying income, } \\
\text { no hardship }\end{array}$ & $\begin{array}{l}\text { Varying income, } \\
\text { causes hardship }\end{array}$ \\
\hline Confident & 74 & 20 & 6 \\
Not confident & 61 & 9 & 29 \\
Overall & $\mathbf{7 1}$ & $\mathbf{1 9}$ & $\mathbf{1 0}$ \\
\hline
\end{tabular}

Note: "Overall" includes those who did not know if they were confident about credit availability. 
14 Report on the Economic Well-Being of U.S. Households in 2019

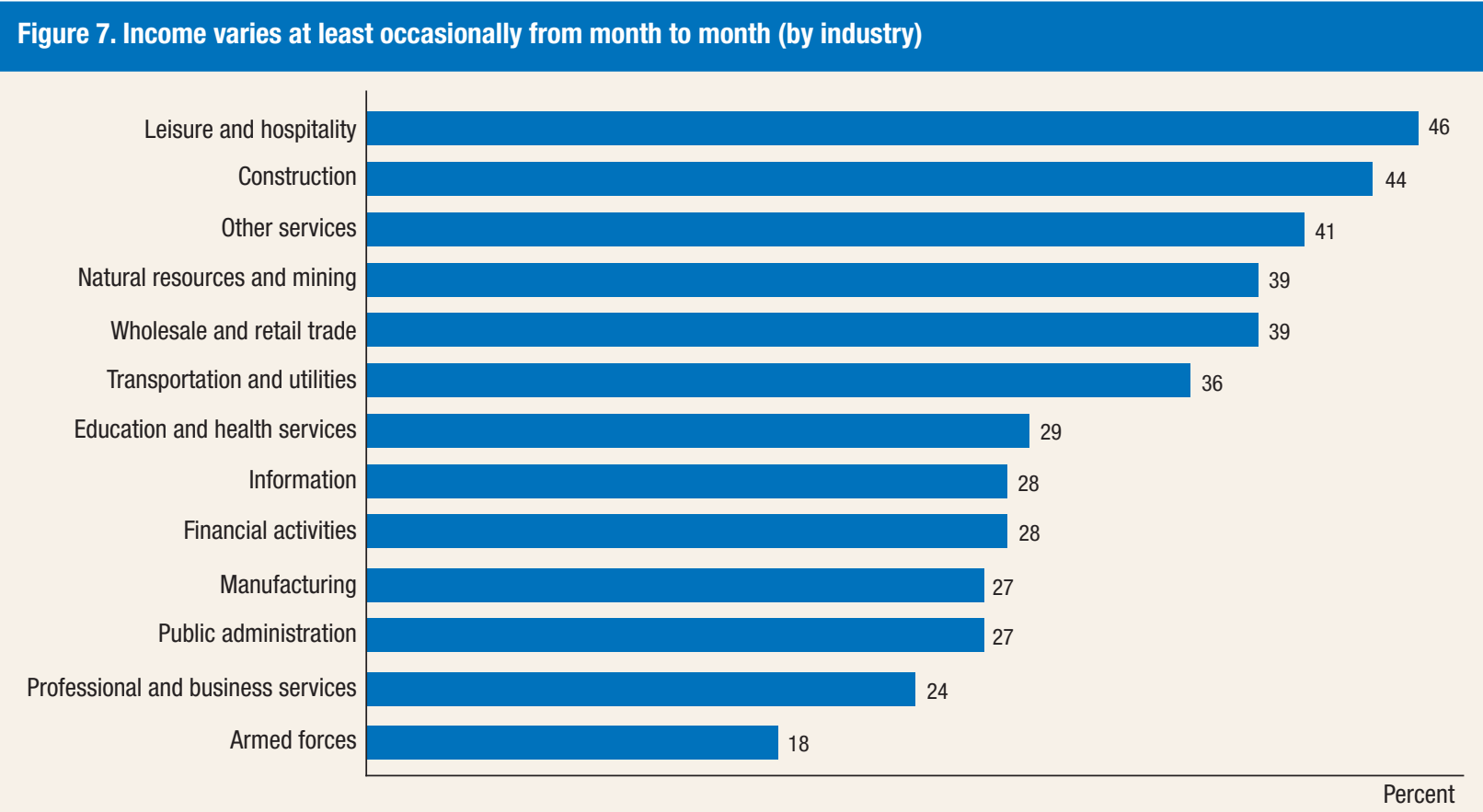




\section{Employment}

Nearly one in five adults - including one in four Hispanic and black adults - were not working full time and wanted more work in late 2019. Many adults also performed gig activities in the month before the survey - both online and offline. Gig activities are treated separately from formal employment in the SHED. Were people who spent more than 20 hours in the last month on gig activities counted as employed, irrespective of any other formal employment, it would increase the share of adults considered to have worked in the month before the survey by 2 percentage points. This increase is equivalent to adding 13 percent more part-time workers. ${ }^{18}$

\section{Wanting to Work}

Despite a strong economy at the time of the survey, nearly one in five adults were not working full time

\footnotetext{
${ }^{18}$ The share of adults who worked in the last month in the SHED differs from the employment rate computed by the Bureau of Labor Statistics (BLS) in terms of its reference period (month versus week). The percentage working in the last month could also differ from the employment rate published by the BLS because the BLS asks about employment using slightly different wording and because the BLS interviews respondents in person and via phone, as opposed to online.
}

and said that they would have liked more work. Eleven percent of adults wanted to work and were not working in the month before the survey; 7 percent wanted more work and were working part time.

The share of people who would have liked more work, but were not working full time, varied by race, ethnicity, and education (figure 8). Black and Hispanic adults were disproportionately likely to say that they would have liked to work more, with one in four saying they would like to do so. Adults with less education were also more likely to want more work. One-quarter of all adults with a high school degree or less were not working full time and wanted more work, compared with 10 percent of bachelor's degree recipients.

Part-time workers were more likely to say they wanted more work than were adults who were not working at all. Forty-six percent of part-time workers said they wanted more work in the month before the survey. This compares to 31 percent of adults who were not working.

There are several reasons people who wanted to work more were not doing so. These included a lack

Figure 8. Not working full time and want to work more than currently working (by education and race/ethnicity)

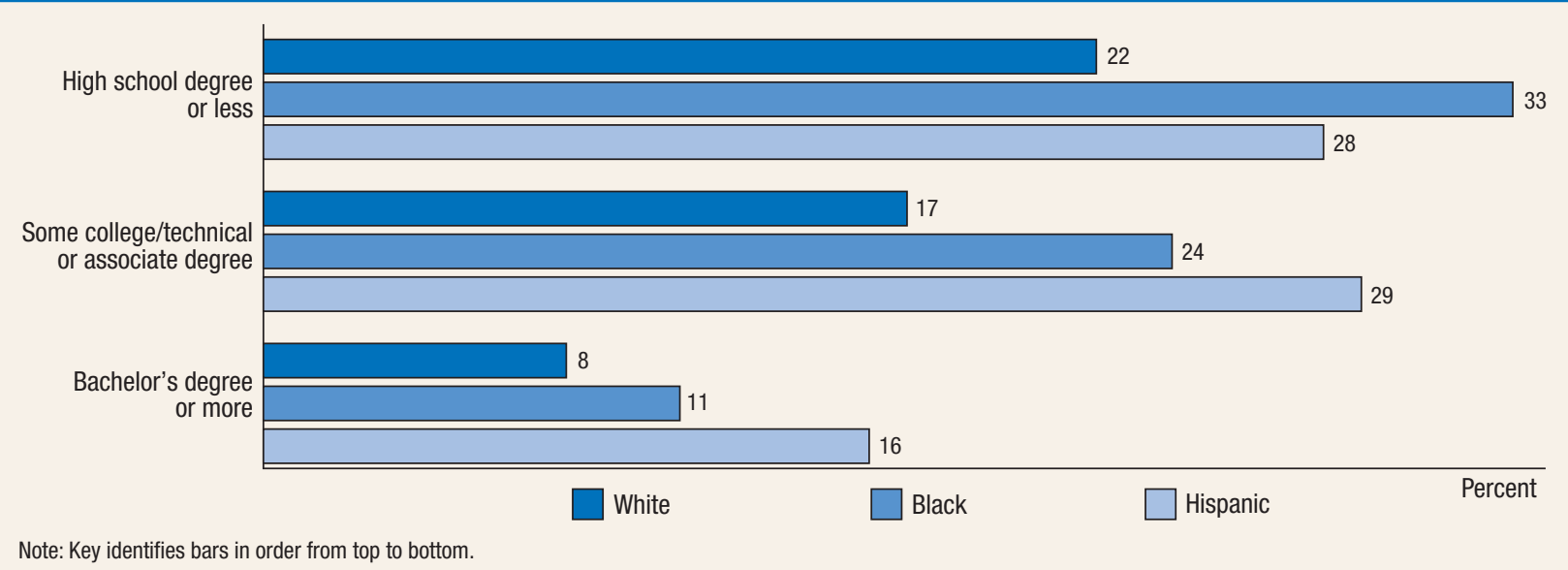


Figure 9. Reasons for not working among prime-age adults

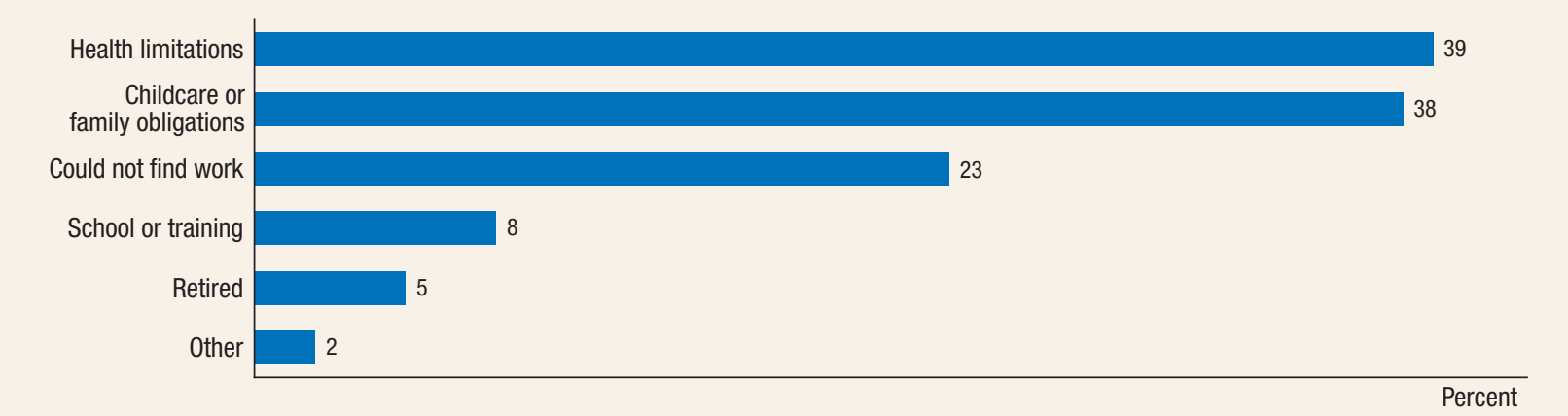

Note: Among adults who were not working. Childcare and family obligations were asked as two separate questions but are combined for the purpose of this report. Respondents could select multiple answers.

of available work, as well as other constraints on people's time. Collectively, half of people wanting more work indicated that a lack of opportunities contributed to their employment situation, including 72 percent of part-time workers and 36 percent of non-workers. ${ }^{19}$ Yet substantial numbers also cited other reasons, including 37 percent who cited childcare or family obligations and 35 percent who cited health limitations.

\section{Reasons for Not Working}

Prime-age adults, or adults ages 25 to 54, have often completed their education and are healthy enough to work. But about one in five of this group reported not working in the month leading up to the survey.

Health limitations, childcare, family obligations, and an inability to find a job kept some prime-age adults from working (figure 9). Thirty-nine percent of non-working prime-age adults said that health limitations contributed to their not working. Thirtyeight percent said that household responsibilities contributed to their not working-including 21 percent who specifically cited childcare. Twentythree percent said they were not working because they could not find work. Relatively few prime-age adults reported that they were not working because they were in school or retired.

Women who were not working disproportionately said that household responsibilities - childcare and family obligations - kept them from working in formal employment. Forty-six percent of non-working prime-age women cited these household responsibili-

\footnotetext{
${ }^{19}$ A similar 35 percent of non-workers who said they wanted work have applied for a job in the 12 months since November 2018 .
}

ties (figure 10). Non-working women ages 30 to 44 were the most likely to cite household responsibilities, at 54 percent.

By contrast, men who were not working often said they either had trouble finding work or that they had health limitations. Forty-six percent cited health limitations or a disability, and 28 percent said they could not find work. A smaller 23 percent cited household responsibilities.

Household responsibilities are particularly a barrier to two-earner couples. Half of non-working primeage adults whose partner worked cited household responsibilities as a reason for not working themselves. For comparison, 3 in 10 of those in a couple where neither partner worked said that household responsibilities contributed to their employment decision.

\section{Part-Time and Temporary Jobs}

In 2019, most workers had full-time, permanent positions, but 15 percent of adults worked part time and 5 percent said that their main job was a temporary position (usually part-time).

People who had a part-time or temporary job reported more financial strain than people who worked full time. Thirty-one percent of part-time and temporary workers said that they were either just getting by or finding it difficult to get by. A smaller 20 percent of full-time, permanent workers exhibited this level of financial strain.

Part-time work was more common among women than among men. It was also more common in rural areas. Eighteen percent of women worked part time, while 12 percent of men did. Similarly, 18 percent of 
Figure 10. Reasons for not working among ages 25-54 (by gender)

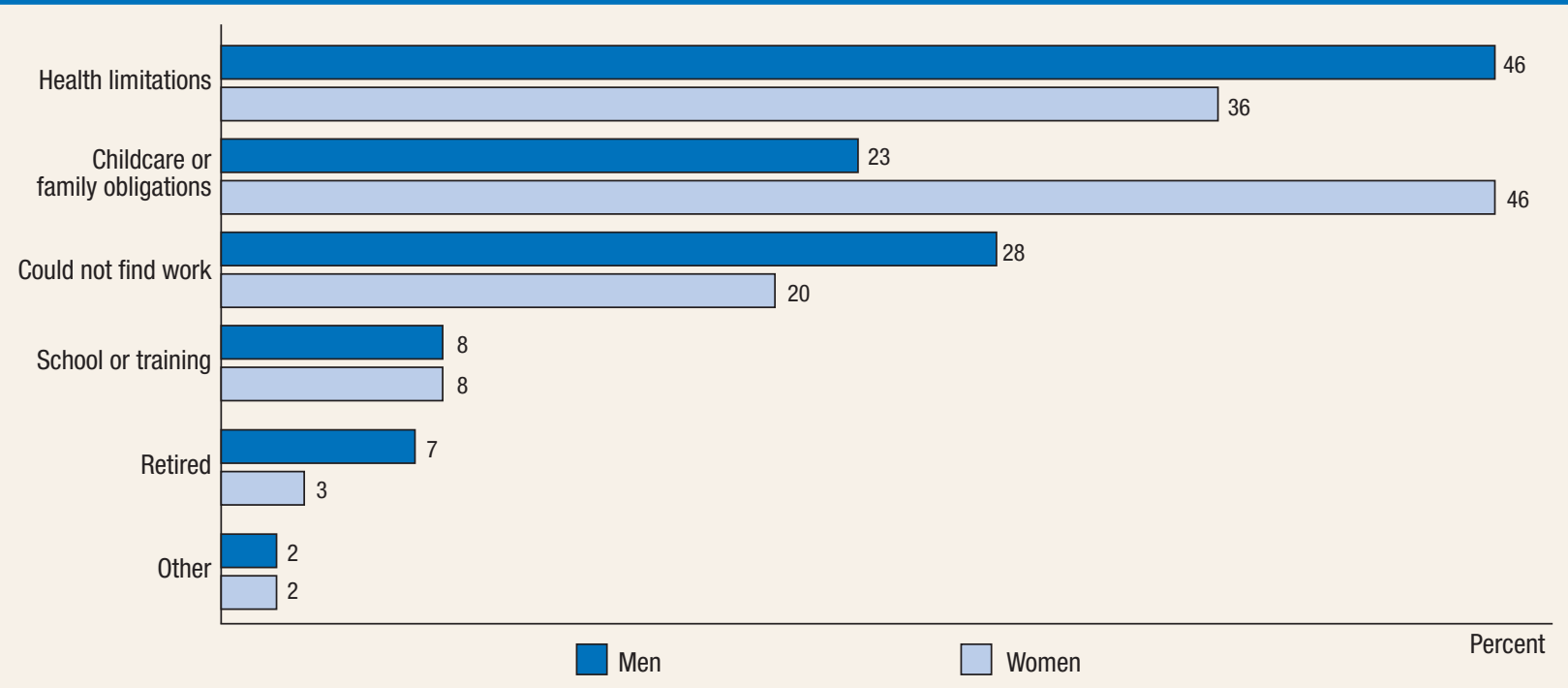

Note: Key identifies bars in order from top to bottom. Among adults who were not working. Childcare and family obligations were asked as two separate questions but are combined for the purpose of this report. Respondents could select multiple answers.

adults in rural areas worked part-time jobs, compared to 15 percent of adults who lived in or near cities.

\section{Schedules and Workplaces}

When and where people work can affect their financial well-being. Seventeen percent of employees had a work schedule that varied based on their employers' needs, and 9 percent had a schedule that varied at their own request. Collectively, one-fourth of employees had a varying work schedule. Working an irregular schedule was often associated with financial strain, but not uniformly so. Sixty-eight percent of workers with a schedule that varied based on their employer's needs said that they were doing at least okay financially (table 7). This compares to 79 per-

Table 7. Doing at least okay financially (by work schedule and usual work location)

\begin{tabular}{l|c}
\multicolumn{1}{c|}{ Schedule and location } & Percent \\
\hline Usual work schedule & \\
\hline Normally work same hours & 79 \\
Varies by my own needs & 83 \\
Varies by employer's need & 68 \\
Usual work location & \\
A place belonging to my employer & 78 \\
At home & 82 \\
Remote location & 71 \\
\hline
\end{tabular}

Note: Among adults working for someone else. cent of workers with a fixed schedule who said that they were doing at least okay financially.

Working at a job site, or at a customer's location, can also add uncertainty in a worker's day. Nine percent of adults who worked for someone else did their work at a place that is neither their home nor a place that belongs to their employer (remote locations). Seven percent worked from home most of the time, with that fraction being slightly higher (7 percent) among those living in or near cities compared to those in rural areas (5 percent).

Workers without college educations were more likely to work at remote locations than workers with more education (figure 11). But more workers with a bachelor's degree ( 9 percent) worked from home, compared to those with no education beyond a high school degree (4 percent). The difference in rates of working from home by education level was amplified during the extensive social distancing in April 2020 (see the "Financial Repercussions from COVID-19" section of this report).

\section{The Gig Economy}

Gig activities (gigs) in this report include childcare, house cleaning, ride sharing, selling goods, and renting out property. ${ }^{20}$ Most gigs predate the internet,

${ }^{20}$ The list of gig activities and analysis of their relationship to reported employment was similar to Anat Bracha and Mary 
Figure 11. Usual place of work (by education)

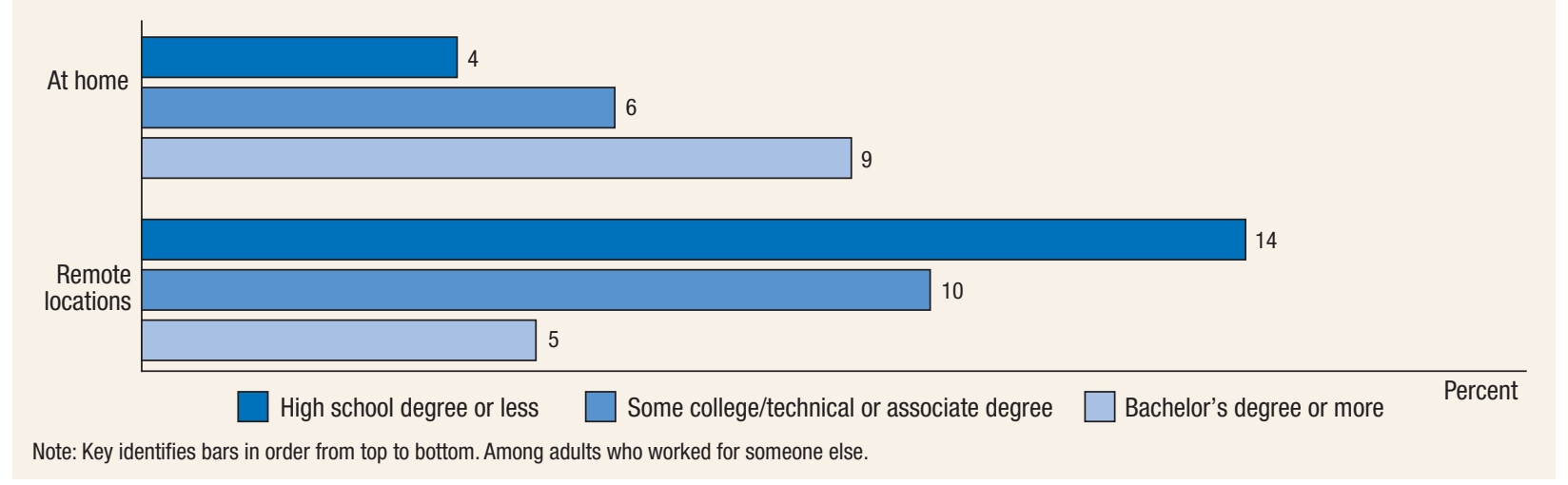

though some occur online. They do not always fit into standard concepts of "employment" because people can do gigs occasionally and without firm time commitments. Yet gigs could help people to supplement incomes in difficult times, and for a few people, they are a primary source of income. ${ }^{21}$

Nearly one in three adults earned money from gigs. However, most only spent a few hours per month on these activities. A smaller 1 in 10 adults were "regular" gig workers, defined here as someone who spent at least 20 hours in the prior month on gigs.

Among regular gig workers (those who spent at least 20 hours per month on gigs), 47 percent also reported working full time, whereas 33 percent also reported working part time. About one-fifth of regular gig workers did not do other work for pay or profit in the last month. Hence, 2 percent of adults spent at least 20 hours in the month before the survey on gig activities, despite saying that they did not work in that month. People only performing gig activities are not included as employed in the SHED. However, were they counted as employed, it would increase the number of part-time workers in the survey by 13 percent.

Burke, "Informal Work in the United States: Evidence from Survey Responses," Current Policy Perspectives (Boston: Federal Reserve Bank of Boston, 2014). For the further development of the gig questions now used in the SHED, see Barbara Robles and Marysol McGee, "Exploring Online and Offline Informal Work: Findings from the Enterprising and Informal Work Activities (EIWA) Survey," Finance and Economics Discussion series 2016-089 (Washington: Board of Governors of the Federal Reserve System, October 2016).

${ }^{21}$ In the Report on the Economic Well-Being of U.S. Households in 2016 , it was observed that 56 percent of adults performing informal gig work felt that this income was somewhat or very important for offsetting the negative effects of reduced hours or wages in a formal job.
Selling goods makes up a substantial share of gig activities reported in 2019 (figure 12). Fourteen percent of all adults sold goods to make money in the month before the survey, including 9 percent who sold goods online and 8 percent who sold goods in person ( 3 percent did both). Among people who sold goods, nearly three-fourths sold goods that they previously owned for their own use, such as used clothing. People less frequently sold goods that they acquired to resell, made themselves, or sold on behalf of a company (table 8).

Other gigs include activities such as house cleaning, yard work, childcare, renting out property, dog walking, and ride sharing. Seven percent of adults said they earned money doing house cleaning, yard work, or maintenance in the last month. Additionally, 4 percent provided childcare, 4 percent rented out property, 3 percent earned money by dog walking, and 3 percent drove to earn money.

Gigs that are coordinated online have received a lot of attention, but in 2019 most people coordinated gigs without apps or online platforms. Thirteen percent of adults who performed gig activities both found customers and received payments through an app or online platform, while the rest found custom-

Table 8. Types of items sold in the gig economy

\begin{tabular}{l|c}
\multicolumn{1}{c|}{ Item type } & Percent \\
\hline Previously owned items for own personal use & 73 \\
Purchased items to resell for a profit & 23 \\
Made or repurposed items & 16 \\
Items sold on behalf of a company & 5 \\
\hline
\end{tabular}

Note: Among adults selling goods as a gig activity. Respondents could select multiple answers. 


\section{Figure 12. Share of adults performing gig activities}

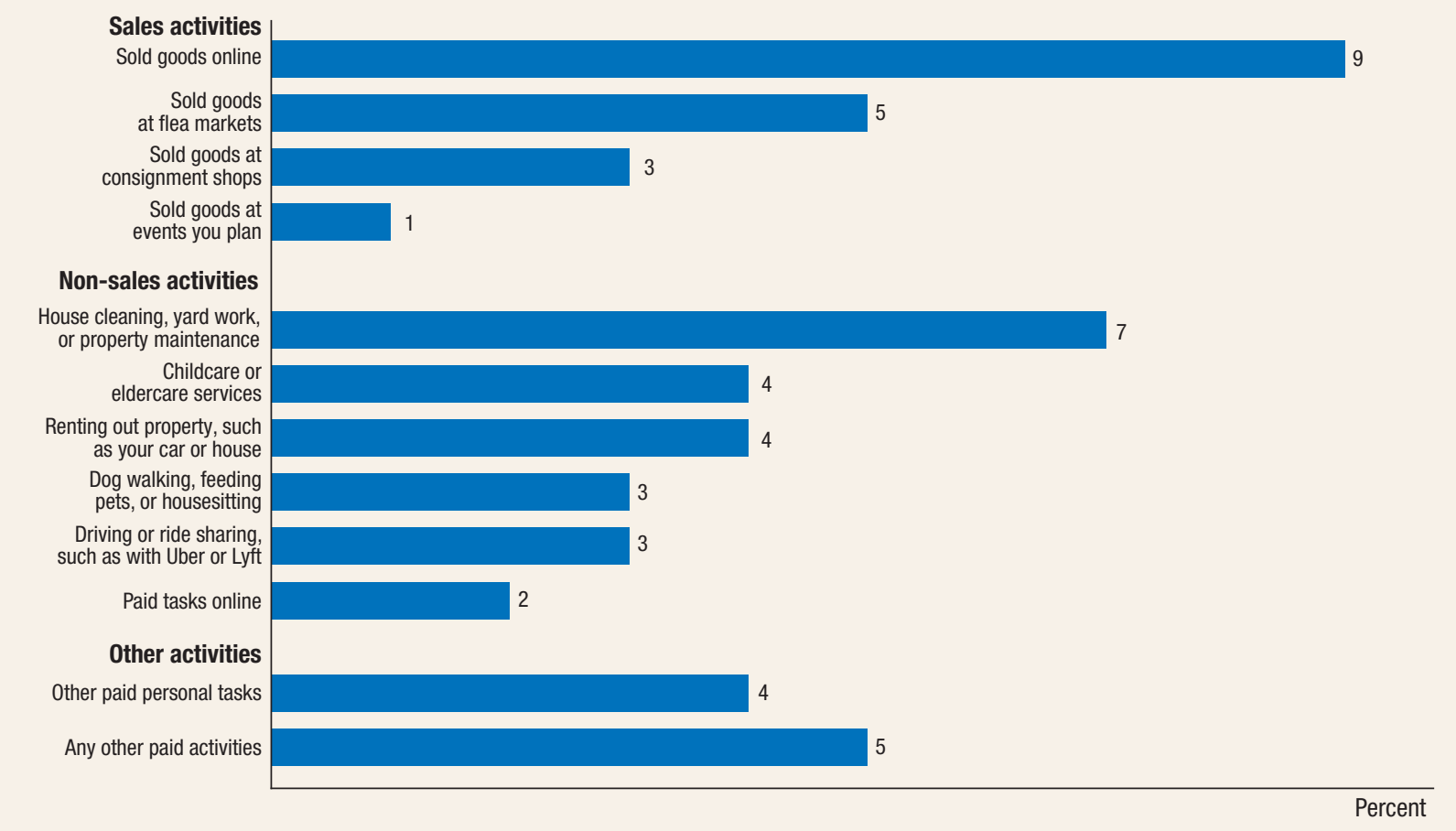

Note: Respondents could select multiple answers.

ers or received payments some other way. Apps were slightly more common among regular gig workers, although even among this group just 19 percent used an app or online platform both to find customers and to receive payments.

Few relied on gigs as a primary source of income at the time of the survey. Three percent of all adults ( 9 percent of people who reported doing gigs in the month before the survey) earned at least half of their income in the past year from gigs. Only 3 percent of all adults said that they performed gig activities primarily because it was their primary source of income in the past month (figure 13). Fifteen percent said that the main reason was to earn additional income, and 7 percent used gigs primarily as a way to sell items they no longer needed. Even among the 10 percent of adults who were regular gig workers, just 22 percent earned at least half of their income in the past year from gig work. Nevertheless, supplemental income from gigs could help some people to get by financially.

Figure 13. Main reason for gig activities

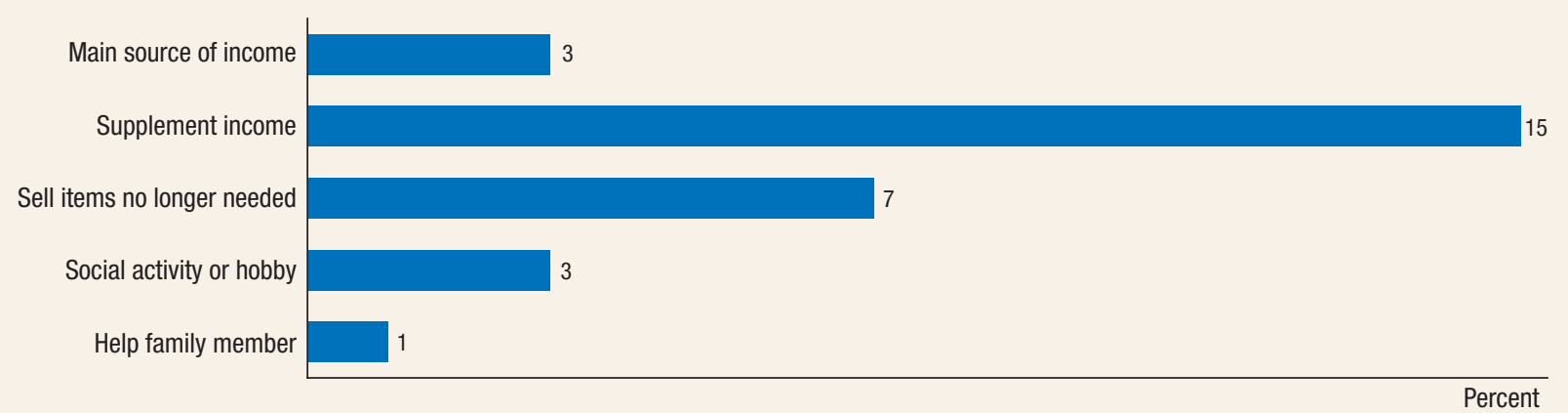

Note: Among all adults, including those not performing gig activities. Less than 1 percent of adults performed activities mainly to develop job-related skills. 



\section{Dealing with Unexpected Expenses}

Many adults were not well prepared to withstand even small financial disruptions in 2019, though the ability to handle unexpected expenses had improved markedly since 2013. Despite the positive trends, financial challenges remained, especially for those with less education as well as for minorities. This highlights the potential for financial disruptions to families' finances from even a relatively short period of lost wages.

\section{Small, Unexpected Expenses}

Relatively small, unexpected expenses, such as a car repair or a modest medical bill, can be a hardship for many families. When faced with a hypothetical expense of $\$ 400,63$ percent of adults in 2019 said they would cover it exclusively using cash, savings, or a credit card paid off at the next statement (referred to, altogether, as "cash or its equivalent") - a 2 percentage point increase from 2018 (figure 14). In 2013, half of adults would have covered such an expense in this way. As discussed in the "Financial Repercussions from COVID-19" section of this report, the share of all adults who would pay using cash or its equivalent was nearly unchanged in April 2020, although those who lost a job or had their hours reduced were less likely to indicate that they would pay the expense in this way.

Figure 14. Would cover a $\$ 400$ emergency expense completely using cash or its equivalent (by survey year)

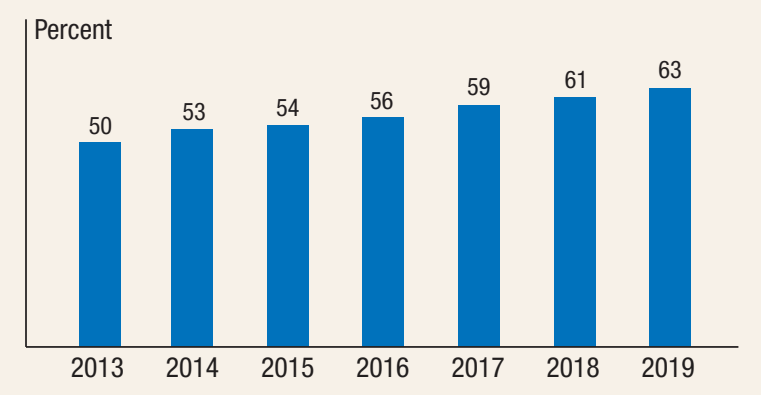

The remaining 37 percent of adults who would not have paid completely with cash or equivalent may have had more difficulty covering such an expense. For these adults, the most common approach was to pay for the expense using a credit card and then carry a balance (figure 15). Twelve percent of adults said they would be unable to pay the expense by any means. However, it is possible that some who would not have paid with cash or its equivalent still had access to $\$ 400$ in cash. Instead of using that cash to pay for the expense, they may have chosen to preserve their cash as a buffer for other expenses (see box 3).

To understand more about covering household expenses, the survey asked about adults' ability to pay their actual monthly bills. Nearly 3 in 10 adults were either unable to pay their monthly bills or were one modest financial setback away from failing to pay monthly bills in full. Sixteen percent of adults did not expect to pay all of their bills in full in the month of the survey in October 2019. An additional 12 percent said they could cover their current bills, but would not have been able to do so if they faced a $\$ 400$ unexpected expense on top of their current bills. $^{22}$

Of people who could not fully cover their monthly bills in late 2019, this most frequently involved not paying a credit card bill or making only a partial payment on it (table 9). Yet, nearly 4 in 10 of those who were not able to pay all their bills in the month of the survey (6 percent of all adults) said that their rent, mortgage, or utility bills would be left at least partially unpaid.

Those with less education, in particular, exhibited more challenges in meeting these expenses. Thirteen percent of adults with a bachelor's degree or more did not expect to pay their current month's

22 A similar question has been asked since 2016, although a change in the question wording between 2017 and 2018 means that the results for 2016 and 2017 are not comparable to results in more recent years. 
Figure 15. Other ways individuals would cover a $\$ 400$ emergency expense

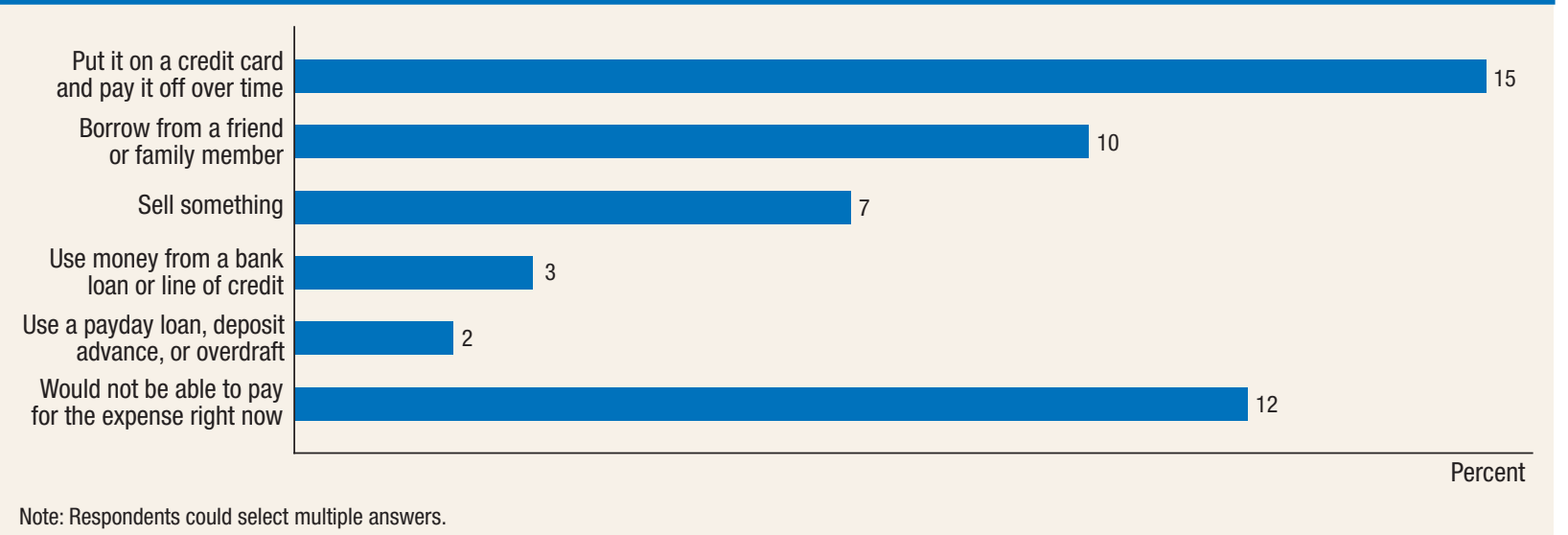

Note: Respondents could select multiple answers.

Table 9. Bills to leave unpaid or only partially paid in the month of the survey

Percent

\begin{tabular}{|l|c|c}
\hline \multicolumn{1}{|c|}{ Bill type } & $\begin{array}{c}\text { Among those } \\
\text { who expect to } \\
\text { defer at least } \\
\text { one bill }\end{array}$ & $\begin{array}{c}\text { Among adult } \\
\text { population }\end{array}$ \\
\hline Housing-related bills & & \\
\hline Rent or mortgage & 23 & 4 \\
\hline Water, gas, or electric bill & 32 & 5 \\
$\quad$ Overall & 38 & 6 \\
Non-housing-related bills & & \\
Credit card & 45 & 7 \\
\hline Phone or cable bill & 34 & 5 \\
\hline Student loan & 11 & 2 \\
Car payment & 17 & 3 \\
Other & 33 & 5 \\
$\quad$ Overall & 76 & 12 \\
\hline Unspecified bills & 18 & 3 \\
\hline Overall & $\mathbf{1 0 0}$ & $\mathbf{1 6}$ \\
\hline
\end{tabular}

Note: Respondents could select multiple answers.

bills in full or would have been unable to do so if faced with an unexpected $\$ 400$ expense, versus 43 percent of those with a high school degree or less. Racial and ethnic minorities at each education level were less well-positioned to handle a financial setback (figure 16). A number of factors, including differences in educational backgrounds or returns to education, discrimination, or differences in credit access, could have led to this difference. (See the "Higher Education" section of this report for a discussion of education, the "Overall Economic WellBeing in 2019" section for a discussion of discrimination, and the "Banking and Credit" section for a discussion of disparities in credit access).
Furthermore, those carrying unpaid debts - including unpaid medical and legal bills - were less able to handle monthly expenses at the time of the survey. For example, 57 percent of those with outstanding medical bills could not have covered their monthly bills or would have had difficulty doing so when faced with an unexpected $\$ 400$ expense. A lower 22 percent of people without such debts had difficulty covering their monthly bills. Fewer adults with student and credit card debt had difficulty covering monthly bills than those with medical or legal debts. Thirty-six percent of those with credit card debt and 42 percent of those with student loan debt could not have covered all of their current monthly expenses.

Some financial challenges require more preparation and advanced planning than would a relatively small, unexpected expense. One common measure of financial preparation is whether people have savings sufficient to cover three months of expenses if they lost their primary source of income. As of late 2019, 53 percent of people had set aside money specifically as emergency savings or "rainy day" funds. For those who did not, some would have dealt with a larger shock by borrowing or selling assets or drawing on other sources of savings. Eighteen percent said that they could have covered three months of expenses in this way. In 2019, 3 in 10 adults said they could not cover three months of expenses by any means.

\section{Health-Care Expenses}

Out-of-pocket spending for health care is a common unexpected expense that can be a substantial hardship for those without a financial cushion. As with 


\section{Box 3. The Credit Card Debt Puzzle}

In 2019, 37 percent of adults said that they would not completely use cash or a cash equivalent to cover a $\$ 400$ emergency expense. For some people, this reflects that they did not actually have $\$ 400$ on-hand to cover the expense. For others, however, it reflected a choice to borrow while preserving cash in their bank account.

Comparing results in the SHED to those from the Survey of Consumer Finances (SCF) provides evidence that payment preferences for some and a lack of cash on-hand for others contributed to this result. Neil Bhutta and Lisa Dettling observed in the 2016 SCF that 24 percent of households had less than $\$ 400$ in liquid assets after accounting for funds earmarked for monthly expenses. ${ }^{1}$ This is a substantial share of households that lacked $\$ 400$ of cash. Yet, it is fewer people than reported in the SHED that they would not use cash or its equivalent to cover a $\$ 400$ emergency expense. ${ }^{2}$ Hence, based on these two surveys it appears that some people who had at least $\$ 400$ in cash would still have chosen to borrow for an emergency of this size.

This observation is consistent with the "credit card debt puzzle," first identified by David Gross and Nicholas Souleles. ${ }^{3}$ They found that some households hold both high-interest credit card debt and low-return liquid savings that could be used to pay down those debts.

Neil Bhutta and Lisa Dettling, "Money in the Bank? Assessing Families' Liquid Savings Using the Survey of Consumer Finances," FEDS Notes (Washington: Board of Governors, November 19, 2018), https://www.federalreserve.gov/econres/ notes/feds-notes/assessing-families-liquid-savings-using-thesurvey-of-consumer-finances-20181119.htm.

2 Results from the SHED and SCF are not strictly comparable, however, due to differences in the sample design. In particular, the SCF considered adult children living at home with their parents as part of the same "consumer unit" as their parents, whereas the SHED treated these adult children independently.

3 David Gross and Nicholas Souleles, "Do Liquidity Constraints and Interest Rates Matter for Consumer Behavior? Evidence from Credit Card Data," Quarterly Journal of Economics 117, no. 1 (February 2002): 149-85.
Nevertheless, borrowing for a small emergency, even if done to preserve liquid savings, can be an indication of financial challenges. For example, Olga Gorbachev and María José Luengo-Prado found that individuals who were less confident about their ability to access credit in the future were more likely to use their current credit and to keep some savings. ${ }^{4}$ Consequently, survey respondents who had $\$ 400$ of cash but still chose to borrow may have had more uncertainty about their financial situation. Indeed, those who said that they could pay a $\$ 400$ expense, but would do so by borrowing or selling something, were less likely to be doing okay financially than those who would pay the expense fully using cash or its equivalent (figure A). Eight percent of people who would use cash or its equivalent said that they were just getting by or struggling financially. By comparison, a higher 43 percent who would pay the expense by borrowing or selling something exhibited this level of overall financial stress.

A separate approach to understand the effect of small emergencies is to consider how a $\$ 400$ emergency affects people's ability to cover their current month's bills. Twenty-eight percent of adults indicated that they either could not pay all of their current bills in full or would no longer have been able to do so if faced with this type of modest emergency, with 2 in 10 deferring at least one non-credit card bill. $^{5}$ This is similar to the 24 percent of households that Bhutta and Dettling observed had less than $\$ 400$ in liquid assets after their monthly expenses in the SCF. Of those who were unable to pay their noncredit card bills in full during the month of the survey, or would not have been able to do so if faced with a $\$ 400$ expense, two-thirds said they were struggling financially or were just getting by overall.

4 Olga Gorbachev and María José Luengo-Prado, "The Credit Card Debt Puzzle: The Role of Preferences, Credit Access Risk, and Financial Literacy," Review of Economics and Statistics 101, no. 2 (May 2019): 294-309.

5 The share deferring at least one non-credit card bill excludes those who said that they could not pay all of their bills in full but did not specify the type of bill they were unable to pay. Including individuals who did not specify the type of bill, 24 percent would defer a non-credit card bill if faced with a $\$ 400$ expense.

\section{Figure A. Struggling to get by or just getting by financially (by how paying a $\$ 400$ emergency expense)}

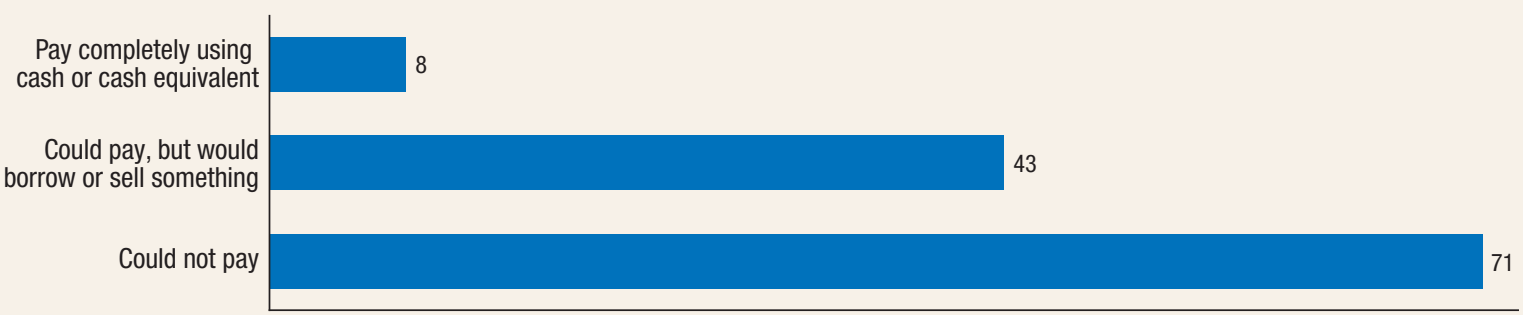


Figure 16. Not able to fully pay current month's bills (by education and race/ethnicity)

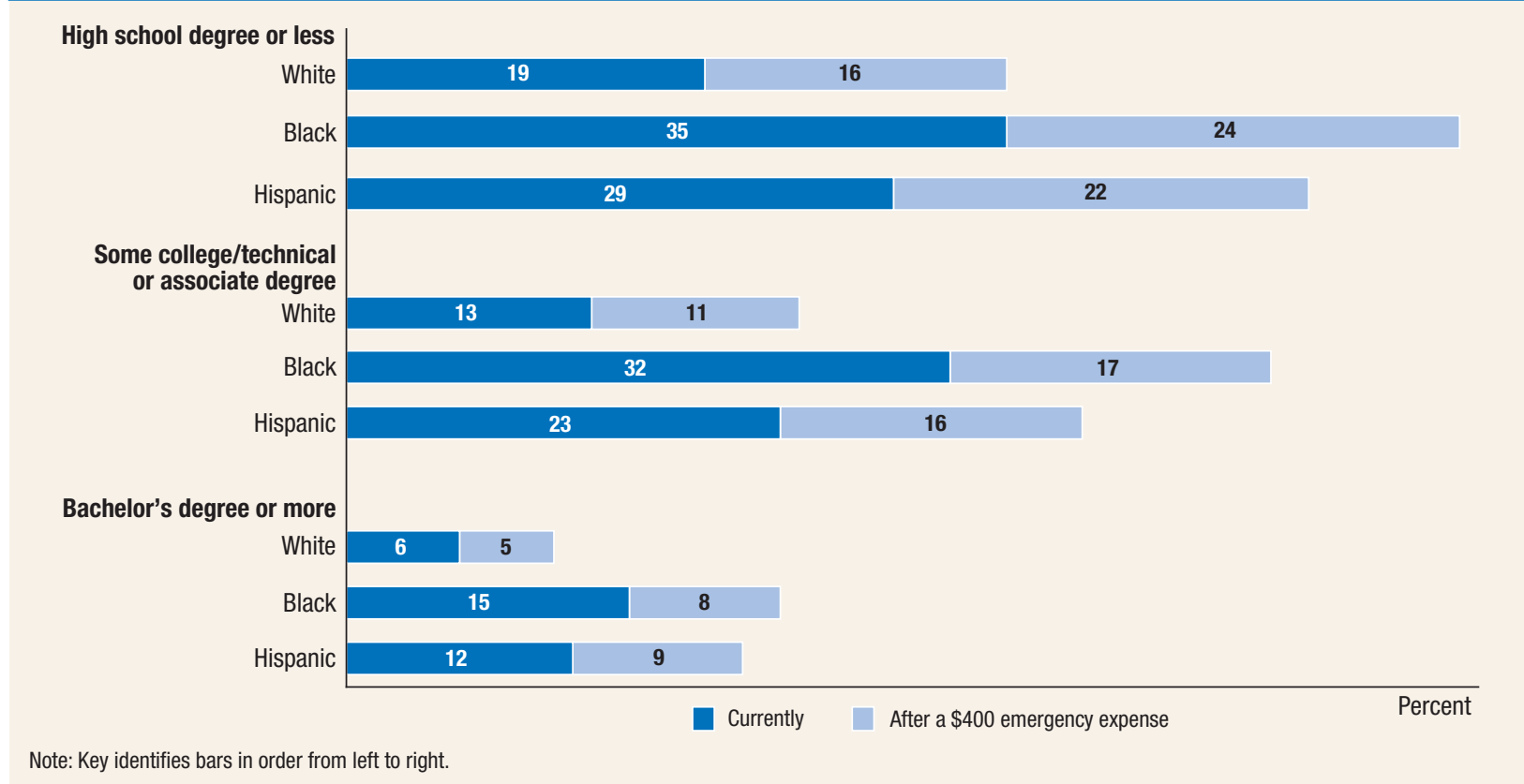

the small financial setbacks discussed above, many adults were not financially prepared for healthrelated costs at the time of the survey in 2019. During 2019, more than one-fifth of adults had major, unexpected medical bills to pay, with the median expense between $\$ 1,000$ and $\$ 1,999$. Overall, 18 percent of adults had unpaid debt from their own medical care or that of a family member.

In addition to the financial strain of additional debt, 25 percent of adults went without some form of medical care due to an inability to pay, slightly up from 24 percent in 2018 but well below the 32 percent reported in 2013. Dental care was the most frequently skipped treatment (18 percent), followed by visiting a doctor (14 percent) and taking prescription medicines (9 percent) (figure 17). Going without medical care was more likely among adults who selfreported that they were in poor health. In 2019, 43 percent of adults in poor health went without medical care versus 20 percent of adults in good health. ${ }^{23}$

There was a strong relationship between family income and individuals' likelihood of receiving medical care in 2019. Among those with family income less than $\$ 40,000,38$ percent went without some

${ }^{23}$ Self-reported health was missing for 11 percent of the sample in 2019.

Figure 17. Forms of skipped medical treatment due to cost during 2019

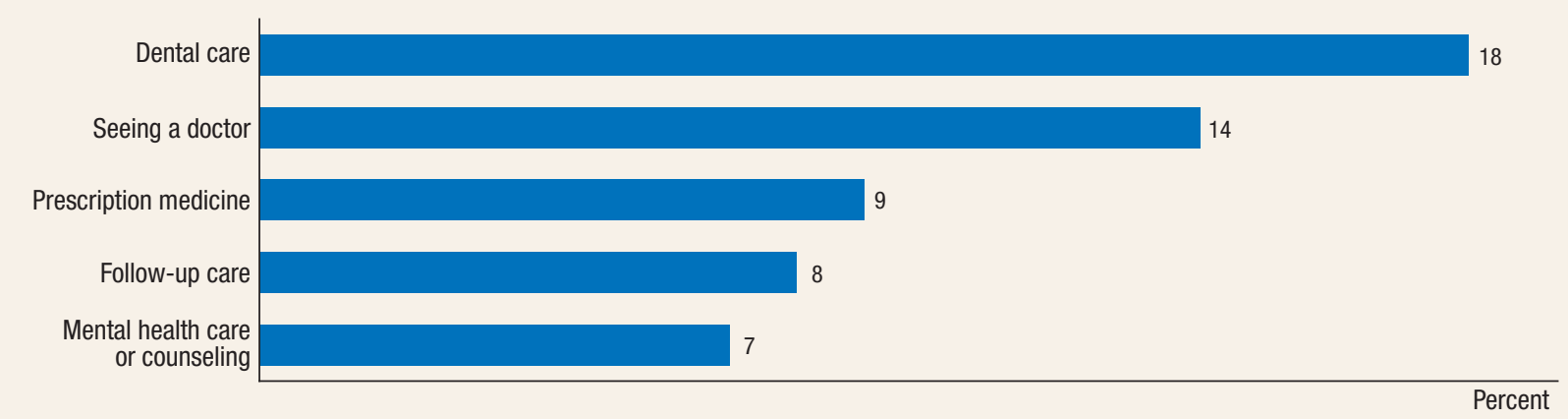

Note: Respondents could select multiple answers. 
medical treatment in 2019, slightly up from 36 percent in 2018. Higher income households were less likely to skip medical care due to cost. In 2019, 23 percent of those with incomes between $\$ 40,000$ and $\$ 100,000$ and 9 percent of those making over $\$ 100,000$ went without care. Moreover, as family income rises, the likelihood a person reported being in good health increases substantially. Among those in families with income less than $\$ 40,000,75$ percent reported being in good health, compared to 93 percent for those in families with income greater than $\$ 100,000 .^{24}$

Health insurance is one way that people can pay for routine medical expenses and hedge against the financial burden of large, unexpected expenses. In

\footnotetext{
${ }^{24}$ This relationship also holds if focusing only on adults of different income levels within the same age range.
}

2019, 91 percent of adults had health insurance. This included 57 percent of adults who had health insurance through an employer or labor union and 32 percent who had insurance through Medicare or Medicaid (some of whom had multiple forms of insurance). Four percent of people purchased health insurance through one of the health insurance exchanges. Those with health insurance were less likely to forgo medical treatment due to an inability to pay. Among the uninsured, 47 percent went without medical treatment due to an inability to pay, versus 22 percent among the insured. ${ }^{25}$

${ }^{25}$ Since the survey asked respondents about their current health insurance status, but also asked about whether they missed medical treatments in the previous year, it is possible that some respondents who had health insurance at the time of the survey were uninsured at the point at which they were unable to afford treatment. 



\section{Banking and Credit}

Most adults had a bank account and were able to obtain credit from mainstream sources in 2019, but notable gaps in access to basic financial services still exist among minorities and those with low income. On average, individuals with capacity to borrow on a credit card were more prepared for financial disruptions.

\section{Unbanked and Underbanked}

Although the majority of U.S. adults had a bank account and relied on traditional banks or credit unions to meet their banking needs, gaps in banking access remained. Six percent of adults in 2019 did not have a checking, savings, or money market account (often referred to as the "unbanked"). Half of unbanked adults used some form of alternative financial service during 2019 — such as a money order, check cashing service, pawn shop loan, auto title loan, payday loan, paycheck advance, or tax refund advance. In addition, 16 percent of adults were "underbanked": they had a bank account but also used an alternative financial service product (figure 18). ${ }^{26}$ The remaining 79 percent of adults were fully banked, with a bank account and no use of alternative financial products.

The unbanked and underbanked were more likely to have low income, have less education, or be in a racial or ethnic minority group. Fourteen percent of those with incomes below $\$ 40,000$ were unbanked, versus 1 percent of those with incomes over that threshold. Additionally, 14 percent of black adults

\footnotetext{
26 The FDIC National Survey of Unbanked and Underbanked Households in 2017 found that a similar 6.5 percent of households were unbanked and 18.7 percent of households were underbanked. However, the FDIC uses a broader underbanked definition, which includes international remittances and rentto-own services as alternative financial services. See Federal Deposit Insurance Corporation, 2017 FDIC National Survey of Unbanked and Underbanked Households (Washington: Federal Deposit Insurance Corporation, October 2018), https://www .economicinclusion.gov/surveys/2017household/.
}

\section{Figure 18. Banking status}

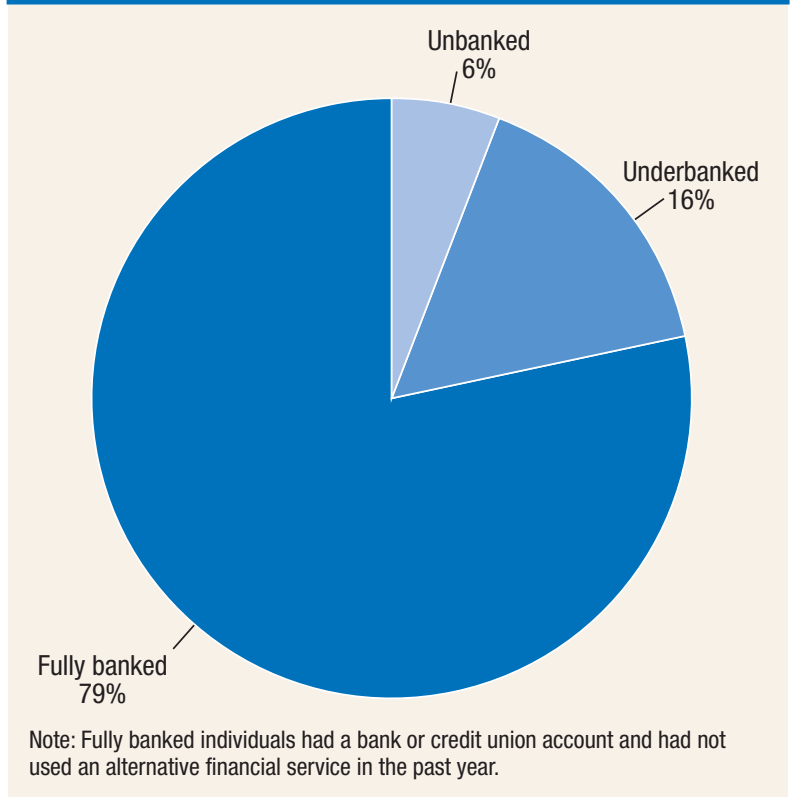

and 10 percent of Hispanic adults were unbanked, versus 6 percent of adults overall (table 10).

Those who used alternative financial services (around one in five adults) may have needed or preferred to conduct certain financial transactions through providers other than traditional banks and credit unions. The vast majority ( 88 percent) of people using alternative financial services used transaction services such as purchasing a money order or cashing a check at a place other than a bank (table 11). Twenty-nine percent borrowed money using an alternative financial service product, including payday loans or paycheck advances, pawn shop or auto title loans, and tax refund advances.

\section{Credit Outcomes and Perceptions}

The majority of U.S. adults who applied for credit in 2019 were able to obtain it, but a sizable share 
reported barriers or limitations to borrowing. During 2019, 41 percent of adults applied for some type of credit. Of those who applied for credit, 24 percent were denied at least once in the year before the survey, and 31 percent were either denied or offered less credit than they requested.

The incidence of denial or limitations on credit differed by the family income of the applicants and by their race and ethnicity. Lower-income individuals were substantially more likely to experience adverse outcomes with their credit applications than those with higher incomes. Among applicants with incomes under $\$ 40,000,43$ percent were denied

Table 10. Banking status (by family income, education, and race/ethnicity)

Percent

\begin{tabular}{l|c|c|c}
\multicolumn{1}{c}{ Characteristic } & Unbanked & Underbanked & Fully banked \\
\hline Family income & & & \\
Less than $\$ 40,000$ & 14 & 23 & 63 \\
$\begin{array}{l}\$ 40,000-\$ 100,000 \\
\text { Greater than } \$ 100,000\end{array}$ & 1 & 16 & 83 \\
Education & $*$ & 6 & 94 \\
High school degree or less & 12 & 21 & 67 \\
$\begin{array}{l}\text { Some college/technical or } \\
\text { associate degree }\end{array}$ & 3 & 17 & 79 \\
Bachelor's degree or more & 1 & 9 & 90 \\
Race/ethnicity & & & \\
White & 3 & 11 & 86 \\
Black & 14 & 32 & 54 \\
Hispanic & 10 & 22 & 68 \\
Overall & $\mathbf{6}$ & $\mathbf{1 6}$ & $\mathbf{7 9}$ \\
\hline
\end{tabular}

* Less than 1 percent.

Table 11. Forms of alternative financial services used Percent

\begin{tabular}{|l|c|c|}
\hline \multicolumn{1}{|c|}{ Service type } & $\begin{array}{c}\text { Among those } \\
\text { using any } \\
\text { alternative } \\
\text { financial } \\
\text { services }\end{array}$ & $\begin{array}{c}\text { Among adult } \\
\text { population }\end{array}$ \\
\hline Transaction services & & \\
\hline Money order, not from a bank & 66 & 12 \\
\hline Cash a check, not at a bank & 41 & 8 \\
\hline Any transaction service & 88 & 16 \\
\hline Borrowing services & 15 & 3 \\
\hline Payday loan or paycheck advance & 14 & 3 \\
\hline Pawn shop or auto title loan & 7 & 1 \\
Tax refund advance & 29 & 5 \\
\hline Any borrowing service & & \\
\hline
\end{tabular}

Note: Respondents could select multiple answers. credit, versus 9 percent of applicants with incomes over $\$ 100,000$. Within each income bracket, black and Hispanic individuals were more likely to report an adverse credit outcome (table 12).

Negative perceptions may be an additional barrier to credit. More than 1 in 10 adults put off at least one credit application because they thought that their application would be denied. This included 8 percent who applied for some credit, but opted against submitting additional applications because they thought they might be turned down, and 4 percent who desired credit but did not apply at all for fear of denial.

Although some people forgo credit applications because they expect a denial, most adults ( 80 percent) were somewhat or very confident that they could obtain a credit card if they were to apply for one (figure 19). Black and Hispanic adults were less confident that their credit card application would be approved, relative to adults overall.

While those with higher incomes were substantially more confident about being approved for credit than those with lower incomes, differences in confidence across racial and ethnic groups were evident at all

Table 12. Credit applicants with adverse credit outcomes (by family income and race/ethnicity)

Percent

\begin{tabular}{|c|c|c|}
\hline Characteristic & Denied & $\begin{array}{l}\text { Denied or } \\
\text { approved for } \\
\text { less than } \\
\text { requested }\end{array}$ \\
\hline \multicolumn{3}{|l|}{ Less than $\$ 40,000$} \\
\hline White & 40 & 48 \\
\hline Black & 58 & 68 \\
\hline Hispanic & 41 & 49 \\
\hline Overall & 43 & 51 \\
\hline \multicolumn{3}{|l|}{$\$ 40,000-\$ 100,000$} \\
\hline White & 17 & 22 \\
\hline Black & 41 & 57 \\
\hline Hispanic & 30 & 39 \\
\hline Overall & 22 & 29 \\
\hline \multicolumn{3}{|l|}{ Greater than $\$ 100,000$} \\
\hline White & 7 & 10 \\
\hline Black & 19 & 31 \\
\hline Hispanic & 17 & 22 \\
\hline Overall & 9 & 13 \\
\hline \multicolumn{3}{|l|}{ All incomes } \\
\hline White & 19 & 24 \\
\hline Black & 44 & 57 \\
\hline Hispanic & 32 & 40 \\
\hline Overall & 24 & 31 \\
\hline
\end{tabular}

Note: Among adults who applied for some form of credit in the past 12 months. 


\section{Figure 19. Confidence that a credit card application would be approved (by race/ethnicity)}

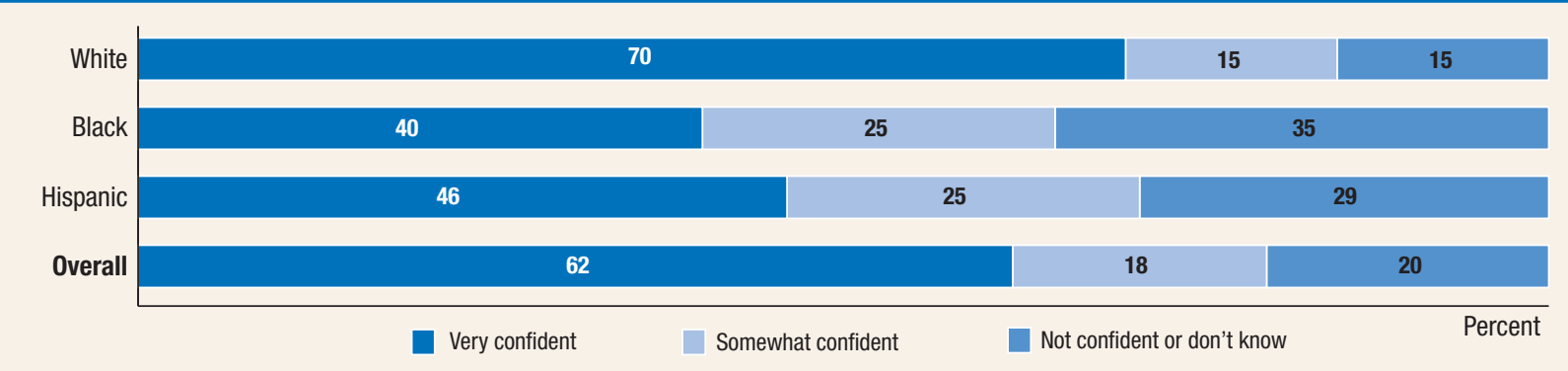

Note: Key identifies bars in order from left to right.

income levels (table 13). However, these gaps may have been at least partially attributable to other factors related to creditworthiness that vary by race. ${ }^{27}$

\section{Credit Cards}

In people's financial lives, credit cards can serve different functions at different times. For people who pay their balances off each month, credit cards are mainly a form of payment convenience and can be thought of more or less the same as using cash. For those who carry a balance, however, use of the card represents borrowing and carries a cost in the interest payment and any fees that are incurred.

${ }^{27}$ In a regression including income, age, presence of a credit card and card payment behavior, and self-reported credit score, the difference in confidence between black and white adults narrows but remains significant. The gap between Hispanic and white adults is largely accounted for by these other factors.

Table 13. Confidence that a credit card application would be approved (by family income and race/ethnicity)

Percent

\begin{tabular}{l|c|c|c}
\hline \multicolumn{1}{|c|}{ Characteristic } & Very confident & $\begin{array}{c}\text { Somewhat } \\
\text { confident }\end{array}$ & $\begin{array}{c}\text { Not confident or } \\
\text { don't know }\end{array}$ \\
\hline Less than $\mathbf{\$ 4 0 , 0 0 0}$ & & & \\
White & 41 & 24 & 34 \\
Black & 24 & 25 & 50 \\
Hispanic & 31 & 28 & 42 \\
$\quad$ Overall & 36 & 25 & 39 \\
\$40,000-\$100,000 & & & \\
White & 74 & 16 & 10 \\
Black & 47 & 27 & 26 \\
Hispanic & 55 & 27 & 18 \\
$\quad$ Overall & 68 & 19 & 13 \\
Greater than $\$ \mathbf{1 0 0 , 0 0 0}$ & & & \\
White & 90 & 7 & 3 \\
Black & 74 & 21 & 5 \\
Hispanic & 77 & 15 & 8 \\
$\quad$ Overall & 87 & 9 & 4 \\
\hline
\end{tabular}

Overall, 83 percent of adults had at least one credit card, and the share with a credit card was higher among those with higher incomes, more education, or who are white (table 14). Among those with a card, 48 percent paid their credit card bill in full every month in the prior year. About one-quarter carried a balance once or some of the time in that year; the remaining one-quarter carried a balance most or all of the time (figure 20). The frequency of regular borrowing with credit cards during 2019 is similar to 2018.

On average, individuals with capacity to borrow on a credit card were more prepared for financial disruptions. Transactional users of credit cards who never carry a balance were much more likely to have said that they would pay an unexpected $\$ 400$ expense with cash or its equivalent, compared to those who carry a balance most or all of the time or those who do not have a credit card (table 15). Similarly, transactional users were more likely to have a three-month rainy day savings fund and to express confidence that their application for a credit card would be approved.

Table 14. Has at least one credit card (by family income, education, and race/ethnicity)

\begin{tabular}{l|c}
\multicolumn{1}{c|}{ Characteristic } & Percent \\
\hline Family income & \\
Less than $\$ 40,000$ & 63 \\
$\$ 40,000-\$ 100,000$ & 92 \\
Greater than $\$ 100,000$ & 98 \\
Education & \\
High school degree or less & 70 \\
Some college/technical or associate degree & 83 \\
Bachelor's degree or more & 95 \\
Race/ethnicity & \\
White & 87 \\
Black & 69 \\
Hispanic & 75 \\
Overall & $\mathbf{8 3}$ \\
\hline
\end{tabular}


Figure 20. Frequency of carrying a balance on one or more credit cards in the past 12 months

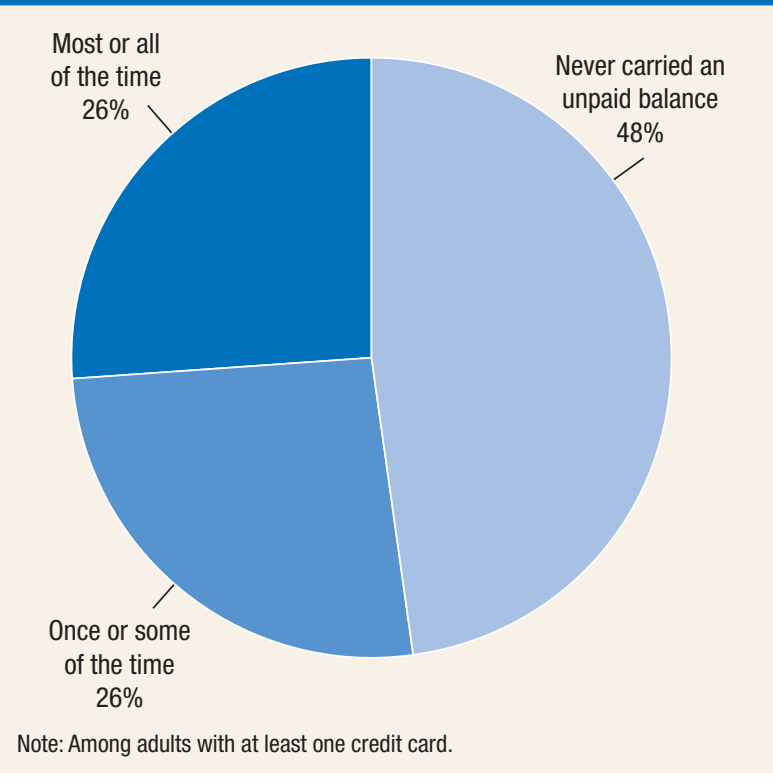

Table 15. Financial preparedness measures among adults (by credit card use)

Percent

\begin{tabular}{|c|c|c|c|}
\hline Card access and payment patterns & $\begin{array}{c}\text { Pay } \\
\text { unexpected } \\
\$ 400 \\
\text { expense with } \\
\text { cash or } \\
\text { equivalent }\end{array}$ & $\begin{array}{c}\text { Have } \\
\text { 3-month } \\
\text { rainy day } \\
\text { savings fund }\end{array}$ & $\begin{array}{l}\text { Confident } \\
\text { credit card } \\
\text { application } \\
\text { would be } \\
\text { approved }\end{array}$ \\
\hline
\end{tabular}

Have a credit card, frequency of carrying balance

$\begin{array}{llll}\text { Never carried an unpaid balance } & 90 & 81 & 96\end{array}$

$\begin{array}{lll}\text { Once or some of the time } & 63 & 54\end{array}$

Most or all of the time

Do not have a credit card

43

Overall

27

29

18

53

79

33

Note: "Confident" includes people reporting that they were either very confident or somewhat confident. Frequency of carrying a balance is for the past 12 months. 


\section{Housing}

Most adults were satisfied with their housing, most lived with someone else, and most owned their own homes in 2019. Adults who were younger, as well as black and Hispanic adults, were less likely to own their own homes and to say that they were satisfied with their housing than the overall average.

\section{Living Arrangements}

During 2019, 86 percent of adults lived with other people, usually a spouse or a partner and frequently their children (table 16). Fifty-two percent of adults lived in a household with a spouse, partner, or child under age 18 and with no one else. Twelve percent of adults lived with a parent, and 15 percent lived with their children age 18 or older. Six percent lived with a sibling, and 5 percent lived with another relative. Four percent of adults lived with someone unrelated to them.

Older adults were the most likely to have lived alone in 2019. Twenty-seven percent of adults age 75 or older lived alone, and 39 percent of women age 75 or older lived alone.

Younger adults were the most likely to live with their parents and the least likely to live with a spouse or partner in 2019. Nearly half of 22- to 24-year-olds

\section{Table 16. People living in household}

\begin{tabular}{lcc} 
& Category & Percent \\
\hline Live alone & 14 \\
Spouse or partner & 67 \\
Children under age 18 & 27 \\
Adult children & 15 \\
Parents & 12 \\
Brothers or sisters & 6 \\
Other relatives & 5 \\
Other non-relatives & 4 \\
\hline
\end{tabular}

Note: Adult children includes those in school and not in school. Respondents (other than those who lived alone) could select multiple answers. lived with a parent, and 30 percent lived with a spouse or partner. ${ }^{28}$ Among 25- to 29-year-olds, a smaller 27 percent lived with parents, and a larger 55 percent lived with a spouse or partner.

Economic circumstances affect household composition and household formation, as adults who live with their parents most commonly did so to save money. Eighty-six percent of adults ages 22 to 24, and 89 percent of those ages 25 to 29 , who lived with their parents said that they did so to save money (table 17). The prevalence of living with parents to save money subsequently declines with age. Conversely, the share of adults living with their parents who said that they did so to provide financial assistance generally increases with age.

\section{Owning and Renting}

Homeownership is deeply intertwined with a household's finances. Many renters said they did not own because of difficulty getting a mortgage, but some cited other reasons, like the affordability and convenience of renting. Five percent of non-homeowners

\footnotetext{
${ }^{28}$ Twelve percent of adults ages 22 to 24 lived with a spouse, while the other 18 percent lived with a partner that they were not
} married to.

\section{Table 17. Reasons for living with parents (by age)}

Percent

\begin{tabular}{l|c|c|c|c|}
\multicolumn{1}{c|}{ Reason } & $22-24$ & $25-29$ & $30-44$ & $45-59$ \\
\hline $\begin{array}{l}\text { To save money } \\
\begin{array}{l}\text { To help those living with } \\
\text { me financially }\end{array}\end{array}$ & 86 & 89 & 72 & 45 \\
$\begin{array}{l}\text { To care for family member } \\
\text { or friend }\end{array}$ & 32 & 43 & 62 & 58 \\
$\quad$ To receive help with childcare & 29 & 34 & 55 & 74 \\
\hline Prefer living with others & 10 & 9 & 18 & 9 \\
\hline
\end{tabular}

Note: Among those who lived with a parent. Respondents could select multiple answers. 
living with children reported an eviction-related move in the past two years.

Nearly two-thirds of adults owned their homes. Homeowners were generally older than renters. White adults were also disproportionately likely to own their home in 2019. One-quarter of 18- to 29-year-olds owned their homes compared with 85 percent of people age 60 and older (figure 21). Young adults under age 30 were more likely to neither own nor rent, often because they lived with parents. Seventy-one percent of white adults owned their homes, as did 48 percent of black adults and 50 percent of Hispanic adults (figure 22).

Renters, who made up 28 percent of the adult population in 2019, often said that they did not own because of difficulty getting a mortgage. ${ }^{29}$ More than 6 in 10 renters said they rented because they lacked a down payment (figure 23), and 4 in 10 said they could not get a mortgage. Respondents could

${ }^{29}$ In addition to those who either owned or rented their home, 8 percent of adults said that they neither owned nor rented at the time of the survey. give multiple answers to this question, and 64 percent cited at least one of these two issues.

A lack of credit was not the only factor that kept people renting. Many renters said that they rented because of the convenience and affordability. Fiftytwo percent of renters cited the convenience of renting. Similar numbers said that it is cheaper to rent and that owning is a bigger financial risk- 55 percent and 50 percent respectively. Thirty-five percent of renters said that they were looking to buy.

One potential convenience of renting is having a landlord who promptly makes repairs. Fiftysix percent of renters said they had a problem that needed to be fixed in the last 12 months, although 6 percent of renters did not attempt to contact their landlord about the problem. Forty-four percent of renters who reported the problem said that the landlord resolved these problems with no difficulty to the renter. The rest of the time, however, resolving the problem involved at least a little difficulty. Eight percent of renters (17 percent of those who contacted their landlord) said that the repair involved substantial difficulty (table 18). Renters who paid higher

\section{Figure 21. Homeownership rate (by age)}

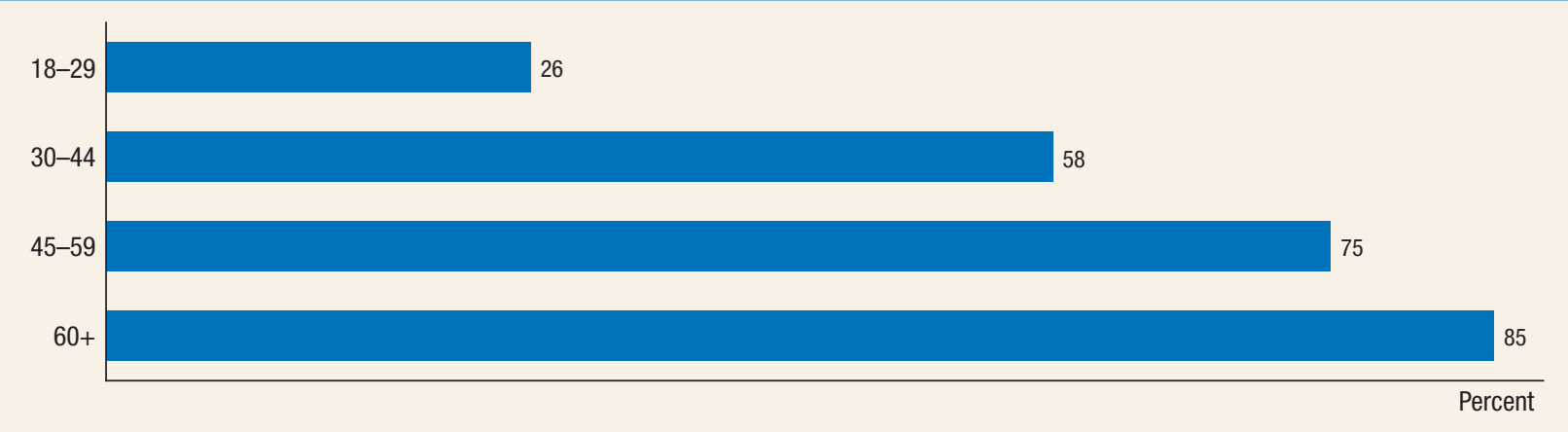

Figure 22. Homeownership rate (by race/ethnicity)

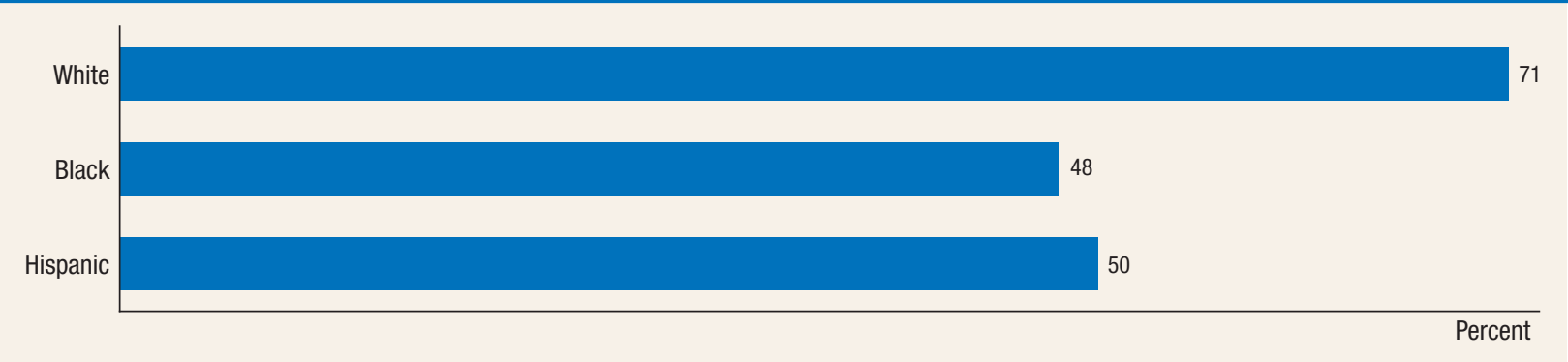




\section{Figure 23. Reasons for Renting}

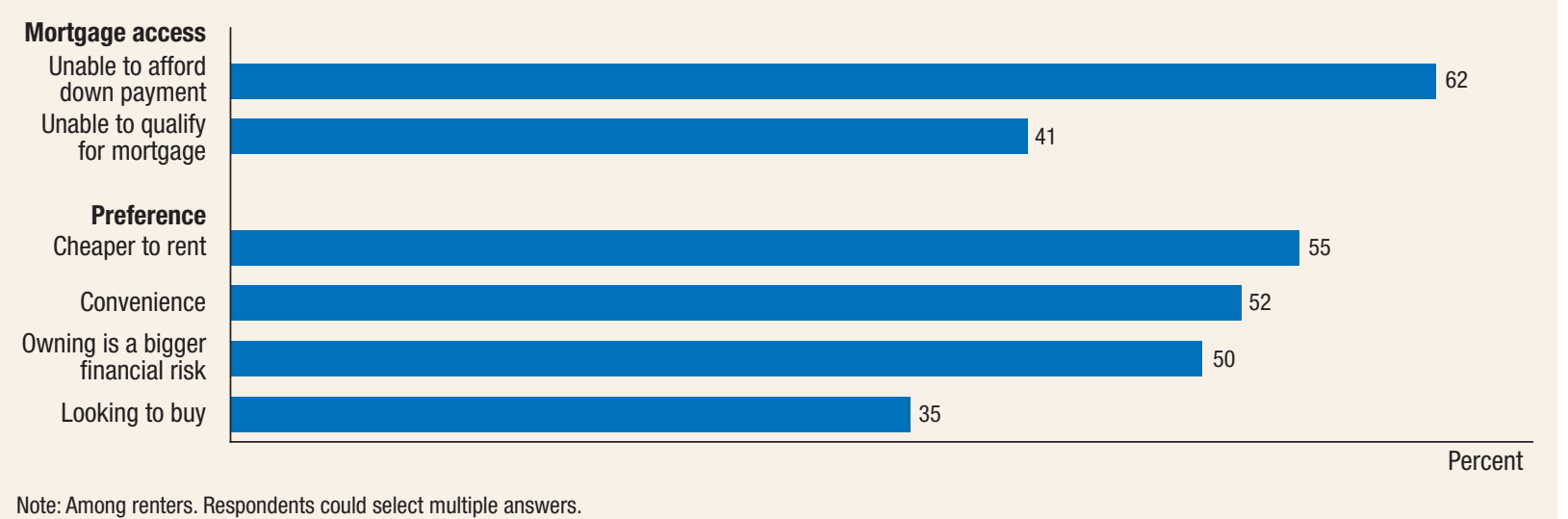

Note: Among renters. Respondents could select multiple answers.

rents were generally more likely to have their problems resolved without experiencing difficulties.

Three percent of non-homeowners moved in the two years before the survey and said that their last move was due to an eviction or a threat of eviction. This equates to about 3 million adults. ${ }^{30}$ Four percent of black non-homeowners and 3 percent of both white and Hispanic non-homeowners experienced either an eviction or the threat of an eviction over this period.

Non-homeowners living with a child under age 18 were twice as likely to have been evicted or threatened with an eviction. Five percent of nonhomeowners living with a child reported an eviction-

${ }^{30}$ National eviction estimates compiled by Matthew Desmond suggest that there were approximately 900,000 evictions in 2016 affecting 2.4 million people. These estimates are not directly comparable to those in the SHED, however, because the SHED also includes near evictions, only counts adults, and covers the most recent move in the past two years. See https://evictionlab .org/national-estimates/

Table 18. Problems with rental units and difficulty getting repairs

\begin{tabular}{l|c}
\multicolumn{1}{c|}{ Response } & Percent \\
\hline No repair needed & 44 \\
Needed repairs, but did not contact landlord & 6 \\
Difficulty repairing if contacted landlord & \\
No difficulty with repairs & 22 \\
A little difficulty with repairs & 12 \\
Moderate difficulty with repairs & 7 \\
Substantial difficulty with repairs & 8 \\
\hline
\end{tabular}

Note: Among renters. related move, compared to 2.5 percent of other nonhomeowners. ${ }^{31}$

\section{Housing and Neighborhood Satisfaction}

Most adults said that they were satisfied with their housing and with their neighborhoods. ${ }^{32}$ People were less satisfied with the cost of housing and with their local schools than they were with other aspects of their housing. Still, most adults said that they were satisfied with the cost of housing and with local schools.

Eighty-seven percent of adults were satisfied with their housing, and 90 percent were satisfied with their neighborhoods in 2019. Adults' satisfaction with each showed in their satisfaction with other amenities in their neighborhoods (figure 24). Eightyeight percent were satisfied with the safety of their neighborhoods. While lower, most people were also satisfied with the cost of their housing and with local schools.

Despite generally being satisfied, renters were less satisfied with their housing than owners (figure 25).

${ }^{31}$ The finding mirrors ethnographic research in Matthew Desmond's Evicted: Poverty and Profit in the American City (New York: Crown, 2016) showing pathways that can lead to evictions among families with small children.

${ }^{32}$ The 2018 SHED asked respondents to report their satisfaction with their housing in terms of five categories. The top two pervious categories indicated satisfaction. In 2019, the survey gave two choices - satisfied or not satisfied. The higher rates of satisfaction in 2019 was likely due to the change in the question's wording and the results are not comparable across these years of the survey. 
Figure 24. Satisfaction with neighborhood and housing characteristics

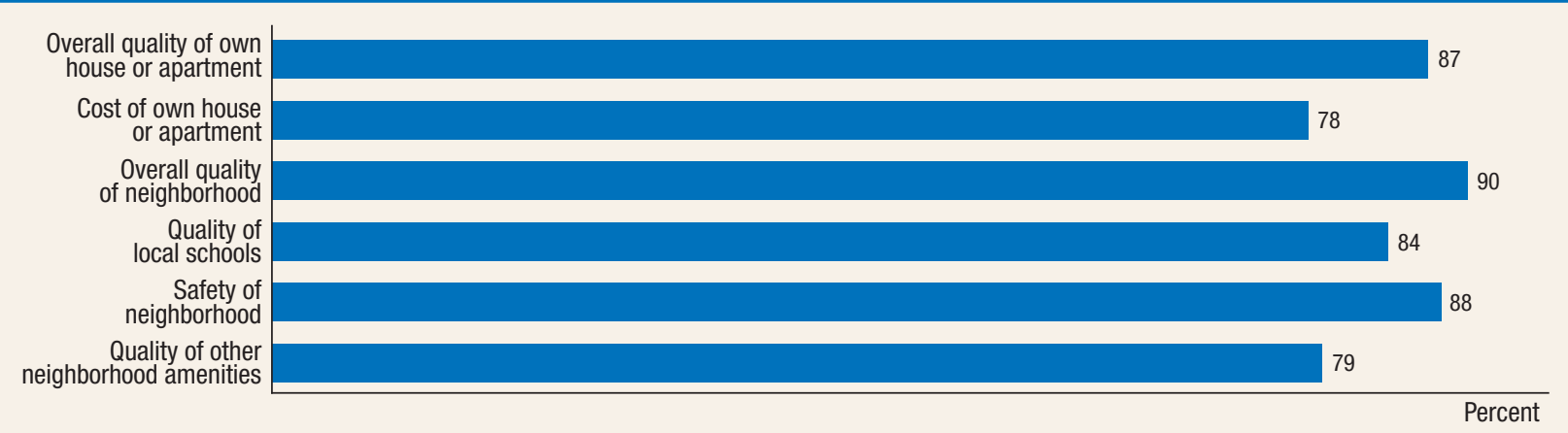

Note: Satisfaction with the cost of own house or apartment excludes those who did not own and were not paying rent.

Seventy-four percent of renters said they were satisfied with their housing overall, compared with 93 percent of owners. Renters were also less satisfied with every aspect of their housing, including its cost.

People's satisfaction with their housing also increased with age and varied by race and ethnicity.

\section{Figure 25. Satisfied with local neighborhood and housing} (by housing tenure)

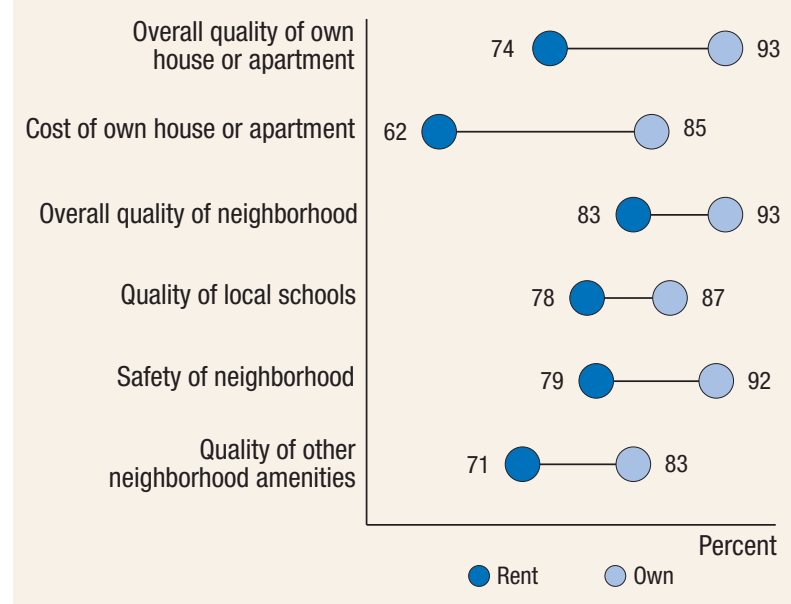

Note: Key identifies circles in order from left to right. Among adults who owned or rented their home.
Ninety-four percent of people age 60 or older were satisfied with their housing, compared with 83 percent of people ages 18 to 44 . Eight in 10 black or Hispanic adults, and 9 in 10 white adults, said that they were satisfied with their housing. Seventyfour percent of black adults, 70 percent of Hispanic adults, and 81 percent of white adults were satisfied with the cost of their housing.

\section{Housing in Rural Areas}

People who live in rural areas have different opportunities and challenges. Rural residents were more likely to own their homes, more likely to have grown up close to where they live, and less likely to have broadband internet in 2019 .

Seventy-one percent of adults who lived in rural areas owned their homes, compared with 62 percent of other adults. Additionally, rural residents reported a higher rate (by 11 percentage points) of owning their homes without a mortgage compared with people living in other areas (figure 26).

Rural residents also were somewhat more likely to have grown up near where they live now. Among adults who indicated the ZIP Code where they lived

Figure 26. Housing tenure (by urban/rural status)

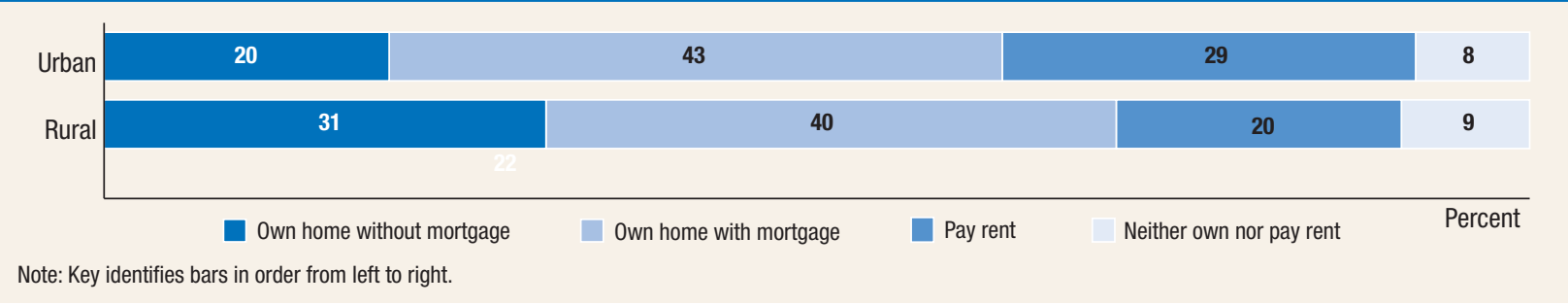


when they started high school, 31 percent lived in the same ZIP Code today. ${ }^{33}$ The percentage was higher -39 percent - for rural residents.

Rural residents also were somewhat less likely to say that they have broadband internet. Eighty-

33 The calculation excludes people who did not provide a ZIP Code, or who gave an invalid ZIP Code. This statistic may understate the number of people who grew up near where they live now because of changes in how the Postal Service allocates ZIP Codes. three percent of rural residents said that they had broadband, compared with 90 percent of adults living in or near cities. ${ }^{34}$ Rural residents were also less likely to have a data plan for a smartphone.

${ }^{34}$ Respondents to the SHED, which was administered online, could have been more likely to have broadband internet access than the general population. If rural respondents differ from the rural population by more than other respondents differ from the rest of the population, then the statistics here could either understate or overstate the gap in broadband access. The "Description of the Survey" section of this report provides additional details on the survey's fielding. 



\section{Higher Education}

Although there are many potential avenues to success, a college education is widely recognized as a path to higher income and greater economic wellbeing. Indeed, 7 out of 10 adults with a bachelor's degree viewed the financial benefits as larger than the costs. However, this is not uniformly the case as there were differences in the perceived value of education across demographic groups. Moreover, the likelihood of pursuing and completing higher education varied by race and ethnicity and by one's family background, as did the reasons for these educational decisions.

\section{Value of Higher Education}

Among all adults, 7 in 10 have ever enrolled in an educational degree program beyond high school, and 35 percent have a bachelor's degree. Economic wellbeing in 2019 increased with education, although the effects differed across demographic groups. Those without any college - and especially those who did not have a high school degree - were the least likely to report doing well financially. Financial well-being was higher for those who attended college, and even more so among those who completed at least an associate degree (figure 27). In contrast to associate degrees, certificates and technical degrees were associated with only modest increases in well-being over those reporting a high school degree. However, this may have been due to either heterogeneity of these programs or the socioeconomic and educational background of students who attend them. ${ }^{35}$

Additional education was associated with greater financial well-being within each racial and ethnic group. Yet, significant racial and ethnic disparities also existed within each level of educational attainment (table 19). For example, overall financial wellbeing among black adults with some college or a technical degree was below that among white adults with a high school education or less. Financial wellbeing was higher among black adults with a bachelor's degree than among those with less education, although the difference across racial groups remained even for those with higher levels of education.

Income levels also increased with education within all racial and ethnic groups, with larger differences between black and Hispanic adults with at least a

\footnotetext{
${ }^{35}$ Recipients of certificates and technical degrees were, for example, more likely to say that the benefits of their education were worth the cost than were those who left college with no degree. Forty-eight percent of certificate or technical degree recipients said that the benefits of their education exceeded the cost, compared to 31 percent of those who left college without a degree. Although the question of the returns for these programs is important, the relatively small sample size and the diversity of programs encompassed by certificates and technical degrees limit the ability to fully explore the returns to certificates and technical degrees in this report.
}

\section{Figure 27. At least doing okay financially (by education)}

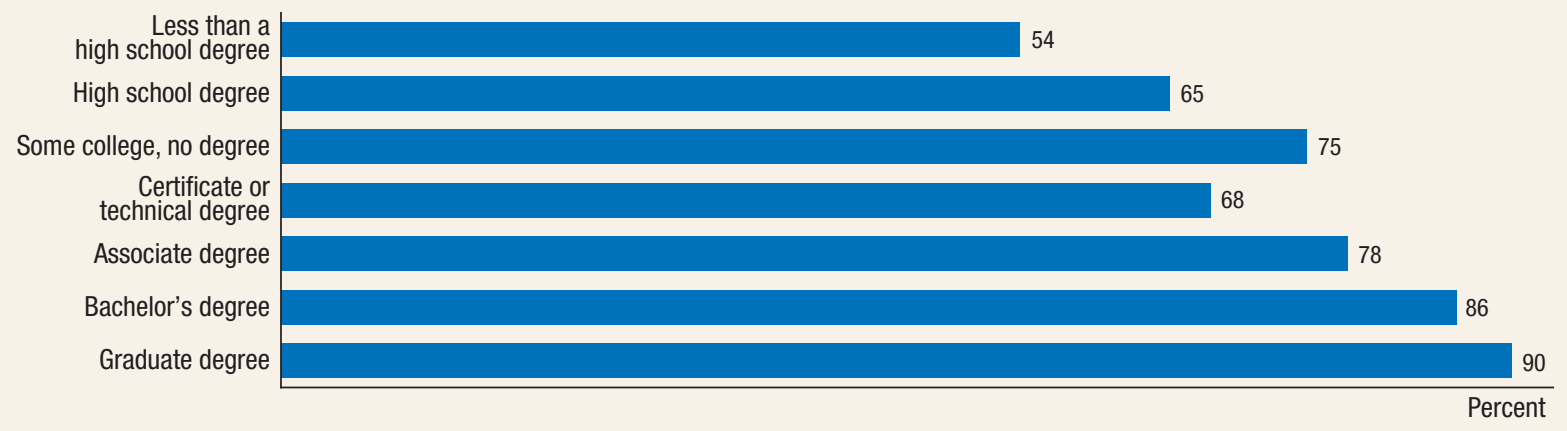




\begin{tabular}{|c|c|c|}
\hline \multicolumn{3}{|l|}{$\begin{array}{l}\text { Table } 19 \\
\text { and rac } \\
\text { Percent }\end{array}$} \\
\hline Characteristic & $\begin{array}{c}\text { At least doing } \\
\text { okay financially }\end{array}$ & $\begin{array}{c}\text { Income over } \\
\$ 40,000\end{array}$ \\
\hline \multicolumn{3}{|l|}{ High school degree or less } \\
\hline White & 67 & 51 \\
\hline Black & 59 & 27 \\
\hline Hispanic & 58 & 34 \\
\hline Overall & 63 & 43 \\
\hline \multicolumn{3}{|l|}{ Some college or technical degree } \\
\hline White & 78 & 64 \\
\hline Black & 59 & 45 \\
\hline Hispanic & 68 & 49 \\
\hline Overall & 74 & 58 \\
\hline \multicolumn{3}{|l|}{ Associate degree } \\
\hline White & 82 & 74 \\
\hline Black & 68 & 57 \\
\hline Hispanic & 71 & 52 \\
\hline Overall & 78 & 67 \\
\hline \multicolumn{3}{|l|}{ Bachelor's degree or more } \\
\hline White & 89 & 87 \\
\hline Black & 81 & 77 \\
\hline Hispanic & 86 & 77 \\
\hline Overall & 88 & 84 \\
\hline
\end{tabular}

bachelor's degree than those with a high school education or less. Yet, within every level of education, the earnings of black and Hispanic adults are below the earnings levels for adults overall. These findings align with the literature about differential economic outcomes by racial group and education. ${ }^{36}$

Consistent with the positive relationship between education and financial well-being, 53 percent of adults who went to college said that the lifetime financial benefits of their higher education exceed the financial costs (table 20). This compares to one in five who said that the costs are higher. The rest saw the benefits as about the same as the costs. These self-assessments of the value of education have changed little over the past five years of the survey.

The self-assessed value of higher education, while generally positive, depended on several aspects of a person's educational experience. Most importantly, those who completed their program and received a degree were more likely to see net benefits than noncompleters. For example, among those who went to

\footnotetext{
${ }^{36}$ Darrick Hamilton, William Darity, Anne E. Price, Vishnu Sridharan, and Rebecca Tippett, Umbrellas Don't Make It Rain: Why Studying and Working Hard Isn't Enough for Black Americans (Oakland: Insight Center, April 2015), http://www .insightcced.org/wp-content/uploads/2015/08/Umbrellas_Dont_ Make_It_Rain_Final.pdf.
}

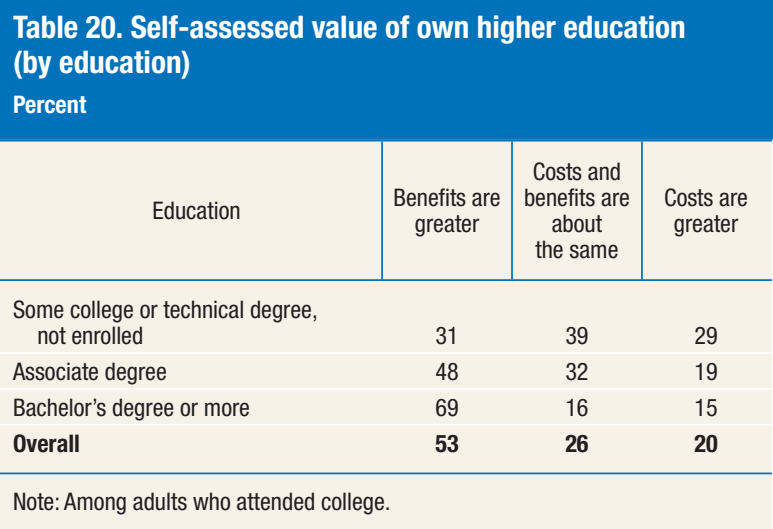

college but did not complete at least an associate degree, 3 in 10 said their education was worth the cost. This fraction jumped to nearly half of those with an associate degree and 7 in 10 among those with at least a bachelor's degree.

The self-assessed value of higher education also differed by race and ethnicity. Among those who completed some college, a technical degree, or an associate degree, there were relatively small differences between white, black, and Hispanic adults' perceptions of whether the benefits of their educations exceed the costs. However, among those who completed at least a bachelor's degree, a larger gap emerged (figure 28). While 69 percent of all bachelor's degree recipients felt that their education was worth the cost, 56 percent of black, 64 percent of Hispanic, and 71 percent of white bachelor's degree recipients felt this way. This suggests that selfperceptions of the value of higher education in 2019 were not equal across racial and ethnic groups.

An additional contributor to differences in how people viewed their education was the type of institution attended. ${ }^{37}$ Consistent with previous years of the survey, 7 in 10 of those with bachelor's degrees from public or private not-for-profit institutions saw their educational benefits as greater than their costs, versus less than half of those from for-profit institutions. A similar gap across institution types existed among those who completed an associate degree.

\footnotetext{
${ }^{37}$ Individuals did not self-report the type of institution in the survey. Instead, the institution type was assigned by matching the name and location of the college reported by the individual with data from the Center on Postsecondary Research at the Indiana University School of Education.
} 
Figure 28. Benefits of education exceed costs (by education and race/ethnicity)

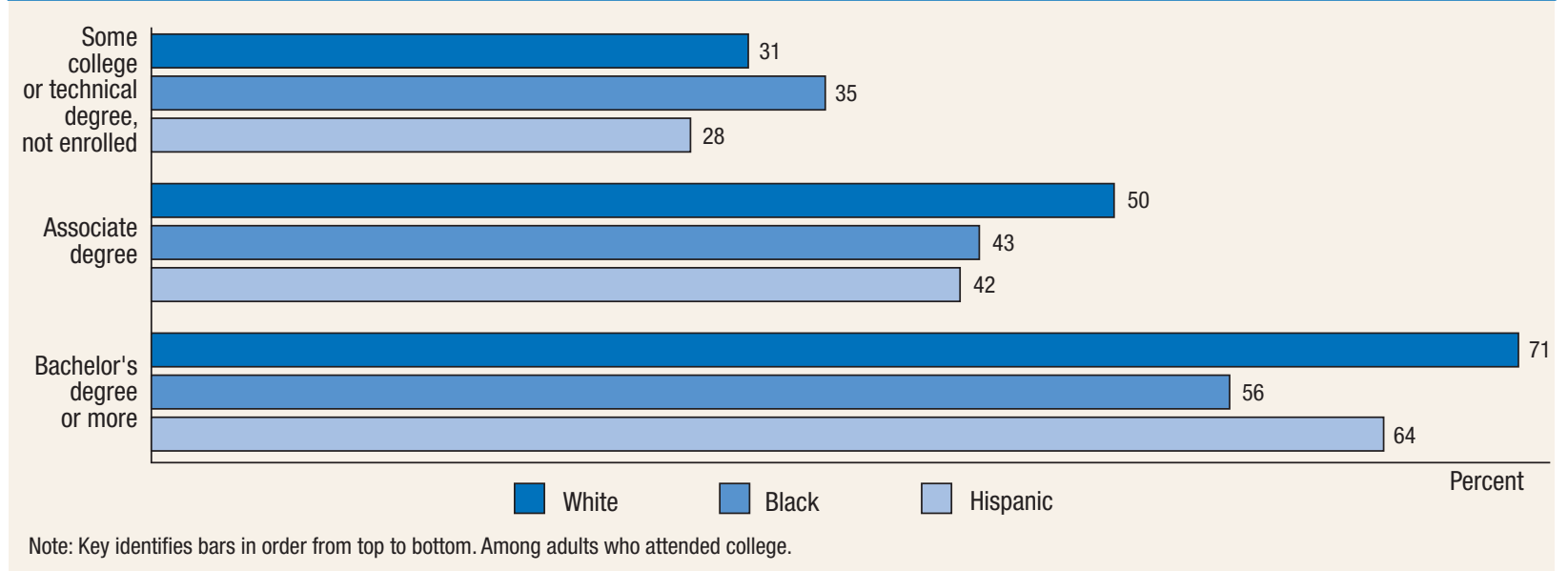

\section{Look Back on Education Decisions}

Another way to assess the value of education is to consider what people would have done differently if given the chance. Most people valued their education, yet with the benefit of hindsight and life experience, it was also common to think that different educational decisions would have been better. Among those with some college or a technical degree who were not enrolled in school at the time of the survey, three-quarters would like to have completed more education, compared to 11 percent who would rather have completed less education or not have attended college (table 21).

Likewise, among those who completed an associate degree, the most common desired change (69 percent) was to have completed more education, followed by choosing a different field of study (34 percent). Seven percent of those with an associate

Table 21. Changes would make now to earlier education decisions (by education)

\section{Percent}

\begin{tabular}{l|c|c|c}
\hline \multicolumn{1}{c|}{ Change } & $\begin{array}{c}\text { Some college } \\
\text { or technical } \\
\text { degree, not } \\
\text { enrolled }\end{array}$ & $\begin{array}{c}\text { Associate } \\
\text { degree }\end{array}$ & $\begin{array}{c}\text { Bachelor's } \\
\text { degree } \\
\text { or more }\end{array}$ \\
\hline Completed more education & 76 & 69 & 35 \\
Not attend college or less education & 11 & 7 & 5 \\
Chosen a different field of study & 42 & 34 & 36 \\
\hline Attended a different school & 37 & 26 & 23 \\
\hline
\end{tabular}

Note: Among adults who attended college. Respondents could select multiple answers. degree and 5 percent of those with at least a bachelor's degree would have completed less education.

The reassessment of education decisions also varied by the type of institution attended. Fiftyfour percent of those who attended a for-profit institution said they would like to have attended a different school, versus one-fourth of those who went to a private not-for-profit or public institution (figure 29). This difference remained even after accounting for the selectiveness of the institution, level of education completed, the parents' level of education, and the student's demographic characteristics.

\section{Intergenerational Mobility in Higher Education}

The survey responses indicate a strong correlation between the education of one's parents and one's own education. Among adults ages 22 to 39, parents' college attendance significantly increased the likelihood of attaining a bachelor's degree. ${ }^{38}$ Seventytwo percent of those with at least one parent with a bachelor's degree went on to complete a bachelor's degree themselves. This exceeded the 18 percent of those whose parents did not go to college who completed a bachelor's degree (figure 30 ).

Irrespective of the education of one's parents, rates of higher education were lower among black and

\footnotetext{
${ }^{38}$ This section excludes adults ages 18 to 21 , since many in this age group have not yet completed their education.
} 
Figure 29. Changes would make now to earlier education decisions (by institution type)

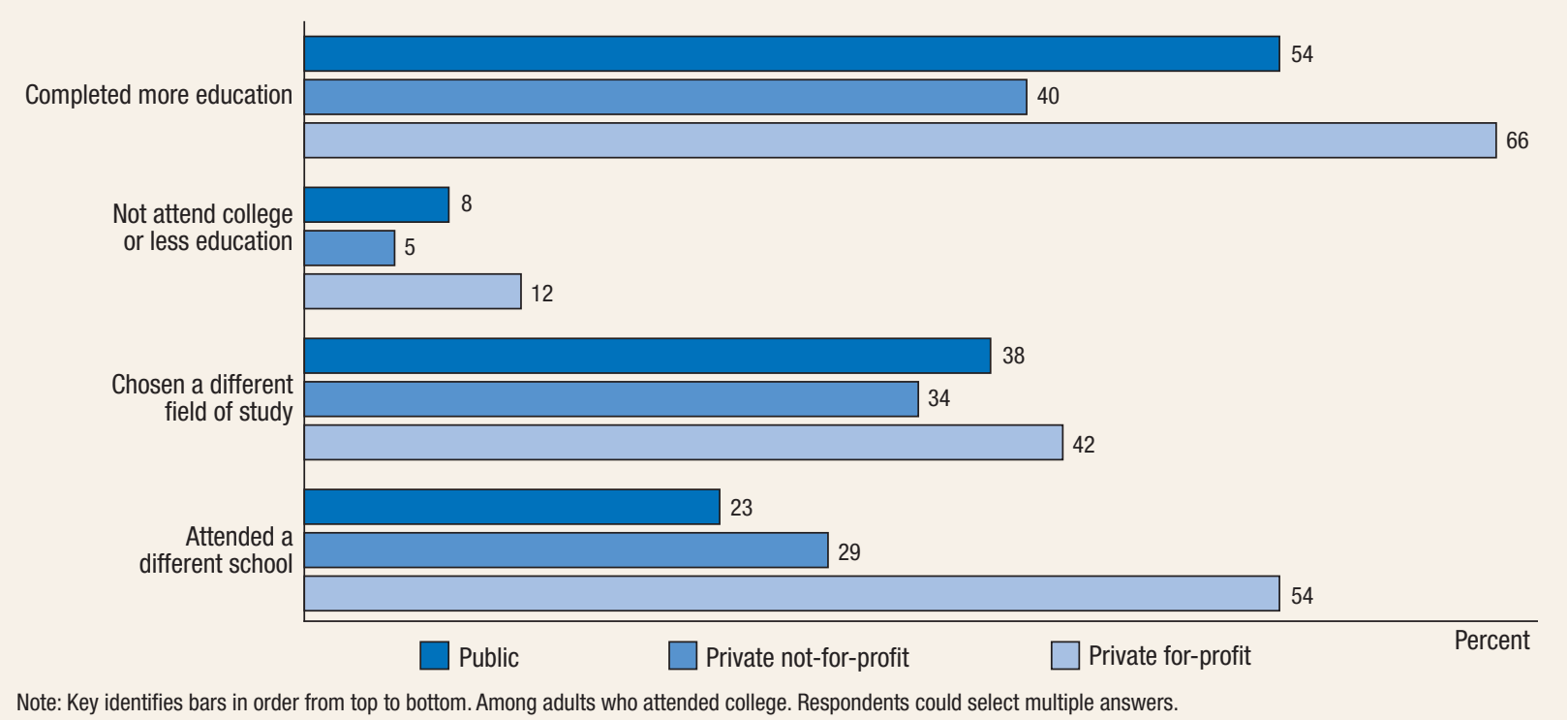

Hispanic young adults. Two in 10 white adults under age 40 whose parents did not go to college completed at least a bachelor's degree themselves. Yet, slightly over 1 in 10 black or Hispanic adults under age 40 whose parents did not go to college went on to get a bachelor's degree (figure 31).

Additionally, some people whose parents went to college did not pursue higher education. Twentyeight percent of adults ages 22 to 39 with a parent who has a bachelor's degree did not have one themselves. Among black and Hispanic adults ages 22 to 39,49 percent and 46 percent, respectively, with a parent with a bachelor's degree did not have a bachelor's degree. Among white adults whose parents completed a bachelor's degree, 24 percent did not have at least this level of education.
Looking at adults of all ages, rather than just those under age 40, highlights the relative consistency of first-generation college attendance over time. Among adults in each age range whose parents did not go to college, between 18 percent and 21 percent obtained a bachelor's degree. Similarly, for those with at least one parent with some college but no degree, between 33 percent and 36 percent obtained a bachelor's degree.

However, the likelihood of college attendance among second-generation students was higher among young adults. Among those with at least one parent having a bachelor's degree, the likelihood of obtaining a bachelor's degree was higher among adults under age 45 than was the case for older age groups (table 22).

\section{Figure 30. Educational attainment (by parents' education)}

\begin{tabular}{|c|c|c|c|c|}
\hline \multirow{2}{*}{$\begin{array}{r}\text { Both parents high school degree or less } \\
\text { At least } 1 \text { parent with some college, } \\
\text { neither with a bachelor's degree }\end{array}$} & \multicolumn{2}{|c|}{55} & 26 & 18 \\
\hline & 24 & 41 & \multicolumn{2}{|r|}{35} \\
\hline \multirow[t]{2}{*}{ At least 1 parent with a bachelor's degree } & 21 & \multicolumn{3}{|c|}{72} \\
\hline & High school degree or less & \multicolumn{2}{|c|}{ Some college/technical or associate degree } & $\begin{array}{r}\text { Percent } \\
\text { Bachelor's degree or more }\end{array}$ \\
\hline
\end{tabular}




\section{Figure 31. Share completing a bachelor's degree (by parents' education and race/ethnicity)}

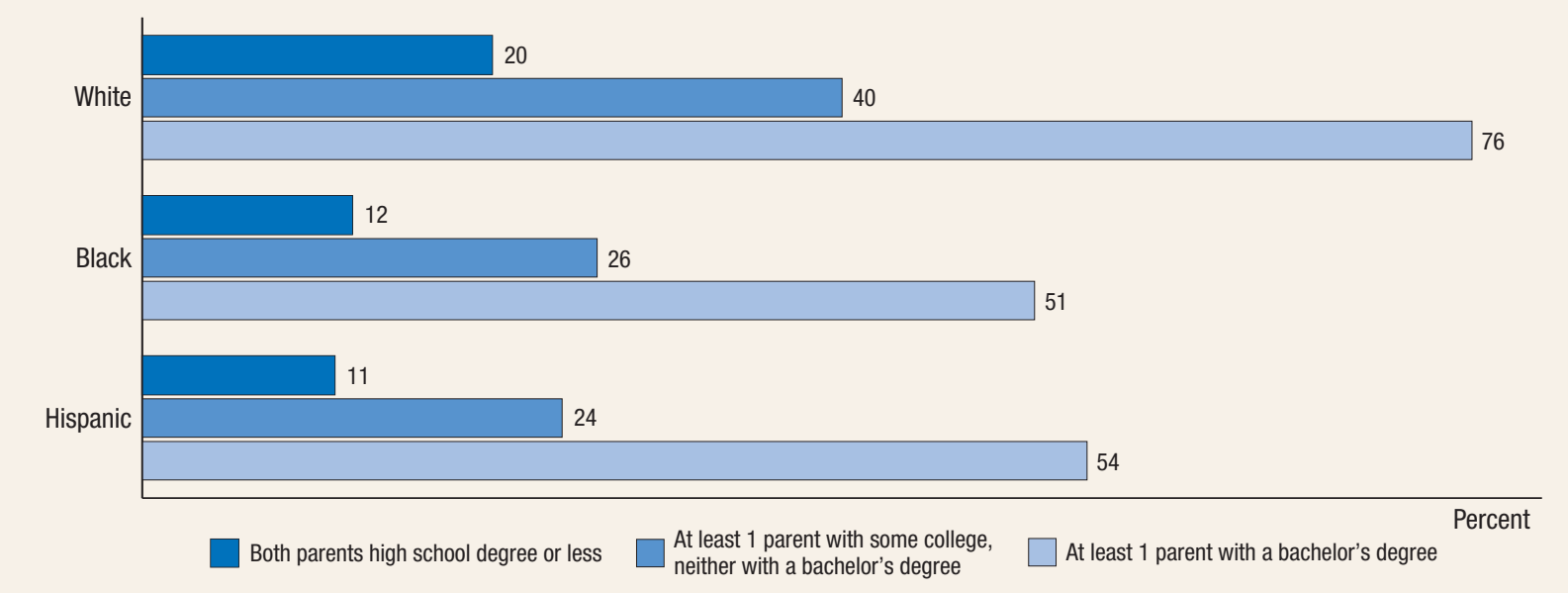

Note: Key identifies bars in order from top to bottom. Among adults ages 22 to 39 .

\section{Factors for Education Decisions}

Respondents cited a variety of reasons - including financial costs, life events, or personal preferences - as contributing to their educational decisions (table 23). Similar to years past, the high cost of college was a contributing factor to not continuing or pursuing education for many people. Six in 10 adults ages 22 to 39 who never went to college or never finished an associate or bachelor's degree cited cost as a reason for their decision. Some also cited other barriers such as childcare, a health issue or illness, or needing to work to support their family. Yet, over half (57 percent) of those who did not go to college, and nearly half (47 percent) of those who did not complete a certificate or degree, said they did not attend college or left college because they preferred to work instead.

\section{Table 22. Share completing a bachelor's degree (by parents' education and age) \\ Percent}

\begin{tabular}{|c|c|c|c|c|}
\hline \multicolumn{1}{c|}{ Parents' education } & $22-29$ & $30-44$ & $45-59$ & $60+$ \\
\hline $\begin{array}{l}\text { Both parents high school degree } \\
\text { or less }\end{array}$ & 19 & 18 & 19 & 21 \\
$\begin{array}{l}\text { At least 1 parent with some } \\
\text { college, neither with a } \\
\text { bachelor's degree }\end{array}$ & 33 & 36 & 32 & 35 \\
$\begin{array}{l}\text { At least 1 parent with a bachelor's } \\
\text { degree }\end{array}$ & 72 & 74 & 63 & 62 \\
\hline
\end{tabular}

Note: Among adults ages 22 and older.
Between racial and ethnic groups, there were differences in reasons for not continuing or not pursuing higher education. Across all groups, the most prevalent reasons for not continuing education were the financial barriers of the direct expense of college and needing to work to support family (table 24). Yet, there were notable differences between races and ethnicities related to familial responsibilities. Sixtythree percent of black and Hispanic adults ages 22 to 39 who left or did not begin college did so in order to support their families financially. Providing financial

Table 23. Reasons for not attending college or not completing at least an associate degree

Percent

\begin{tabular}{l|c|c}
\hline \multicolumn{1}{|c|}{ Reason } & $\begin{array}{c}\text { Did not attend } \\
\text { college }\end{array}$ & $\begin{array}{c}\text { Did not } \\
\text { complete } \\
\text { associate or } \\
\text { bachelor's } \\
\text { degree }\end{array}$ \\
\hline Financial and family obligations & 62 & 56 \\
Too expensive & 25 & 24 \\
Childcare responsibilities & 52 & 52 \\
Needed to earn money to support family & 57 & 47 \\
\hline Preferences & 45 & 37 \\
\hline Preferred to work & & \\
Did not think benefits worth the cost & 11 & 22 \\
Other reasons & n/a & 22 \\
\hline IIness or health issues & 57 \\
\hline Low grades & & \\
\hline
\end{tabular}

Note: Among adults ages 22 to 39 who did not attend college or who went to college but did not complete a certificate or degree and were not currently enrolled in school. Respondents could select multiple answers.

n/a Not applicable. 
Table 24. Reasons for not attending college or not

completing college degree (by race and ethnicity)

\section{Percent}

\begin{tabular}{l|c|c|c}
\multicolumn{1}{c|}{ Reason } & White & Black & Hispanic \\
\hline Financial and family obligations & & & \\
Too expensive & 62 & 47 & 62 \\
Childcare responsibilities & 21 & 19 & 34 \\
Needed to earn money to support family & 42 & 63 & 63 \\
Preferences & & & \\
Preferred to work & 52 & 50 & 53 \\
Did not think benefits worth the cost & 50 & 26 & 33 \\
Other reasons & & & \\
IIIness or health issues & 16 & 20 & 13 \\
Low grades & 22 & 23 & 20 \\
\hline
\end{tabular}

Note: Among adults ages 22 to 39 who did not attend college or who went to college but did not complete a certificate or degree and were not currently enrolled in school. "Low grades" is among those who completed at least some college. Respondents could select multiple answers. support was a reason for not completing a certificate or degree for 42 percent of white adults in this age range.

Not completing education due to family financial needs also differed between those who would have been first-generation college graduates and those with a parent who went to college. Adults ages 22 to 39 who did not complete college but who had a parent who did so were less likely to say that financially supporting one's family contributed to their decision (39 percent) than were those with parents with high school educations or less (59 percent). 


\section{Student Loans and Other Education Debt}

Fifty-five percent of people under age 30 who went to college took on some debt, such as student loans, for their education. Repaying this debt can be challenging. Seventeen percent of those with education debt were behind on their payments in 2019. This share changed little from the 19 percent who were behind in the prior survey. Individuals who did not complete their degree or who attended a for-profit institution were more likely to struggle with repayment than those who completed a degree from a public or not-for-profit institution. Additionally, those with outstanding student loan debt reported lower levels of financial well-being across several dimensions.

\section{Overview}

As of late 2019, 43 percent of those who went to college, representing 31 percent of all adults, had incurred at least some debt for their education. This included 22 percent of college attendees who still owed money and 21 percent who already repaid their education debts. Younger cohorts who attended college were more likely to have taken out loans than older adults, consistent with the upward trend in educational borrowing over the past several decades (figure 32 ). ${ }^{39}$

${ }^{39}$ Student loan borrowing has declined since its peak in 2010-11 but remains substantially above the levels from the mid-1990s

Figure 32. Acquired debt for own education, including repaid (by age and highest degree completed)

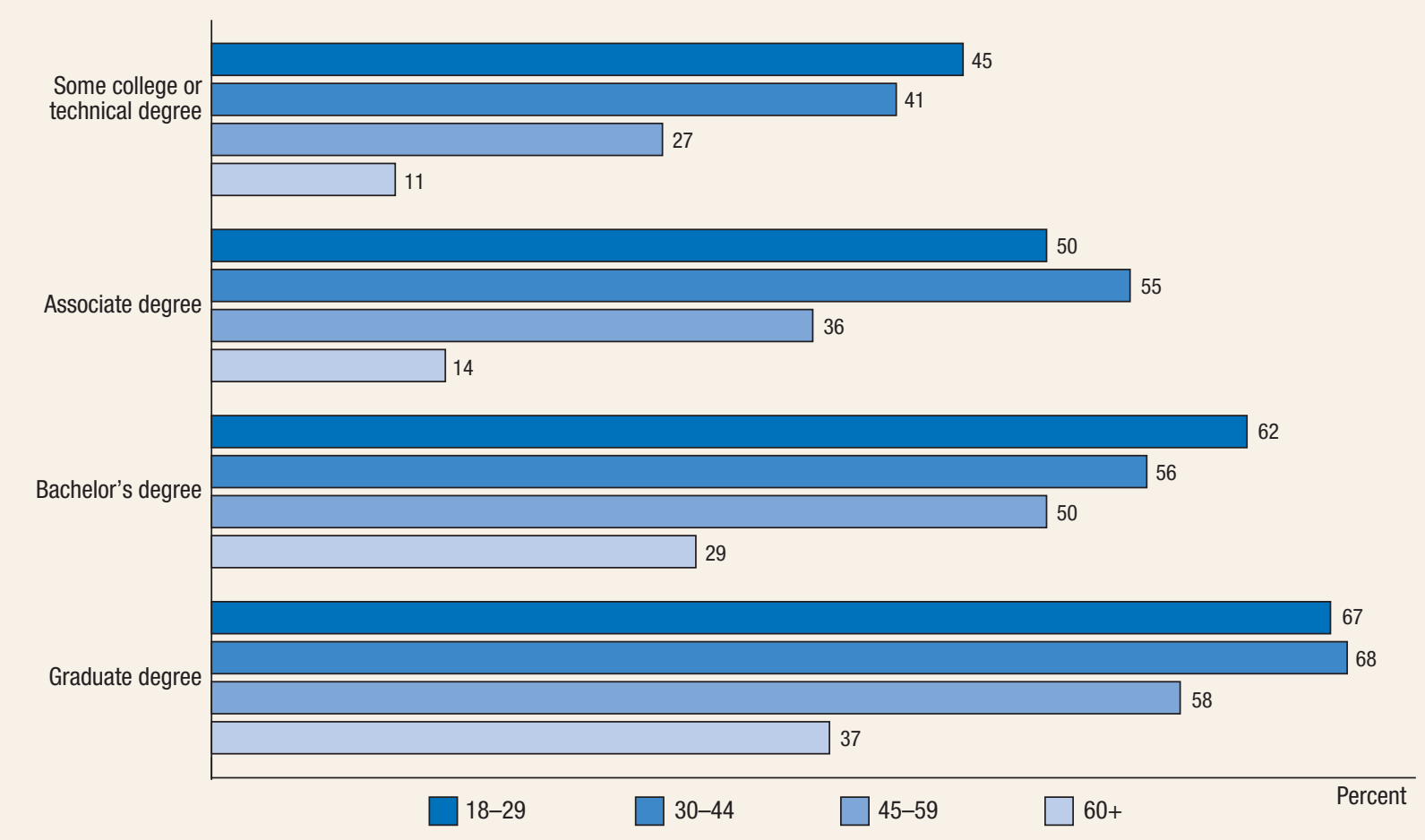

Note: Key identifies bars in order from top to bottom. Among adults who attended college. 
Table 25. Type of education debt (by whose education funded)

Percent

\begin{tabular}{l|c|c}
\hline Debt type & Own education & $\begin{array}{c}\text { Child's/ } \\
\text { grandchild's } \\
\text { education }\end{array}$ \\
\hline Student loan & 95 & 85 \\
Credit card & 23 & 16 \\
Home equity loan & 4 & 11 \\
Other loan & 11 & 11 \\
\hline
\end{tabular}

Note: Among adults with at least some debt outstanding for their own education or a child's or grandchild's education. Some people had more than one type of debt.

The incidence of incurring education debt varied by institution type. Among those who attended public institutions, 40 percent either previously held debt or had outstanding debt, compared with 56 percent of those who attended private not-for-profit institutions and 64 percent of those who attended private forprofit institutions. ${ }^{40}$ This difference in student loan usage across institution types similarly persisted among younger cohorts of students.

Not all education debt was in the form of student loans. Ninety-five percent of those with their own education debt outstanding had student loans, but many borrowers had other forms of education debt as well. This included 23 percent who borrowed with credit cards, 4 percent with a home equity line of credit, and 11 percent with some other form (table 25). Collectively, 28 percent of borrowers had at least one form of education debt besides student loans. The typical amount of education debt in 2019 among those with any outstanding debt from their own education was between $\$ 20,000$ and $\$ 24,999 .{ }^{41}$

Some people also took out education debt to assist family members with their education (through either

(Sandy Baum, Jennifer Ma, Matea Pender, and Meredith Welch, Trends in Student Aid 2017 (New York: The College Board, 2017), https://trends.collegeboard.org/sites/default/files/ 2017-trends-student-aid.pdf).

${ }^{40}$ Students who attended for-profit institutions account for a disproportionate share of education debt, including both count of borrowers and dollar amount of student loans. See Rajashri Chakrabarti, Michael Lovenheim, and Kevin Morris, "The Changing Role of Community-College and For-Profit-College Borrowers in the Student Loan Market," Federal Reserve Bank of New York Liberty Street Economics (blog), September 8 , 2016, for a discussion of trends in federal student loan borrowing by institution type (http://libertystreeteconomics .newyorkfed.org/2016/09/the-changing-role-of-the-communitycollege-and-for-profit-college-borrowers-in-the-student-loanmark.html).

${ }^{41}$ Education debt levels and monthly payments were asked in ranges rather than exact dollar amounts. a co-signed loan with the student or a loan taken out independently). Although this is less frequent than borrowing for one's own education, 4 percent of adults owed money for a spouse's or partner's education, and 5 percent had debt that paid for a child's or grandchild's education. Similar to debt outstanding for the borrower's education, debt for a child's or grandchild's education could be in forms other than a student loan (table 25).

\section{Student Loan Payment Status}

Most borrowers were required to make payments on their loans in 2019, although some were not. Reasons that payments may not be required included deferments on payments while still enrolled in school. Nearly 3 in 10 adults with outstanding education debt were not required to make payments on their loans in 2019. Of those who were making payments, the typical required monthly payment was between \$200 and \$299 per month.

Among those with outstanding debt from their own education, 17 percent of adults were behind on their payments. Those who did not complete their degree were the most likely to be behind. Four in 10 adults with outstanding education loans, not enrolled, and less than an associate degree were behind. This compares to 15 percent of borrowers with an associate degree who were behind. The delinquency rate was lower among borrowers with a bachelor's degree ( 8 percent) or graduate degree (6 percent).

Consistent with previous years of the survey, those with the least debt often had the most difficulty with repayments in 2019. Twenty-one percent of borrowers with less than $\$ 15,000$ of outstanding debt were behind on their payments, compared with 14 percent of those with $\$ 15,000$ of debt or more.

The difference in delinquency rates by loan amount was likely because education levels, and the associated earning power, generally rose with debt levels. Among those with over $\$ 15,000$ of education debt, two-thirds had at least a bachelor's degree and onethird had a graduate degree. This compares to onethird of those with smaller amounts of outstanding debt who had at least a bachelor's degree.

Excluding those who already repaid their student loans could overstate difficulties with repayment. The remainder of this section therefore considers the repayment status of all borrowers, including those 
who completely repaid their debt. The share of adults who were behind on their payments is much lower when accounting for all borrowers, including those who completely repaid that debt. Among those who ever incurred debt for their education, 9 percent were behind on their payments at the time of the survey, 44 percent had outstanding debt and were current on their payments, and 47 percent had completely paid off their loans.

Borrowers who were first-generation college students were more likely to be behind on their payments than those with a parent who completed college. Among borrowers under age 40, first-generation college students were over twice as likely to be behind on their payments as those with a parent who completed a bachelor's degree (figure 33).

Difficulties with repayment also varied by race and ethnicity in 2019. The share of black and Hispanic borrowers who were behind on their loans was higher than the overall share of borrowers who were behind (figure 34). These patterns partly reflect differences in rates of degree completion, institution type, and wages for a given educational credential (see the "Higher Education" section of this report for additional discussions of these differences by race and ethnicity).

\begin{tabular}{|c|c|c|c|}
\hline \multicolumn{4}{|l|}{ Percent } \\
\hline Institution type & Behind & Current & Paid off \\
\hline Public & 9 & 63 & 27 \\
\hline Private not-for-profit & 7 & 65 & 28 \\
\hline Private for-profit & 24 & 61 & 15 \\
\hline Overall & 11 & 62 & 26 \\
\hline
\end{tabular}

Note: Among adults ages 18 to 39 who borrowed to pay for their own education.

Repayment status also differed by the type of institution attended. Nearly one-fourth of borrowers under age 40 who attended private for-profit institutions were behind on student loan payments, versus 9 percent who attended public institutions and 7 percent who attended private not-for-profit institutions (table 26).

Greater difficulties with loan repayment among attendees of for-profit institutions may partly reflect the lower returns on degrees from these institutions. ${ }^{42}$ Indeed, when accounting for race and ethnicity, first-generation status and institution selectivity,

${ }^{42}$ See David J. Deming, Claudia Goldin, and Lawrence F. Katz,

"The For-Profit Postsecondary School Sector: Nimble Critters

\section{Figure 33. Payment status of loans for own education (by parents' education and current age)}

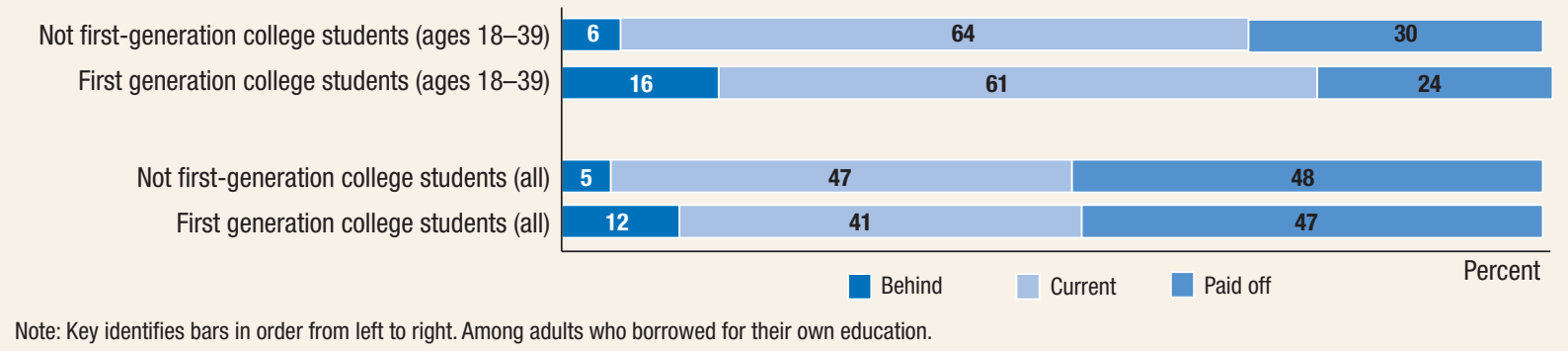

Figure 34. Payment status of loans for own education among borrowers under age 40 (by race/ethnicity)

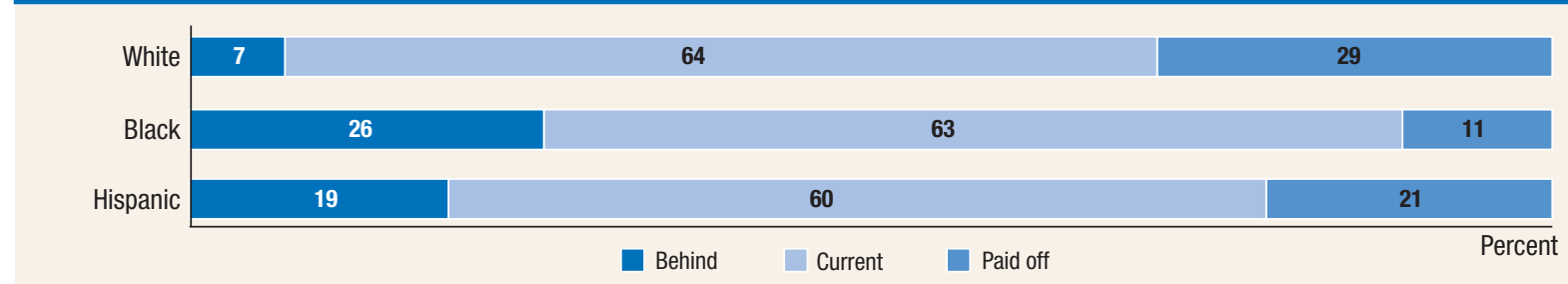


the relationship between for-profit institution attendance and student loan default persisted. This suggests that the high default rates for attendees of forprofit institutions reflect characteristics of the schools and is not simply due to the characteristics of their students.

\section{Relation to Financial Well-Being}

Adults carrying student loan debt reported lower levels of financial well-being than did similar adults without outstanding debt. Among adults with the same level of education, those with outstanding student loan debt were less likely to say they were doing okay financially. For example, three-quarters of bachelor's degree recipients under age 40 with outstanding education debt were at least doing okay financially. But this was less than the 93 percent of similarly educated adults in this age range who previously had debt and said they were at least doing okay, and the 90 percent of those who never had debt and said the same. This trend similarly holds for those with some college, a technical degree, or an associate degree (table 27).

Adults under age 40 with education debt were also less likely to feel that their retirement savings were currently on track. Forty percent of adults under age 40 with at least a bachelor's degree who had outstanding education debt felt their retirement savings plan was currently on track. This compares with 56 percent who previously had debt and 55 percent who never had debt.

or Agile Predators?" Journal of Economic Perspectives 26, no. 1 (Winter 2012): 139-64, for a discussion of the rates of return by education sector.
Table 27. Well-being measures (by education and debt status)

Percent

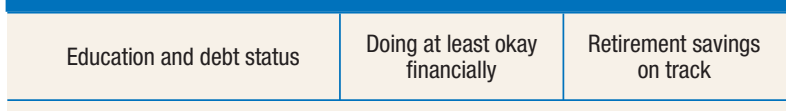

Some college/technical or associate degree

Never had education debt $\quad 75$

Previously had debt, now repaid

Currently has debt

$75-27$

Bachelor's degree or more

Never had education debt

Previously had debt, now repaid

Currently has debt

71

53

29

18

$90 \quad 55$

$93 \quad 56$

76

40

Note: Among adults ages 18 to 39 who completed at least some college.

This pattern also emerges among those who had some college, a technical degree, or an associate degree. That said, progress toward retirement savings was notably lower among those without a bachelor's degree, irrespective of student loan debt levels. There were many possible explanations for this trend. This may reflect an inability to contribute to retirement accounts after meeting monthly student loan obligations. Alternatively, holding student debt may have a substantial influence on prioritization of debt repayment over saving, even if borrowers were able to both meet minimum loan obligations and contribute to retirement accounts. ${ }^{43}$

${ }^{43}$ See Matthew S. Rutledge, Geoffrey T. Sanzenbacher, and Francis M. Vitagliano, "Do Young Adults with Student Debt Save Less for Retirement?" Center for Retirement Research at Boston College, Issue Brief no. 18-13 (June 2018), https://crr.bc.edu/ wp-content/uploads/2018/06/IB_18-13.pdf for a discussion of possible effects of student loans on retirement savings among young people. 


\section{Retirement}

Most retirees reported that they retired from their job before typical ages for claiming Social Security benefits. While preferences played a role in the timing of retirement for the majority of retirees, unanticipated life events contributed to the timing of retirement for a substantial share. Many non-retired adults were struggling to save for retirement in 2019 and felt that they were not on track with their savings. While preparedness for retirement increased with age, concerns about inadequate savings were still common for those near retirement age.

\section{Current Retirees}

Retirees represent a sizeable portion of the adult population. More than one-fourth of adults in 2019 considered themselves to be retired, even though some also reported that they were still working in some capacity. ${ }^{44}$ Fifteen percent of retirees said that they had done some work for pay or profit in the prior month. Consequently, 4 percent of all adults considered themselves retired and were still working.

Most retirees reported that they retired from their job before the standard ages to claim Social Security benefits, although average retirement ages differed across demographic groups (table 28). ${ }^{45}$ In 2019, half of retirees said they retired before age 62 , and nearly one-fourth retired between the ages of 62 and 64 . Black and Hispanic retirees were more likely to have retired before age 62 (56 percent and 65 percent, respectively) than white retirees (48 percent). Retirees with a bachelor's degree or more were also slightly more likely to have retired before age 62 , relative to

${ }^{44}$ In this report, descriptions of current retirees include everyone who reported being retired, including those who also reported that they are working.

${ }^{45}$ Individual expectations about the timing of retirement vary, but the U.S. Social Security System may provide reference points for typical retirement ages. Eligible individuals can begin to draw Social Security retirement benefits as early as age 62 . Unreduced benefits are available at full retirement age, which varies from age 65 to 67 depending on birth year. See https:// www.ssa.gov/planners/retire/agereduction.html.
Table 28. Retirement age (by race/ethnicity and education)

Percent

\begin{tabular}{lcccc}
\multicolumn{1}{c|}{ Characteristic } & 61 or earlier & $62-64$ & $65+$ \\
\hline Race/ethnicity & & & \\
White & 48 & 24 & 27 \\
Black & 56 & 23 & 17 \\
Hispanic & 65 & 19 & 15 \\
Education & & & \\
High school degree or less & 50 & 24 & 24 \\
$\begin{array}{l}\text { Some college/technical or associate } \\
\quad \text { degree }\end{array}$ & 50 & 25 & 24 \\
Bachelor's degree or more & 55 & 18 & 26 \\
Overall & $\mathbf{5 1}$ & $\mathbf{2 3}$ & $\mathbf{2 4}$ \\
\hline
\end{tabular}

Note: Among retirees.

those who have less education. However, this was somewhat offset by the fact that retirees with more education were also more likely to report that they were working in retirement.

In deciding when to retire, most retirees indicated that their preferences played a role, but life events contributed to the timing of retirement for a substantial share (figure 35). Fifty-three percent of retirees said a desire to do other things or to spend time with family was important for their decision to retire, and 39 percent said they retired because they reached a normal retirement age. Nonetheless, 30 percent said that a health problem was a factor in their decision to retire, and 15 percent said they retired to care for family members. Eleven percent reported they were forced to retire or that work was not available. Collectively, health problems, caring for family, and forced retirements contributed to the timing of retirement for 47 percent of retirees.

Economic well-being among retirees varied considerably by whether the reasons for retirement appeared to be voluntary and determined by preferences or were unanticipated and driven by life events (see box 4).

Even though Social Security was the most common source of income in retirement in 2019, 8 in 10 retir- 


\section{Box 4. Reasons for Retirement and Retiree Financial Well-Being}

Research on retirement expectations has shown that shocks like health problems, job-related changes, and family transitions are important for explaining why some people retire earlier than planned. ${ }^{1}$ These types of unanticipated or involuntary reasons for retirement may affect family finances in many ways, including reducing income and increasing expenses. Consequently, the reasons for retirement could contribute to financial well-being and financial challenges in retirement.

Retirees with less education disproportionately reported that they retired due to unanticipated or involuntary reasons like health problems and job loss (figure A). ${ }^{2}$ Twenty-eight percent of those of those

1 See Alicia Munnell, Matthew S. Rutledge, and Geoffrey T. Sanzenbacher, "Retiring Earlier than Planned: What Matters Most?" Center for Retirement Research at Boston College, Issue Brief no. 19-3 (February 2019), https://crr.bc.edu/wp-content/uploads/ 2019/01/IB_19-3.pdf.

2 In this box, "unanticipated or involuntary" reasons for retirement include health problems, caring for family members, and being forced to retire or a lack of available work. "Voluntary" reasons include a desire to do other things or to spend time with family, reaching normal retirement age, and not liking the work. Those who chose answers from both the voluntary and involuntary categories are included as giving a "combination" of reasons for their decision to retire. Eight percent of retirees did not respond to the question on reasons why they retired and are included with the combination category. While caring for family members is included in the "unanticipated or involuntary" category, it may be an affirmative choice for some. That said, a small share of retirees reported this as their only reason for retiring. If it is excluded from the unanticipated or involuntary category, the share of those retir- with a high school degree or less said that they retired only because of these unanticipated reasons, compared to 13 percent of those with a bachelor's degree or more. The higher incidence of unanticipated or involuntary retirement among those with less education is consistent with research showing that these workers are more likely to apply for disability benefits and claim Social Security early. ${ }^{3}$ For some, the higher likelihood of health problems and employment transitions may have been related to employment in more physically demanding occupations and more cyclical industries.

The acceleration in the timing of retirement can contribute to lower financial well-being in a number of ways. Early retirement leads to the loss of wage income and employer-provided benefits like health insurance, shortens the time for accumulating retirement savings, and may necessitate that families spend down assets sooner than they had anticipated. Those who are eligible for Social Security can claim benefits beginning at age 62 , but at a permanently reduced rate relative to what they could have received by starting benefits later.

(continued on next page)

ing for only involuntary reasons would decline from 22 percent to 19 percent of retirees.

3 See Steven Venti and David Wise, "The Long Reach of Education: Early Retirement," Journal of the Economics of Ageing 6 (December 2015): 133-48, https://www.sciencedirect.com/science/ article/pii/S2212828X15000201.

Figure A. Whether reasons for retirement were unanticipated/involuntary or voluntary (by education)

\begin{tabular}{|c|c|c|c|}
\hline High school degree or less & 28 & 33 & 38 \\
\hline \multirow{2}{*}{$\begin{array}{r}\text { Some college or associate degree } \\
\text { Bachelor's degree or more }\end{array}$} & 21 & 33 & 46 \\
\hline & 13 & 31 & 56 \\
\hline Overall & 22 & 33 & 45 \\
\hline
\end{tabular}

Note: Key identifies bars in order from left to right. Among retirees.

ees had one or more sources of private income. This included 59 percent of retirees with income from a pension; 44 percent with interest, dividends, or rental income; and 32 percent with wage income. ${ }^{46}$ More than three-fourths of retirees received income from

\footnotetext{
46 The type of pension was not specified, so pension income may include income from defined benefit plans, which pay a fixed monthly amount and defined contribution plans, such as 401(k) and 403(b) plans.
}

Social Security in the past 12 months, including 93 percent of retirees age 65 or older (table 29).

\section{Retirement Savings among Non-Retirees}

Although three-fourths of non-retired adults had at least some retirement savings, one-fourth indicated 


\section{Box 4. Reasons for Retirement and Retiree Financial Well-Being-continued}

Consistent with these expectations, retirees who cited unanticipated or involuntary reasons for the decision to retire express lower rates of well-being across multiple dimensions. Those forced into retirement were less likely to have income from private sources-including pensions, interest, dividends, or wages - relative to those who chose when to retire voluntarily (62 percent versus 91 percent, respectively). They were also more likely to rely on public assistance programs such as Supplemental Security Income (SSI) (16 percent) compared to those who retired voluntarily (1 percent). Additionally, they reported lower rates of overall financial well-being (64 percent versus 94 percent).

Although financial well-being in retirement was lower on average for all people retiring for unanticipated or involuntary reasons, this was particularly the case among those with less education (figure B). Among retirees with a high-school degree or less, those who retired for unanticipated or involuntary reasons were much less likely to say they were doing at least okay financially (57 percent) than are those who retired for voluntary reasons (90 percent). Among retirees with at least a bachelor's degree, the difference was smaller: 87 percent compared to 97 percent.

The substantially lower rates of financial well-being among less-educated involuntary retirees is consistent with their being in a less stable financial position as they approach retirement. As a result, they may be less able to withstand the additional shock of an unexpectedly early retirement. Prior research indicates that retirees with less education have lower lifetime earnings and are less likely to have had employer-sponsored retirement benefits and health insurance during their working years. ${ }^{4}$ Consistent with their lower lifetime earnings, fewer benefits, and less capacity to save, 29 percent of non-retirees in their 50s with a high school degree or less had no

4 See Lauren Schudde and Kaitlin Bernell, "Educational Attainment and Nonwage Labor Market Returns in the United States," AERA Open 5, no.3 (July-September 2019): 1-18, https://doi.org/ $10.1177 / 2332858419874056$.
Figure B. At least okay financially (by education and whether retirement decision was involuntary or voluntary)

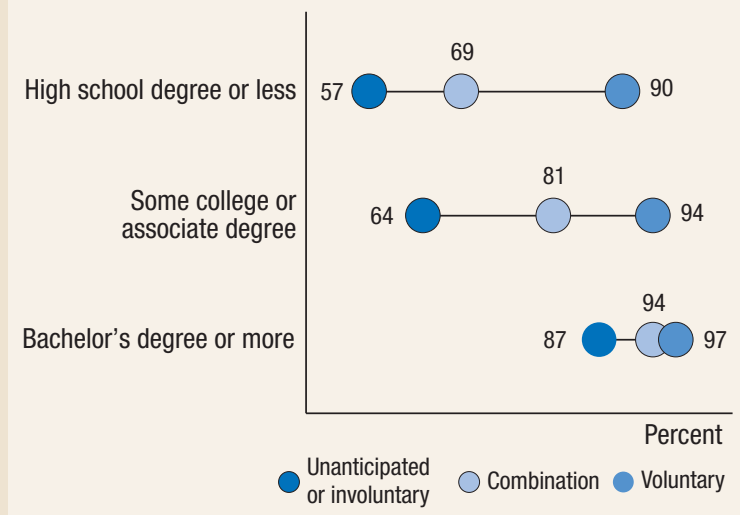

Note: Key identifies circles in order from left to right. Among retirees.

retirement savings, compared to 2 percent of those with a bachelor's degree.

Existing policies seek to address needs of workers facing health shocks or job loss, and changes in the nature of work over time may also work in favor of some older adults' ability to continue working longer in spite of health limitations. ${ }^{5}$ Even so, these results suggest that unstable financial situations approaching retirement age along with unpredictable events that prevent working longer are associated with higher rates of economic hardship in retirement among those with less education.

5 Such policies include those that protect workers from age-related discrimination, allow time off for medical treatment and care for family members, provide income in the case of disability, and enable early access to retirement savings without penalties in some circumstances. On the changing nature of work, see Richard W. Johnson, Gordon B.T. Mermin, and Matthew Resseger, Employment at Older Ages and the Changing Nature of Work (Washington: AARP Public Policy Institute, November 2007), https://www.urban.org/sites/default/files/publication/31146/ 1001154-Employment-at-Older-Ages-and-the-Changing-Natureof-Work.PDF. they did not have any at the time of the survey (figure 36). Among those with retirement savings, these savings were most frequently in defined contribution plans, such as a 401(k) or 403(b), with 55 percent of non-retired adults reporting they had money in such a plan. These accounts were more than twice as common as traditional defined benefit plans such as pensions, which 22 percent of non-retirees held. Forty-seven percent of non-retirees had savings outside of retirement accounts.
While most non-retired adults had some type of retirement savings, fewer than 4 in 10 thought their retirement saving was on track. Because retirement saving strategies differ by circumstances and age, survey respondents assessed whether or not they felt that they are on track, but they defined that for themselves. Thirty-seven percent of non-retired adults thought their retirement saving was on track, while 44 percent said it is not and the rest were not sure. 


\section{Figure 35. Reasons for the timing of retirement}

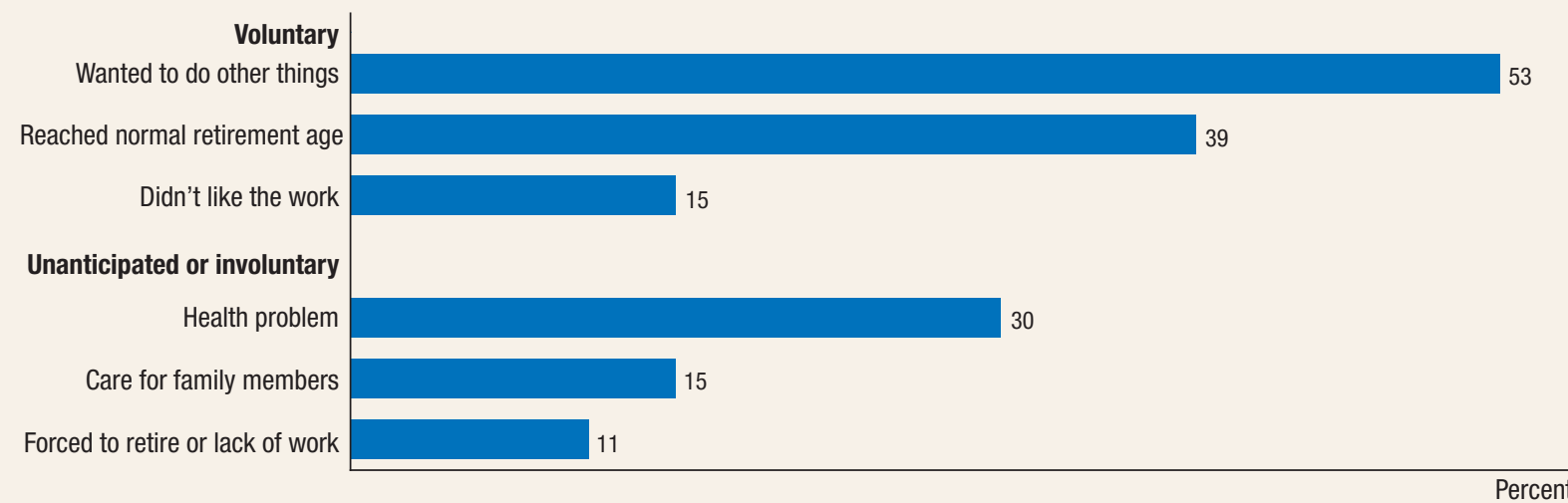

Note: Among retirees. Respondents could select multiple answers.

Retirement savings and perceived preparedness differed across demographic groups. Younger adults were both less likely to have retirement savings and to view their savings as on track than older adults. Additionally, black and Hispanic non-retirees were less likely to have retirement savings and to view

Table 29. Sources of income in the past 12 months among retirees (by age)

Percent

\begin{tabular}{l|c|c}
\multicolumn{1}{c|}{ Source } & $\begin{array}{c}\text { Retires age 65 } \\
\text { and older }\end{array}$ & All retirees \\
\hline Social Security & 93 & 77 \\
Pension & 68 & 59 \\
Interest, dividends, or rents & 49 & 44 \\
Wages, salaries, or self-employment & 25 & 32 \\
Cash transfers other than Social Security & 4 & 8 \\
\hline
\end{tabular}

Note: Among retirees. Respondents could select multiple answers. Sources of income include the income of a spouse or partner. their retirement savings as on track (table 30). The lower rates of savings among black and Hispanic non-retirees partly reflects the fact that black and Hispanic adults are, on average, younger than the non-retired population overall. Even within age cohorts, however, significant differences remained in retirement savings by race and ethnicity.

At all ages, a sizeable minority of non-retirees with modest retirement savings felt that they were on track toward their retirement savings goals. Most non-retirees of all ages without retirement savings recognized that they were not on track. However, one-third of people in their 30s who had some selfdirected retirement savings, but less than $\$ 50,000$ worth, felt that they were on track. Even among older ages, one-fourth of those with this level of self-directed savings in their 40s felt they were on track, and one-fifth of those in their 50s felt that they were. However, for many individuals this level of savings falls short of the recommended

\section{Figure 36. Forms of retirement savings among non-retirees}

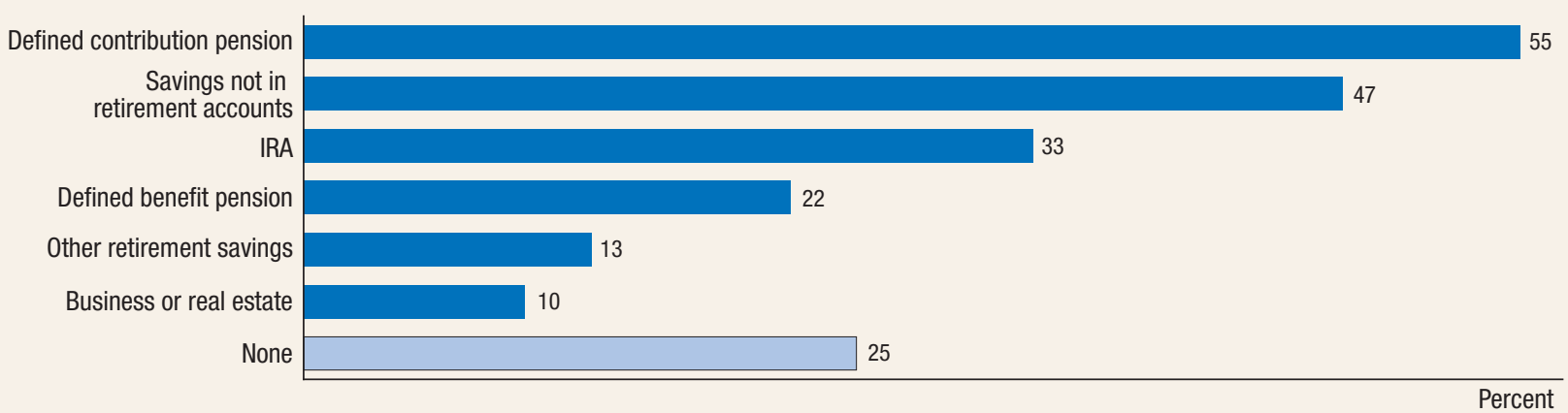

Note: Among non-retirees. Respondents could select multiple answers. 
Table 30. Retirement savings and self-assessed

preparedness (by age, race/ethnicity)

Percent

\begin{tabular}{l|c|c}
\hline \multicolumn{1}{|c|}{ Characteristic } & $\begin{array}{c}\text { Any retirement } \\
\text { savings }\end{array}$ & $\begin{array}{c}\text { Retirement } \\
\text { savings on track }\end{array}$ \\
\hline Age & & \\
$18-29$ & 62 & 29 \\
$30-44$ & 73 & 35 \\
$45-59$ & 83 & 44 \\
$60+$ & 88 & 51 \\
Race/ethnicity & & \\
White & 80 & 43 \\
Black & 64 & 29 \\
Hispanic & 61 & 22 \\
Overall & $\mathbf{7 4}$ & $\mathbf{3 7}$ \\
\hline
\end{tabular}

Note: Among non-retirees.

retirement savings goals, by age range, suggested by financial planners. ${ }^{47}$

\section{Comfort Managing Savings and Financial Literacy}

Non-retirees with self-directed retirement savings varied in their comfort with making investment decisions for their accounts. Nearly 6 in 10 non-retirees with self-directed retirement savings expressed low levels of comfort in making investment decisions with their accounts.

Among those non-retirees with self-directed savings, women of all education levels, and men with less

\footnotetext{
${ }^{47}$ While there is not a consensus of retirement savings goals by age, for examples of these recommendations see Kristin Stoller, "How Much Should You Have Saved by Age?" Forbes.com, February 25, 2020, https://www.forbes.com/advisor/personalfinance/how-much-should-you-have-saved-by-age/.
}

education, were not as comfortable as men with at least a bachelor's degree at managing their retirement investments (figure 37). While 60 percent of men with at least a bachelor's degree were mostly or very comfortable making investment decisions, 43 percent of men with a high school degree or less expressed that level of comfort. Women with any level of education were less comfortable making investment decisions than men. Thirty-two percent of women with a bachelor's degree were comfortable managing their investments, and the share was similar for women with less education.

To get some sense of individuals' financial knowledge, respondents were asked three questions commonly used as measures of financial literacy (figure 38). ${ }^{48}$ Higher shares of adults provided correct answers to questions about interest and inflation than to the question on risk diversification. The average number of correct answers was 1.8 out of 3 , and 35 percent of adults got all three correct.

Self-assessed comfort in managing investments was correlated with these measures of financial literacy. Among those with self-directed retirement accounts, those who expressed comfort with managing their investments answered a larger share of questions (75 percent) correctly, on average, than those who expressed little or no comfort (62 percent) (table 31$)$. Notably, the share of incorrect answers did not vary with investment comfort. Instead, the number of "don't know" responses fell as investment comfort rose. Overall, however, non-retirees with such accounts still answered more financial literacy ques-

${ }^{48}$ These questions were developed by Annamaria Lusardi and Olivia Mitchell (see "Financial Literacy around the World: An Overview," Journal of Pension Economics and Finance 10, no. 4 (2011): 497-508) and have been widely used to study financial literacy.

Figure 37. Mostly or very comfortable investing self-directed retirement savings (by gender and education)




Figure 38. Financial literacy questions

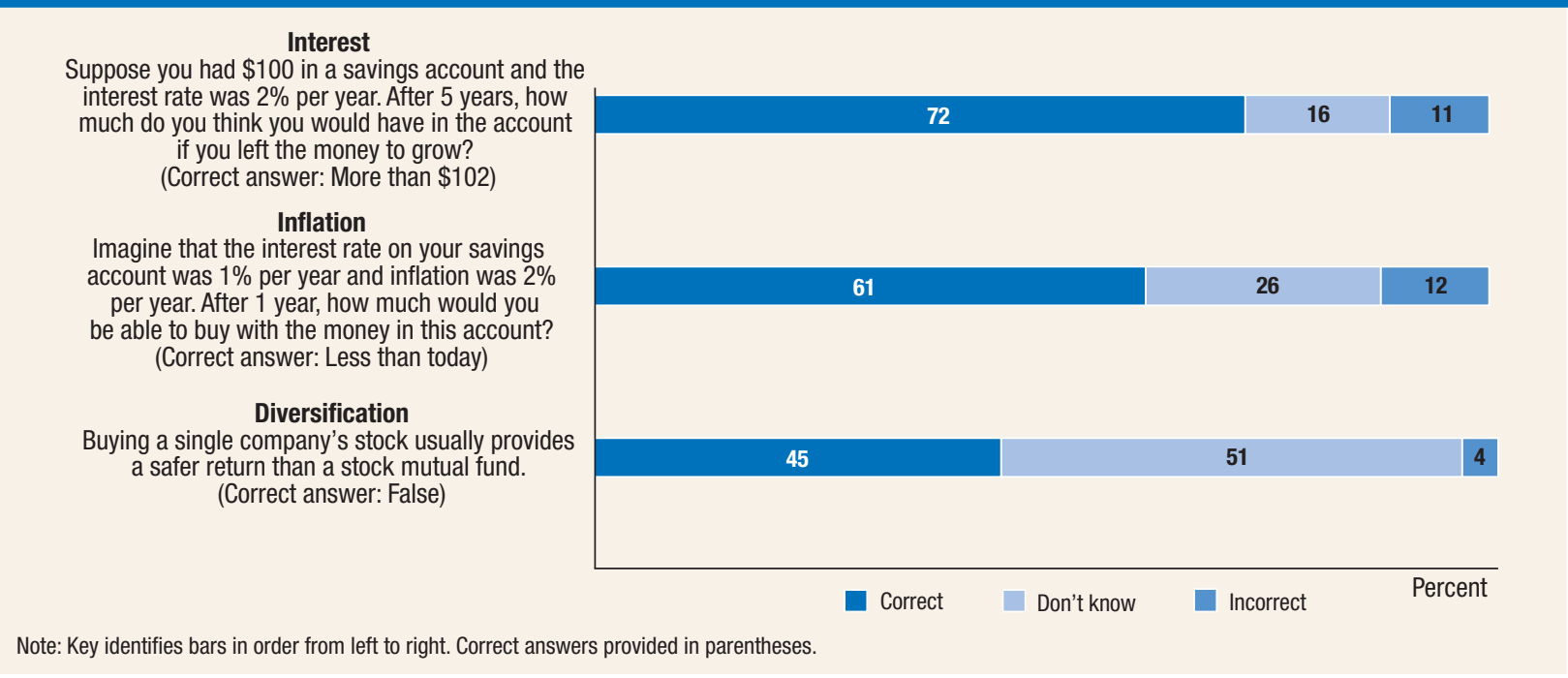

tions correctly, on average, than either non-retirees who did not have such accounts or people who were already retired.

Table 31. Financial literacy (by retirement savings and comfort investing)

Percent of answers

\begin{tabular}{l|c|c|c}
\hline $\begin{array}{c}\text { Presence of retirement savings and } \\
\text { level of investing comfort }\end{array}$ & Correct & Incorrect & $\begin{array}{c}\text { Don't know/ } \\
\text { refused }\end{array}$ \\
\hline Has self-directed retirement savings & 67 & 8 & 25 \\
Mostly or very comfortable investing & 75 & 8 & 17 \\
$\quad$ Not or slightly comfortable investing & 61 & 8 & 30 \\
No self-directed retirement savings & 36 & 11 & 53 \\
Retired & 62 & 9 & 29 \\
Overall & $\mathbf{5 9}$ & $\mathbf{9}$ & $\mathbf{3 2}$ \\
\hline
\end{tabular}

Gender differences in financial literacy mirrored differences in being comfortable with the investment decisions. Women, on average, answered a lower share of financial literacy questions correctly (52 percent) than men (67 percent). Women were also more likely to select "don't know" (38 percent) than men (25 percent). As a result, women, on average, had lower levels of financial literacy by this measure. Some evidence suggests that one driver of this gender difference may relate to different levels of experience with financial decisions. ${ }^{49}$

\footnotetext{
${ }^{49}$ Some of the gender gap in financial literacy may relate to specialization in financial tasks within a household, with women being less likely to handle the finances. Joanne Hsu finds that women's financial literacy increases after the death of a spouse (see "Aging and Strategic Learning: The Impact of Spousal Incentives on Financial Literacy," Journal of Human Resources 51, no. 4 (Fall 2016): 1036-67).
} 


\section{Financial Repercussions from COVID-19}

For many families, financial circumstances in 2020 look very different than they did in late 2019 when the SHED was fielded. In order to gain further information about these changing circumstances, the Federal Reserve Board fielded a supplemental survey in April 2020. From the start of March through early April 2020, 19 percent of adults reported losing a job, being furloughed, or having their hours reduced. Among those experiencing these employment disruptions, over one-third expected to have difficulty with their bills in April. Yet, for those not experiencing an employment disruption, financial outcomes at the time of the supplemental survey were largely similar to those observed in the fourth quarter of 2019.

\section{Employment and Work from Home}

Thirteen percent of adults, representing 20 percent of people who had been working in February, reported that they lost a job or were furloughed in March or the beginning of April 2020 (figure 39). ${ }^{50}$ These job losses were most severe among workers with lower incomes. Thirty-nine percent of people

\footnotetext{
${ }^{50}$ Respondents were asked about employment events between March 1 and when they took the survey. The survey was in the field from April 3 through April 6. Subsequent references in this section to events in March include the beginning of April
}

working in February with a household income below $\$ 40,000$ reported a job loss in March. Another 6 percent of all adults had their hours reduced or took unpaid leave. Taken together, 19 percent of all adults reported either losing a job or experiencing a reduction in work hours in March.

Despite these widespread employment losses, some people took on new or additional employment in March. Seven percent of adults reported that they increased their hours worked or worked overtime. Four percent of adults, including 8 percent of those who experienced a job loss, took on a side job to supplement their income. Some people who lost jobs may also have started other full-time employment or already had second jobs.

Many people who lost a job remained connected to their employer and expected to return to the same job eventually. Nine in 10 people who lost a job said that their employer indicated that they would return to their job at some point. In general, however, people were not told specifically when to expect to return to work. Seventy-seven percent said that their

prior to the respondent taking the survey; 1,030 adults responded to the supplemental survey, and results were weighted to be nationally representative. Additional details can be found in the "Description of the Survey" section of this report.

\section{Figure 39. Employment events in March 2020}

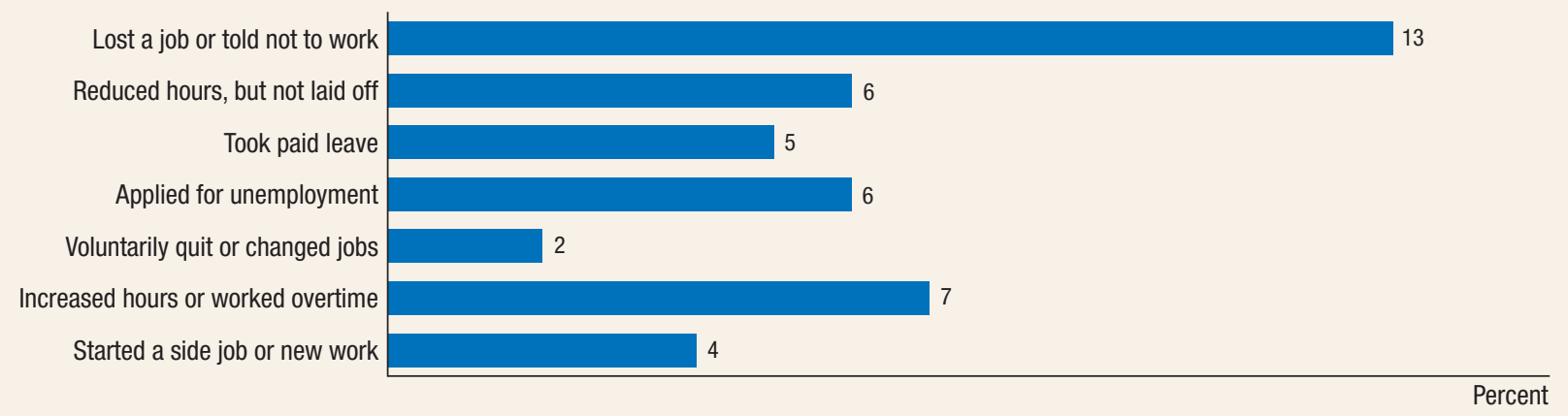


employer told them to expect to return, but did not give them a return date. A smaller 14 percent were given a specific return date or had already returned to work. It is difficult to predict, however, how long layoffs will ultimately last.

Many of those who were still working worked from home. More than half of workers (53 percent) did at least some work from home in the last week of March, and 41 percent did all their work from home. For comparison, in October 2019, 7 percent of people working for someone else usually worked from home (see the "Employment" section of this report).

Workers with higher levels of education, particularly bachelor's degrees, were more likely to work from home. Sixty-three percent of workers with at least a bachelor's degree worked entirely from home. Among workers with a high school degree or less, 20 percent worked entirely from home, as did 27 percent of workers who have completed some college or an associate degree (figure 40).

Some people also said that childcare, family obligations, or health concerns contributed to them working less in March. Including those taking paid leave or who had their hours reduced but who were not laid off, 9 percent of adults worked fewer hours in March. Among this group, 21 percent said they worked fewer hours because of family responsibilities or childcare. Seventeen percent said that illness or health limitations had contributed to their reduction in hours. Nevertheless, 47 percent of those working fewer hours said it was due to fewer hours offered by their employer.

\section{Effects on Family Finances}

For the majority of adults, income, ability to pay current bills, and their approach to covering a hypothetical $\$ 400$ unexpected expense appear to be generally stable during the initial period of the COVID-19 pandemic. Yet among those who experienced employment losses, financial well-being is substantially lower.

Consistent with the employment declines in March, many people experienced declines in their incomes. Overall, 23 percent of adults said their income in March was lower than in February, while 5 percent said their income increased and the rest indicated it was about the same (figure 41). Among those who lost a job or had their hours reduced, 70 percent reported that their income declined. Most people who did not report a job loss or reduced hours said that their income was about the same, although 12 percent said their month-to-month income declined between February and March.

A loss of income can affect people's ability to pay regular monthly bills. Eighty-one percent of adults said they could pay all the current month's bills in full in April, which was essentially unchanged from the fourth quarter of 2019 (table 32). Yet, the survey found far greater rates of difficulty among those experiencing employment disruptions. Sixty-

\section{Figure 40. Amount of work performed remotely in week ending April 4, 2020 (by education)}

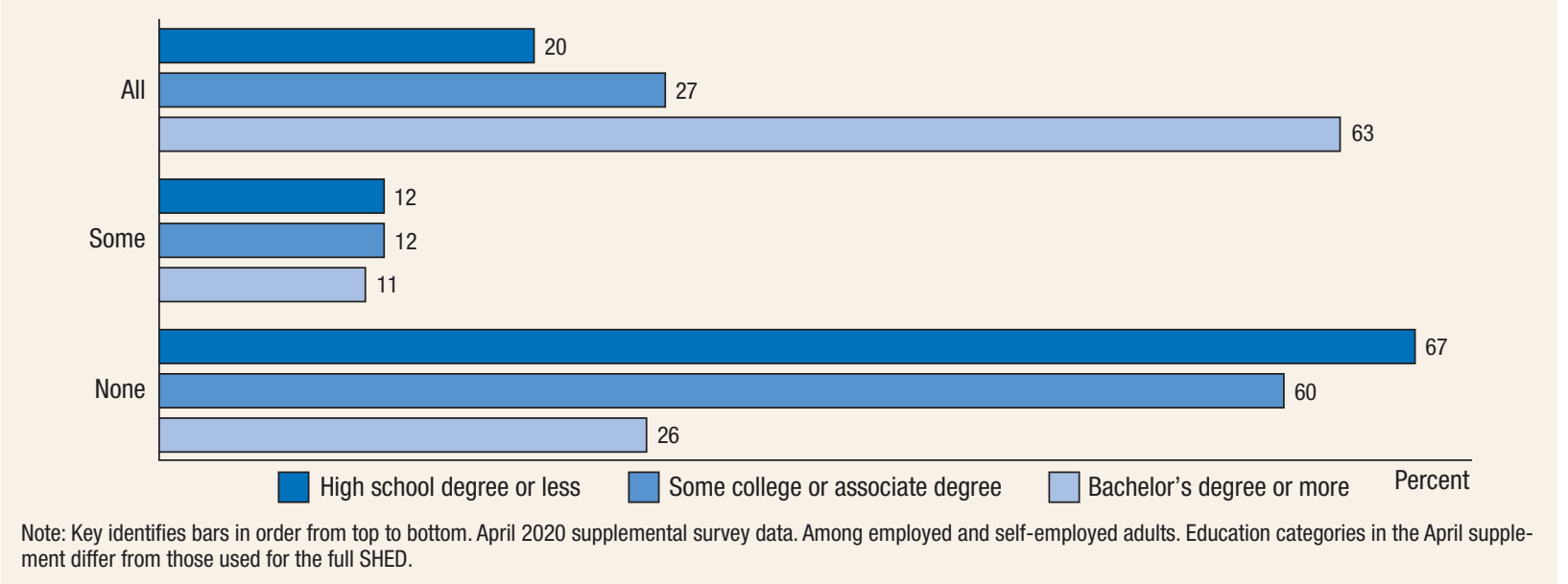


Figure 41. Income in March 2020 relative to February (by employment disruptions since March 1)

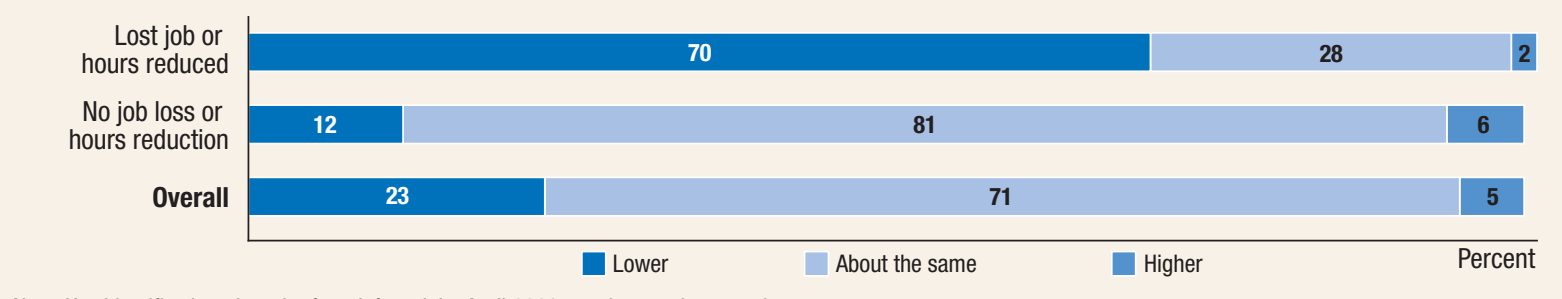

Note: Key identifies bars in order from left to right. April 2020 supplemental survey data.

Table 32. Financial resiliency measures (by year and employment disruptions since March 1)

Percent

\begin{tabular}{l|c|c}
$\quad$ Year and employment disruption & $\begin{array}{c}\text { Able to pay all } \\
\text { current month's } \\
\text { bills in full }\end{array}$ & $\begin{array}{c}\text { Would pay } \\
\text { \$400 expense } \\
\text { with cash } \\
\text { or equivalent }\end{array}$ \\
\hline $\begin{array}{l}\text { 2019 SHED } \\
\text { Overall }\end{array}$ & 84 & 63 \\
2020 April supplement & & \\
Lost job or hours reduced & 64 & 46 \\
No job loss or hours reduction & 85 & 68 \\
$\quad$ Overall & 81 & 64 \\
\hline
\end{tabular}

Note: Data from both the 2019 SHED and April 2020 supplemental survey.

four percent of adults who reported a job loss or reduction in hours expected to be able to pay all their bills in full in April, compared to 85 percent of those without an employment disruption. ${ }^{51}$

${ }^{51}$ The April supplement was conducted after the passage of the Families First Coronavirus Response Act and the CARES Act, which provided financial relief to many families and expanded the availability of paid leave for some workers who contract COVID-19. However, the survey was conducted before most benefits were received, so it is unclear how many respondents considered these new policies when responding to the survey.
Similarly, for adults overall in April, the share who reported they would pay an unexpected $\$ 400$ emergency expense entirely using cash, savings, or a credit card paid off at the next statement was essentially unchanged from the fall of 2019. Yet those who experienced the loss of a job or work hours were less likely to report they would pay an unexpected $\$ 400$ expense in these ways.

In addition to the economic effects from the broader employment disruptions related to COVID-19, individuals may experience additional financial challenges if they, or someone close to them, gets sick. Workers who lack paid leave are more likely to face financial hardships or deplete financial resources if they become sick with coronavirus symptoms. Fiftythree percent of employed adults, including those who are self-employed, indicated that could take two or more weeks of paid leave if they got sick with coronavirus symptoms (figure 42). Nonetheless, one-fifth of employed adults reported that they could not take any time off without a reduction in income under these circumstances. On average, those with more education had more leave available. Sixty-four percent of adults with a bachelor's degree or more said that they had at least two weeks of leave, while 42 percent of adults with a high school

\section{Figure 42. Amount of leave available to use if sick with coronavirus symptoms without a reduction in pay}

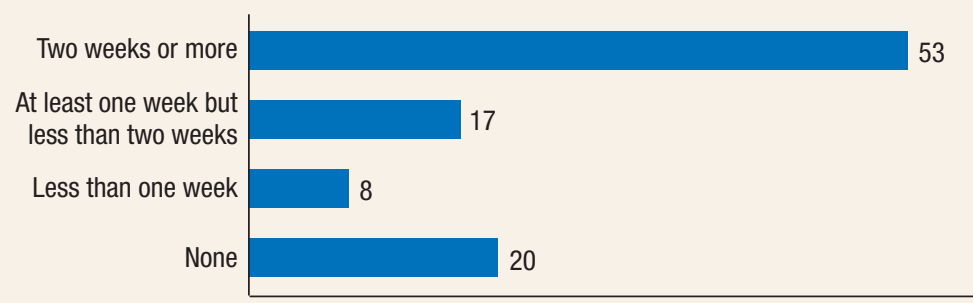

Note: April 2020 supplemental survey data. Among employed and self-employed adults. 
Figure 43. Would you try to contact a doctor if sick with symptoms of the coronavirus?

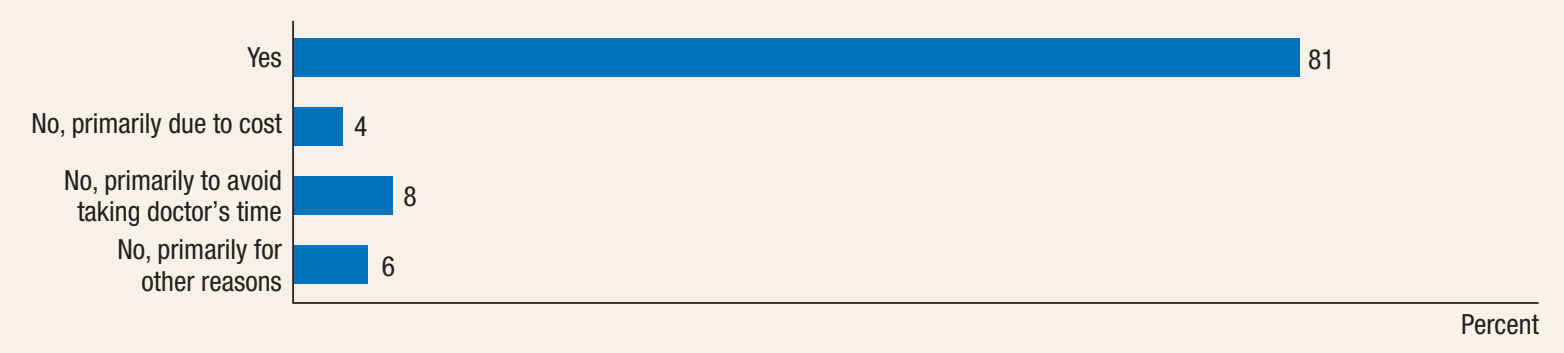

Note: April 2020 supplemental survey data.

degree or less said that they could take off at least two weeks without a reduction in income.

Financial circumstances can also affect decisions to seek medical care. Most adults (81 percent) said they would try to contact a doctor if they were to get sick with coronavirus symptoms, although a small share (4 percent) indicated that concerns about cost would deter them (figure 43). Those who experienced a job loss or reduced hours were more likely not to contact a doctor because of costs ( 8 percent), relative to those who had not ( 3 percent). However, this is well below the share who reported in the fall that they skipped any medical care due to an inability to pay (see the "Dealing with Unexpected Expenses" section of this report). This lower rate of expecting to skip medical care for COVID-19 likely reflects its serious nature.

Results from the supplemental survey reflect financial conditions at the beginning of April 2020 and indicate the nature of families' experiences of financial conditions at that time. However, the financial repercussions from COVID-19 continue to evolve, and the Federal Reserve Board will continue to monitor the financial conditions of households. 


\section{Description of the Survey}

The Survey of Household Economics and Decisionmaking was fielded from October 11 through October 24 of 2019. This was the seventh year of the survey, conducted annually in the fourth quarter of each year since 2013.$^{52}$ Staff of the Federal Reserve Board wrote the survey questions in consultation with other Federal Reserve System staff, outside academics, and professional survey experts.

Ipsos, a private consumer research firm, administered the survey using its KnowledgePanel, a nationally representative probability-based online panel. Ipsos selected respondents for KnowledgePanel based on address-based sampling (ABS). ${ }^{53}$ SHED respondents were then selected from this panel.

\section{Survey Participation}

Participation in the 2019 SHED depended on several separate decisions made by respondents. First, they agreed to participate in Ipsos' KnowledgePanel and then they completed an initial demographic profile survey. According to Ipsos, 12.2 percent of individuals contacted to join KnowledgePanel agreed to join (study-specific recruitment rate), and 62.1 percent of recruited participants completed the initial profile survey and became a panel member (study-specific profile rate). Finally, selected panel members agreed to complete the 2019 SHED.

Of the 19,994 panel members contacted to take the 2019 SHED, 12,238 (excluding breakoffs) participated, yielding a final-stage completion rate of 61.2 percent. All the stages taken together, the cumulative response rate was 4.6 percent. The final sample used in the report included 12,173 respondents. ${ }^{54}$

\footnotetext{
${ }^{52}$ Data and reports of survey findings from all past years are available at https://www.federalreserve.gov/ consumerscommunities/shed.htm.

${ }^{53}$ Prior to 2009 , respondents were also recruited using randomdigit dialing.

54 Of the 12,238 respondents who completed the survey, 65 were excluded from the analysis in this report due to either leaving
}

\section{Targeted Outreach and Incentives}

To increase survey participation and completion among hard-to-reach demographic groups, Board staff and Ipsos utilized a targeted communication plan with monetary incentives. The target groupsyoung adults ages 18 to 29 , adults with less than a high school degree, and those who are a race or ethnicity other than white and non-Hispanic - received additional email reminders and text messages during the field period, as well as additional monetary incentives.

All respondents to the survey received a $\$ 5$ incentive payment after survey completion. Respondents in the target groups received a higher $\$ 15$ incentive. These targeted individuals also received follow-up emails during the field period to encourage completion. Additionally, the incentives offered to some targeted individuals increased modestly to $\$ 20$ during the field period to increase the incentive for completion. ${ }^{55}$

Final-stage completion rates for all population groups increased in 2019 relative to 2018. As was the case in 2018 when the targeted incentive plan was first introduced, response rates in 2019 were similar between the targeted and non-targeted groups.

Hence, this targeted incentive system reduced the differences in response rates across subpopulations and improved the quality of the final data.

\section{Survey Questionnaire}

On average, the survey in 2019 took respondents 19 minutes (median time) to complete, two minutes

responses to a large number of questions missing, completing the survey too quickly, or both.

${ }^{55}$ All targeted adults received an email encouraging completion between three and six days into the field period. Targeted adults under age 60 received a follow-up email between 5 and 8 days into the field period mentioning the increased incentive payment, as well as a third reminder between 8 and 10 days into the field period. 
shorter than the previous survey. The shorter interview length reflected a continued effort to lessen respondent burden. The number of questions was reduced and the length of the questionnaire was shortened.

Because one motivation for the survey was to understand where there may be vulnerabilities or weaknesses in the economy, one priority in selecting questions was to provide information on the financial experiences and challenges among low- and moderate-income populations. The questions were intended to complement and augment the base of knowledge from other data sources, including the Board's Survey of Consumer Finances. In addition, some questions from other surveys were included to allow direct comparisons across datasets. ${ }^{56}$ The full survey questionnaire can be found in appendix A of the appendixes to this report.

\section{Survey Mode}

While the sample was drawn using probability-based sampling methods, the SHED was administered to respondents entirely online. Online interviews are less costly than telephone or in-person interviewing, and can still be an effective way to interview a representative population. ${ }^{57}$ Ipsos' online panel offers some additional benefits. Their panel allows the same respondents to be re-interviewed in subsequent surveys with relative ease, as they can be easily contacted for several years.

Furthermore, internet panel surveys have numerous existing data points on respondents from previously administered surveys, including detailed demographic and economic information. This allows for the inclusion of additional information on respondents without increasing respondent burden. The respondent burdens are further reduced by automatically skipping irrelevant questions based on responses to previous answers.

\footnotetext{
${ }^{56}$ For a comparison of results to select overlapping questions from the SHED and Census Bureau surveys, see Jeff Larrimore, Maximilian Schmeiser, and Sebastian Devlin-Foltz, "Should You Trust Things You Hear Online? Comparing SHED and Census Bureau Survey Results," Finance and Economics Discussion Series Notes (Washington: Board of Governors of the Federal Reserve System, October 15, 2015).

${ }^{57}$ David S. Yeager et al., "Comparing the Accuracy of RDD Telephone Surveys and Internet Surveys Conducted with Probability and Non-Probability Samples," Public Opinion Quarterly 75 , no. 4 (2011): 709-47.
}

The "digital divide" and other differences in internet usage could bias participation in online surveys, so recruited panel members who did not have a computer or internet access were provided with a laptop and access to the internet to complete the surveys. Even so, individuals who complete an online survey may have greater comfort or familiarity with the internet and technology than the overall adult population.

\section{Sampling and Weighting}

The SHED sample was designed to be representative of adults age 18 and older living in the United States. Because the sample size was large enough to obtain sufficient coverage of low-income populations without an oversample, unlike previous years the 2019 survey did not include a low-income oversample. This change improved the overall representativeness of the sample and reduced the importance of survey weights in analyses of the results.

The Ipsos methodology for selecting a general population sample from KnowledgePanel ensured that the resulting sample behaved as an equal probability of selection method (EPSEM) sample. This methodology started by weighting the entire KnowledgePanel to the benchmarks in the latest March supplement of the Current Population Survey along several geodemographic dimensions. This way, the weighted distribution of the KnowledgePanel matched that of U.S. adults. The geo-demographic dimensions used for weighting the entire KnowledgePanel included gender, age, race, ethnicity, education, census region, household income, homeownership status, and metropolitan area status.

Using the above weights as the measure of size (MOS) for each panel member, in the next step a probability proportional to size (PPS) procedure was used to select study specific samples. This methodology was designed to produce a sample with weights close to one, thereby reducing the reliance on poststratification weights for obtaining a representative sample.

After the survey collection was complete, statisticians at Ipsos adjusted weights in a post-stratification process that corrected for any survey nonresponse as well as any non-coverage or under- and over-sampling in the study design. The following variables were used for the adjustment of weights for this study: age, gender, race, ethnicity, census region, 
residence in a metropolitan area, education, and household income. Demographic and geographic distributions for the noninstitutionalized, civilian population age 18 and older from the March Current Population Survey were the benchmarks in this adjustment.

Although weights allow the sample population to match the U.S. population (not in the military or in institutions, such as prisons or nursing homes) based on observable characteristics, similar to all survey methods, it remains possible that non-coverage, nonresponse, or occasional disparities among recruited panel members result in differences between the sample population and the U.S. population. For example, address-based sampling likely misses homeless populations, and non-English speakers may not participate in surveys conducted in English. ${ }^{58}$

Despite an effort to select the 2019 SHED sample such that the unweighted distribution of the sample more closely mirrored that of the U.S. adult population, the results indicate that weights remain necessary to accurately reflect the composition of the U.S. population. Consequently, all results presented in this report utilize the post-stratification weights produced by Ipsos for use with the survey.

\footnotetext{
${ }^{58}$ For example, while the survey was weighted to match the race and ethnicity of the entire U.S. adult population, there is evidence that the Hispanic population in the survey were somewhat more likely to speak English at home than the overall Hispanic population in the United States. Sixty-four percent of Hispanic adults who responded to the SHED speak Spanish at home, versus 71 percent of the overall Hispanic population who did so based on the 2018 American Community Survey. See table B16006 at https://data.census.gov. See the Report on the Economic Well-Being of U.S. Households in 2017 for a comparison of results to select questions administered in Spanish and English.
}

\section{April 2020 Supplemental Survey}

As discussed in box 1 and in the "Financial Repercussions from COVID-19" section of this report, the Federal Reserve Board also conducted a survey in April 2020 to understand recent financial conditions and how circumstances for families have changed since the main survey was fielded in the fall. This survey was also fielded using the Ipsos KnowledgePanel. As such, the same sampling and weighting approaches apply to this survey as applied for the main SHED survey conducted in the fall. However, the sample size, survey length, and incentive structure differs from the main SHED survey. The respondents to the April supplement are drawn from the entire KnowledgePanel and typically did not also complete the fall survey.

The April 2020 survey included 13 questions and was fielded from April 3 through April 6. Respondents to the survey receive a small incentive from Ipsos for their participation, but because of the short length of the survey respondents are not offered additional incentives for completion.

Of the 2,853 panel members contacted to take the survey, 1,030 participated, yielding a final-stage completion rate of 36.1 percent. All the stages taken together, the cumulative response rate is 2.5 percent. The final stage completion rate is lower than it was for the fall 2019 SHED because this survey was conducted over a single weekend in order to obtain timely results. As is the case for the SHED survey that was fielded in fall 2019, after the survey collection is complete, statisticians at Ipsos adjust weights in a post-stratification process that corrects for any survey non-response as well as any non-coverage or under- and over-sampling in the study design. 
www.federalreserve.gov

0520

\section{f $\bullet \bullet \square$}

